Published in final edited form as:

Chem Rev. 2018 February 28; 118(4): 1460-1494. doi:10.1021/acs.chemrev.7b00510.

\title{
Eight Kinetically Stable but Thermodynamically Activated Molecules that Power Cell Metabolism
}

\author{
Christopher T. Walsh ${ }^{1,{ }^{*}}$, Benjamin P. Tu ${ }^{2,}{ }^{*}$, and Yi Tang $3{ }^{3,}$ \\ ${ }^{1}$ Stanford University Chemistry, Engineering, and Medicine for Human Health (ChEM-H), Stanford \\ University, 443 Via Ortega, Stanford, CA \\ ${ }^{2}$ Department of Biochemistry, University of Texas Southwestern Medical Center, Dallas, TX \\ ${ }^{3}$ Department of Chemical and Biomolecular Engineering and Department of Chemistry and \\ Biochemistry, University of California, Los Angeles, CA
}

\section{Abstract}

Contemporary analyses of cell metabolism have called out three metabolites: ATP, NADH, and acetyl-CoA, as sentinel molecules whose accumulation represent much of the purpose of the catabolic arms of metabolism and then drive many anabolic pathways. Such analyses largely leave out how and why ATP, NADH, and acetyl-CoA (Figure 1) at the molecular level play such central roles. Yet, without those insights into why cells accumulate them and how the enabling properties of these key metabolites power much of cell metabolism, the underlying molecular logic remains mysterious. Four other metabolites, $S$-adenosylmethionine, carbamoyl phosphate, UDP-glucose, and $\Delta^{2}$-isopentenyl-PP play similar roles in using group transfer chemistry to drive otherwise unfavorable biosynthetic equilibria. This review provides the underlying chemical logic to remind how these seven key molecules function as mobile packets of cellular currencies for phosphoryl transfers (ATP), acyl transfers (acetyl-CoA, carbamoyl-P), methyl transfers (SAM), prenyl transfers (IPP), glucosyl transfers (UDP-glucose), and electron and ADP-ribosyl transfers $\left(\mathrm{NAD}(\mathrm{P}) \mathrm{H} / \mathrm{NAD}(\mathrm{P})^{+}\right)$to drive metabolic transformations in and across most primary pathways. The eighth key metabolite is molecular oxygen $\left(\mathrm{O}_{2}\right)$, thermodynamically activated for reduction by one electron paths, leaving it kinetically stable to the vast majority of organic cellular metabolites.

\section{Graphical Abstract}

Correspondence: cwalsh2@stanford.edu, Benjamin.Tu@utsouthwestern.edu, yitang@ucla.edu. DISCLOSURE STATEMENT

The authors are not aware of any affiliations, memberships, funding, or financial holdings that might be perceived as affecting the objectivity of this review. 


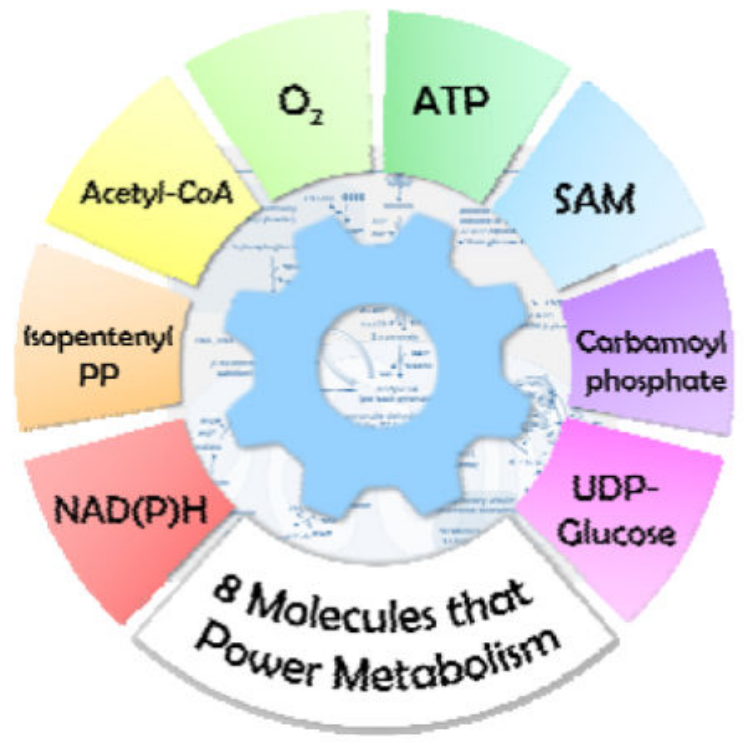

\section{INTRODUCTION}

Delineation of metabolic pathways, the tandem conversion of one cellular small molecule (MW <1000 daltons) to the next, from initial entry point to final product - each termed a metabolite - were the tasks of two to three generations of biochemists and molecular physiologists during the first half of the twentieth century. Because metabolites are by and large stable small molecules, they were most readily accessible to purification and structural characterization compared to biological macromolecules such as oligosaccharides, proteins, and both RNA and DNA. As the pathways for some 8000 (see human metabolome database, release $3.0^{1}$ ) stable small molecule metabolites became filled in, there were parallel efforts to characterize the high molecular weight protein catalysts - enzymes - that carry out the separate steps in each metabolic pathway.

Primary sequence determination and three-dimensional structural elucidation of the macromolecular biomolecule classes, proteins, RNA, DNA and oligosaccharides, consumed much of the focus of the second half of the twentieth century. That structural work went hand in hand with invention of advances in protein and nucleic acid crystallographic methods as well as high-resolution solution techniques in NMR and mass spectrometry. The recent advent of systems biology approaches has led to the hierarchy of omics platforms. ${ }^{2}$ Integration of genomics, transcriptomics, proteomics, and metabolomics to connect any or all of these system-wide changes to phenotype is now a dominant contemporary paradigm in cell biology.

In particular, the ability to measure simultaneously hundreds of small molecule cellular metabolites by mass spectrometry in many cell types and under many perturbation conditions has generated the sub-field of cell metabolism as a window into the moment to moment biology of cells, tissues, and organs. ${ }^{3}$ In turn this has sparked a renaissance of interest in how metabolic pathways function and interact, including how they are linked to 
the plethora of parallel, orthogonal, and converging signaling inputs from temporal and spatial regulation of enzymes in various pathways. The simultaneous measure of many metabolites at once (metabolomics) promises to give new insights into the physiology of cells and tissues.

At first glance maps of metabolic pathways pose stultifying complexity. They are so data rich that they are unreadable except in highly abbreviated form where molecules are not represented with chemical structures or even cartoons but typically one word descriptors. With more than eight thousand known metabolites of MW $<1500$ daltons and hundreds of enzymes catalyzing their interconversions, dozens of pathway nodal points, and the existence of several layers of regulation at key points, (such as gatekeeper enzymes and ratelimiting enzymes) the challenge of full integration and predicting cellular responses remains complex and yet unrealized.

\subsection{Seven Molecules with Group Transfer Potential}

We argue in this review that much of the intertwined logic of metabolic pathways, e.g. in human and other higher eukaryotic cells, can be understood by focus on seven molecules whose structures enable a diverse set of group transfer reactions (Figure 1). ${ }^{4}$ Three of these molecules, ATP, NADH, and acetyl-CoA are prominently accumulated in catabolic (degradative) metabolism and then used to drive anabolic small molecule and macromolecule pathways, including protein, nucleic acid and oligosaccharide biosynthetic metabolism. Four others, $S$-adenosylmethionine (SAM), UDP-glucose, carbamoyl phosphate, and $\Delta^{2}$-isopentenyl-PP, are additional key building blocks in biosynthetic pathways, also by virtue of group transfer chemistry. An eighth, inorganic molecule, molecular oxygen, is the ur-electron acceptor in respiratory chains but is otherwise substantially restricted in its metabolic roles in higher eukaryotes. Of course, $\mathrm{O}_{2}$ is not a functional energy source in anaerobic organisms.

ATP, NADH, and acetyl-CoA are called out as central in every analysis of the endpoints of cellular energy metabolism. ${ }^{5,6}$ The reasons these chemicals are so versatile and universally valued lies in their ability to act as phosphoryl or nucleotidyl donors (ATP), ${ }^{7}$ acyl donors for building up biosynthetic carbon scaffolds (acetyl-CoA), and electron donors (NADH, NADPH) most notably to respiratory chain components on the way down to molecular oxygen. These three metabolites have the common capacity for thermodynamically favored group transfer potential to drive otherwise unfavorable reactions and allow accumulation of useful quantities of materials far away from equilibrium (e.g. DNA, RNA, proteins, oligosaccharides). Figure 2a illustrates how a generic coupling of metabolites $\mathrm{X}$ and $\mathrm{Y}$ to $\mathrm{X}$ $\mathrm{Y}$ in which the desired $\mathrm{X}-\mathrm{Y}$ might only accumulate to one part in a hundred, can be driven to 999 parts in a thousand by coupled cleavage of ATP (the mechanisms may often involve X$\mathrm{PO}_{3}$ or $\mathrm{Y}-\mathrm{PO}_{3}$ intermediates ${ }^{8}$ ).

Four additional molecules whose physiological roles are tied to comparable group transfer potential are SAM, carbamoyl phosphate, $\Delta^{2}$-isopentenyl-PP (IPP), and UDP-glucose (and congeners). SAM is the source of essentially all methyl groups transferred in cells, and that can number in the millions of events per cell cycle. This is formally a transfer of an electron deficient $C_{1}$ alkyl group to cosubstrate nucleophilic $\mathrm{O}, \mathrm{N}, \mathrm{S}$, and $\mathrm{C}$ atoms (Figure 1). ${ }^{9} \mathrm{In}$ 
analogy the IPP regioisomer, while looking nothing like SAM structurally, is a facile source of a resonance-stabilized five carbon allyl cation. The iterated head to tail condensation $\Delta^{2}-$ IPP with its $\Delta^{3}$-regioisomer is the chemical reaction manifold to build isoprenoid scaffolds both on the way to thousands of steroid metabolites and to polyprenyl Coenzyme Q and dolichol-P derivatives.

UDP-glucose is the entry point metabolite for thousands of sugar residues that are incorporated in anabolic pathways into oligosaccharides, for structural (cellulose), defense (bacterial lipopolysaccharide) and energy storage (glycogen, starch) purposes. ${ }^{9}$ UDPglucose and related NDP-hexoses are likewise the building blocks for all $\mathrm{N}$-linked and $\mathrm{O}$ linked carbohydrate chains in the major forms of glycoproteins. The transfer is always of a glycosyl ring that is electron deficient at $\mathrm{C}_{1}$ (as an oxocarbonium ion equivalent).

Carbamoyl-P is more restricted in its physiologic roles, sequestered in two arms of nitrogen metabolism, but exemplifies the acyl transfer chemical potential built into the mixed anhydride scaffold. Most notably, carbamoyl-P is a metabolic device for capturing free $\mathrm{NH}_{3}$ and then directing it either to pyrimidine biosynthesis or to safe excretion as unreactive urea by action of a pair of carbamoyl transferase enzymes. ${ }^{10}$

Four of the seven molecules in Figure 1 are derivatives of adenine (ATP, NAD $(\mathrm{P}) \mathrm{H}$, acetylCoA, SAM), while the fifth is a derivative of the UTP pyrimidine riboside (UDP-glucose). Carbamoyl-P arises directly from reaction of carbamic acid with ATP. On the one hand this could reflect that they are all remnants of an RNA world ${ }^{11}$ and remain current as useful fragments for both recognition and chemistry. The recognition could be that adenosine/ adenine/AMP- and uracil/uridine/UMP/UDP-binding proteins evolved early in transition from an RNA world to a protein world. Such recognition domains might have been preconcentration devices for enrichment of adenine and uridine derivatives (high local concentrations in protein binding sites would favor reaction with additional reactants) that became CoASH, NADH, SAM or progenitors thereof. In their current forms the adenine and uracil moieties are not in the business ends of any of these five key metabolites. The distinct group transfer capacities have come into play as the other parts of the molecular scaffolds evolved (e.g the dihydronicotinamide ring in $\mathrm{NAD}(\mathrm{P}) \mathrm{H}$, the sulfonium side chain of SAM, the thiol arm in $\mathrm{CoASH})$.

The seventh metabolite, isopentenyl-PP, lacks any nucleoside moieties and is assembled in a short pathway from three molecules of acetyl-CoA that are condensed to the branched six carbon hydroxymethylglutaryl-CoA. Double reduction of the thioester to the alcohol gives mevalonate and then three ATP molecules are utilized (see section 7 and Figure 7). Two of these are for kinase-mediated phosphoryl transfer to the -PP linkage at $\mathrm{C}_{1}$ and the third to give transiently the phosphate ester of the tertiary alcohol which eliminates to generate the key olefinic linkage in $\Delta^{3}$-IPP. Subsequent isomerization of the olefin to the 2-position gives an equilibrium mixture of the $\Delta^{2}$-IPP and the characteristic prenyl chain pathway elongations can begin. As such, IPP isomers come directly from three acetyl group equivalents. In the $\mathrm{C}_{27}$ major sterol cholesterol the remains of 18 acetyl groups from acetylCoA can be spotted. 
All five of these molecules require ATP or equivalent nucleotide triphosphate consumption for their assembly, stressing the energy expenditure for their accumulation. Coenzyme A and $\mathrm{NAD}^{+}$require both separate phosphoryl (- $\left.\mathrm{PO}_{3}\right)$ and adenylyl (-AMP) transfers in their biosynthetic pathways. We noted just above that three ATPs are consumed on the way to IPP isoforms. SAM is sufficiently uphill from ATP that the two phosphoric anhydride linkages are cleaved during SAM synthetase action. Carbamoyl-P has a mixed acyl-phosphoric anhydride linkage as the business end of the molecule. The seventh key metabolite UDPglucose is formed via uridylyl transfer from UTP.

In sum, a small number of group transfer reactions embedded within seven diffusable, kinetically stable but thermodynamically activated metabolites suffice to power most primary metabolic pathways. This is equivalent to stating that parsimonious chemical logic underlies the contemporary metabolic diversity ( 2000-8000 known low molecular weight metabolites) in both prokaryotic and eukaryotic cells. Much of catabolic metabolism builds ATP, NADH (which builds up when respiration rates are low; e.g., low $\mathrm{pO}_{2}$ /hypoxia) and acetyl-CoA (both in mitochondria and cytoplasm) and these molecules can straightforwardly be converted to make SAM, IPP, and UTP (for UDP-glucose) and yield the master set.

Each of the seven molecules detailed in this section employ a distinct structural motif to provide a thermodynamically activated, kinetically stable framework that can be unlocked by metabolic enzymes to do useful cellular work. Figure 1 indicates the activated moieties are: pyrophosphoric anhydrides, dihydropyridine, sugar aminals and acetals, allyl pyrophosphates, trivalent sulfonium ion, acyl phosphoric anhydrides, and acetyl thioesters. 8,12 Vastly different chemical functional groups have been recruited into biologically stable frameworks to be spent at times and places in cells determined by the availability and activity of cosubstrates and the requisite enzyme catalysts.

Table I indicates major metabolic pathways in (higher) eukaryotic cells with the one or more of these seven metaboilites activated for group transfer driving key steps in those pathways. For numeric estimates of the substrates, including concentrations, $\mathrm{K}_{\mathrm{eq}}$ values in different organisms, cellular compartments, etc, one can refer to the Bionumbers website (http:// bionumbers.hms.harvard.edu/). ${ }^{13}$

\subsection{Oxygen as a Thermodynamically Activated Inorganic Molecule}

The definition of aerobic organisms is that they use molecular oxygen, $\mathrm{O}_{2}$, as a metabolite. They do so carefully while reaping an enormous energy yield compared to organisms that run anaerobic respiratory chains and use alternate terminal acceptors with much less of a potential drop through which electrons are funneled.

Because of the energetics of how its molecular orbitals are filled, $\mathrm{O}_{2}$ is a ground state triplet (essentially a stable diradical) ${ }^{14}$ that reacts only sluggishly with spin-paired organic molecules - essentially all the molecules of primary metabolic pathways. Therefore, $\mathrm{O}_{2}$ is kinetically stable and has accumulated to $20 \%$ of the earth's atmosphere. On the other hand, as noted earlier, it has an enormously favorable reduction potential, to undergo four-electron reduction to two molecules of water (Figure 2b). Without getting into the analytics of Nernst 
potential equations ${ }^{15}$ we noted above that the $K_{\text {eq }}$ for passage of electrons from $2 \mathrm{NADH}$ to $\mathrm{O}_{2}$ to yield $2 \mathrm{H}_{2} \mathrm{O}$ is about $10^{38}$ in favor of electron flow as written.

Thus, $\mathrm{O}_{2}$ is kinetically stable but thermodynamically activated and joins the other seven molecules noted in the previous sections in this key attribute. One could argue that metabolism is all about selectively parsing/unleashing those seven thermodynamic potentials in the active site microenvironments of enzymes to direct flux to specific product metabolites. One clear distinction between the prior seven thermodynamically activated, kinetically stable metabolites is that they are all organic molecules. $\mathrm{O}_{2}$ by contrast is an inorganic molecule, since nearly all of the $20 \%$ of the earth's atmosphere that is $\mathrm{O}_{2}$ has been biogenically derived via $\mathrm{O}_{2}$-producing photosynthesis.

\section{ATP}

ATP is the key metabolite from both the glycolytic pathway in cell cytoplasm and from the combined action of the tricarboxylate cycle and respiratory chain function in mitochondria. The net production of ATP from the ten enzyme glycolytic pathway is two ATPs per glucose molecule broken down to two molecules of pyruvate (Figure 3). A net of 32 ATPs is realizable from passage of all 24 glucose-derived electrons down the respiratory chain to $\mathrm{O}_{2}$ as terminal acceptor (Figure 3). ${ }^{10,16}$ This 16 -fold disparity indicates the tremendous thermodynamic advantage of utilizing the favorable thermodynamics of reduction of $\mathrm{O}_{2}$ to $\mathrm{H}_{2} \mathrm{O}$ (see section 4) and of taking all 24 electrons, as opposed to four electrons (at the end of glycolysis), out of glucose.

ATP approaches perfection as a cellular packet of molecular energy currency. It is kinetically stable under physiologic conditions, despite containing two pyrophosphoric anhydride linkages in its triphosphate side chain. ${ }^{7,17}$ Anhydrides are uphill energetically from their hydrolyzed acid products. In the case of ATP this is $-7 \mathrm{kcal} / \mathrm{mole}(-30.5 \mathrm{~kJ} / \mathrm{mole})$, corresponding to an equilibrium constant favoring hydrolysis of $10^{5}$ (Figure 2a) ${ }^{18}$. Thus, cleaving ATP to ADP and $\mathrm{P}_{\mathrm{i}}$ or to AMP and $\mathrm{PP}_{\mathrm{i}}(-45.6 \mathrm{~kJ} / \mathrm{mole})$ creates a large driving force to couple otherwise unfavorable processes. The kinetic basis of stability lies in the ionization of the phosphate side chains such that ATP is tetra-anionic at physiologic $\mathrm{pH}$ and water and other adventitious electron rich atoms cannot readily penetrate that phalanx of repulsive negative charges. Indeed, ATP is stable enough to be used by thermophilic microbes. In every enzymatic reaction, it is $\mathrm{Mg}$-ATP that is the substrate with divalent $\mathrm{Mg}^{++}$ serving to shield two of the side chain negative charges in a given enzyme active site and enable directed nucleophilic attack and side chain cleavage.

ATP is spent in every anabolic pathway in cells for both low molecular weight and high molecular weight metabolites. ATP experiences two major modes of side chain triphosphate cleavage, reflecting two different families of cleaving enzymes, as it drives hundreds of millions of coupled reactions in every cell (Figure 1). The global concentration of ATP in a cell is estimated to range between $0.5-5 \mathrm{mM}^{19}$ but could differ in subcellular compartments from moment to moment and can be higher in metabolically active tissues such as muscle. At these concentrations, many, if not most of the myriad enzymes that utilize ATP (e.g. the proteasome for degradation of short-lived proteins) will be saturated with this equilibrium- 
driving cosubstrate. Kornberg has estimated that eukaryotic cells contain on average $10^{9}$ molecules of ATP. ${ }^{20}$

\subsection{Phosphoryl Transfers}

One mode is phosphoryl transfer where a cosubstrate nucleophile, most commonly an oxygen atom attacks the $\gamma$-phosphorus, with net transfer of $\mathrm{PO}_{3}{ }^{2-}$. For example, this is the reaction catalyzed by hexokinase (Figure 4a), trapping glucose inside cells as glucose-6-P, with an equilibrium constant of around $10^{3}$, and functionally irreversible. It is also the mode of action of phosphofructokinase in step 3 of glycolysis as fructose-6-P is converted to fructose-1,6- $\mathrm{P}_{2}$ in preparation for aldolase cleavage. ${ }^{17}$

The gatekeeper enzyme in fatty acid biosynthesis, acetyl-CoA carboxylase, ${ }^{21}$ uses ATP cleavage to activate bicarbonate, as carboxy phosphate, for the biotin-dependent $\mathrm{C}-\mathrm{C}$ bondforming step to yield malonyl-CoA (Figure 4a). In steroidogenesis, three ATPs are cleaved to ADP sequentially as mevalonate is processed to $\Delta^{3}$-isopentenyl-PP, the building block to all isoprenoid downstream metabolites (see Figure 11). ${ }^{22}$ Of the ten enzymatic steps required to build the purine ring building blocks for RNA and DNA, six of those enzymes cleave ATP at the $\gamma$-phosphoryl group. All $\sim 500$ protein kinases in the human kinome also use this mechanism for posttranslational modifications of myriad protein substrates in signal transduction manifolds with rate accelerations up to $10^{11}$ over uncatalyzed transfer. ${ }^{23}$

\subsection{Nucleotidyl Transfers}

The second mode of ATP cleavage, attack of a cosubstrate nucleophile at a-P, defined as nucleotidyl transfer, again breaks a phosphoric anhydride linkage and so drives coupled equilibria by $10^{8}$ increment (Figure $4 \mathrm{~b}$ ) ${ }^{7,8}$ This is the key cleavage mode in four biosynthetic pathways to biological macromolecules: proteins, RNA, DNA, and oligo- and polysaccharides. All aminoacyl-tRNA synthetases generate aminoacyl-AMPs in the first step of their catalytic cycles before transfer of the now activated aminoacyl moiety to cognate tRNAs. Analogously, RNA polymerases transfer XMP moieties from XTP (X = A, G, C, U) monomers during chain elongation by RNA polymerases. In strict analogy DNA polymerases transfer dXMP fragments from dXTPs $(X=A, G, C, T)$.

The preference for XMP (nucleotidyl) transfer to cosubstrate nucleophiles over phosphoryl transfer in the thermodynamically uphill accumulation of proteins, and nucleic acids may be due to the presence of active pyrophosphatase enzymes in cells (Figure $4 \mathrm{~b}$ ). ${ }^{24} \mathrm{The}_{\mathrm{PP}}$ coproduct released in nucleotidyl transfers is hydrolyzed to 2 molecules of inorganic phosphate, providing another kick of $10^{3}$ in the equilibrium constant in the forward, biopolymer-accumulating, direction. The activity of pyrophosphatases is enough to keep $\left[\mathrm{PP}_{\mathrm{i}}\right]$ levels at micromolar levels or below, drawing off the equilibria in the front direction. The coupling of nucleotidyl transferases and pyrophosphatase tandem action makes NMP transfers the most effective NTP/ATP cleavage pattern for accumulating biopolymers. The flux of nucleoside triphosphates, via NMP transfer, to drive DNA replication $\left(\sim 2 \times 10^{8}\right.$ ATP to replicate the E. coli chromosome), RNA transcription ( 200/typical mRNA of 1000 nucleotides), and the many peptide bonds in each protein ( 1500 ATP per $30 \mathrm{kDa}$ protein) may be the largest energy drain in proliferating cells. ${ }^{13}$ 


\subsection{Pyrophosphoryl and Adenosyl Transfers}

Attack of cosubstrate nucleophiles on $\beta$-P of ATP to fragment the $\alpha, \beta$-phosphoric anhydride linkage and get the $10^{8}$ boost in equilibrium can occur although this regiochemistry is quite rare in metabolic pathways. ${ }^{8}$ One example at the start of the purine biosynthetic pathway is the enzyme PRPP synthase ${ }^{25}$ which converts 5-phosphoribose (from the pentose phosphate pathway noted below in discussion of NADPH formation) to 5-Pribose-a-1-PP (PRPP) with release of AMP. ${ }^{26}$ In the very next step, catalyzed by amidophosphoribosyltransferase, nascent $\mathrm{NH}_{3}$, generated via glutaminase action, displaces the $\mathrm{PP}_{\mathrm{i}}$ at $\mathrm{C}_{1}$ of the ribose moiety and generates 5-P-ribose- $\beta$ - 1 -amine, the starting point for elaboration of the imidazole ring of AMP (Figure 4c).

There are two well-described enzymatic reactions in which ATP is attacked at the $5^{\prime}$ carbon of the ribose moiety, for unusual adenosyl transfers, rather than any of the three electrophilic phosphorus side chain atoms. One is in the formation of $S$-adenosylmethionine (SAM) by SAM synthetase, discussed in section 7 below (Figure 4d). The other is in the biosynthesis of coenzyme $\mathrm{B}_{12}$, carried out by bacteria, including those in human gut microbiomes to provide this essential vitamin to the host. Salmonella have three adenosyltransferases, operating under different conditions. ${ }^{27,28}$ The reaction requires reduction of the cobalt in the corrin ring of the vitamin $\mathrm{B}_{12}$ cosubstrate from $\mathrm{Co}$ (II) to nucleophilic $\mathrm{Co}$ (I) as the species attacking $\mathrm{C}_{5}{ }^{\prime}$ of ATP. The nascent product from side chain cleavage is the inorganic triphosphate which can be cleaved by pyrophosphatases to draw the equilibria in the biosynthetic direction.

In sum, ATP, and the other three common nucleotide triphosphates (GTP, CTP, UTP) are perfectly balanced between kinetic stability and thermodynamic activation. The phosphoric anhydrides $(\mathrm{Pa}-\mathrm{P} \beta, \mathrm{P} \beta-\mathrm{P} \gamma)$ shielded by the cloud of anionic charges, are the structural keys and could not have been replaced with neutral carbon-based anhydrides which are hydrolytically labile. Finally, the negative charge makes ATP and related purine and pyrimidine nucleotides unable to cross cell membranes and requires population of ATP pools in each cellular organelle, most notably in nuclei and cytoplasm as well as mitochondria, to drive organelle-specific pathway steps.

\section{NADH and NADPH}

\subsection{The Molecular Basis of the Utility of NADH}

The second most cited molecule connoted as "energy rich" in cell metabolism is NADH. The oxidized form $\mathrm{NAD}^{+}$has recently been touted as an anti-aging metabolite. ${ }^{29,30}$ The assessment of energy released and stored in glycolysis includes the two NADH molecules formed during glyceraldehyde-3-P catalysis, reflecting storage of four electrons removed from the starting glucose molecule up to that point (Figure 3). Then the conversion of two molecules of pyruvate to the $6 \mathrm{CO}_{2}$ final product molecules at the end of the TCA cycle yields another $8 \mathrm{NADH}$ molecules within the mitochondria. The remaining four electrons that have been removed, ultimately from the pyruvate scaffolds, are stored as two Enz$\mathrm{FADH}_{2}$ equivalents. It is most productive to think of NADH as packets of cellular electron 
transfer currency, via hydride group transfer (Figure 1): the two electrons move with the hydrogen atom.

One can ask why is NADH a thermodynamically activated metabolite and how does it funnel electrons to $\mathrm{O}_{2}$ to make all those ATP molecules? The answer to the first question lies in the chemical nature of the reduced form of the coenzyme(s) NADH and NADPH. Dozens of $\mathrm{NAD}^{+}$-dependent reductases all catalyze hydride transfer from a cosubstrate undergoing oxidation to the 4-position of the positively charged nicotinamide ring, yielding the dihydronicotinamide. This is uphill energetically from the resonance-stabilized pyridinium ion of the oxidized nicotinamide $\left(\mathrm{NAD}^{+}\right)$and is thermodynamically activated to revert back to the oxidized form, gaining aromaticity, and giving up the hydride ion (Figure 5A).

Given the two available oxidation states, $\mathrm{NAD}^{+}$and $\mathrm{NADH}$, the predominant form in cells is the oxidized $\mathrm{NAD}^{+}$, the thermodynamically more stable form, in ratios estimated from 10/1 to $700 / 1$ for $\mathrm{NAD}^{+} / \mathrm{NADH},{ }^{31-33}$ with a total concentration estimated around $0.3-1.0 \mathrm{mM} .{ }^{34}$ At $1 \mathrm{mM}$ levels there would be about $2 \times 10^{9}$ molecules of total $\mathrm{NAD}^{+} / \mathrm{NADH}$ per human cell. The ratio in different organelles can clearly vary, e.g. in mitochondria carrying out TCA cycle flux where $\mathrm{NADH}$ will accumulate transiently. The concentration of $\mathrm{O}_{2}$, normoxia or hypoxia, will also affect NADH concentrations in mitochondria, affecting respiratory chain electron flux.

$\mathrm{NADH}$ and $\mathrm{NAD}^{+}$levels oscillate with circadian rhythm, connecting circadian and metabolic cycles. ${ }^{35,36} \mathrm{~A}$ variety of mechanisms could be involved in sensing and determining cause and effect. SIRT-1 and PARP-1, which both modify the covalent state of clock proteins (deacetylation and ADP ribosylation, respectively) could be contributors to circadian and metabolic coupling. ${ }^{35-37}$

The most common measure of the tendency of $\mathrm{NAD}(\mathrm{P}) \mathrm{H}$ to give up the hydride and associated two electrons is its reduction potential. ${ }^{38}$ At physiologic $\mathrm{pH}$ and temperature, the reduction potential for the $\mathrm{NADH} / \mathrm{NAD}^{+}$couple is $-320 \mathrm{mV}$ (Figure $2 \mathrm{~b}$ ). The corresponding potential for the vitamin $\mathrm{B}_{2}$-based coenzyme forms FMN and FAD are in the range of -220 to $-200 \mathrm{mV}$. Thus, the equilibrium for electron transfer of NADH to Enz-FAD is $10^{4}$, consistent with the observation of many flavoenzymes reduced by $\mathrm{NAD}(\mathrm{P}) \mathrm{H}$ in cellular metabolism (Figure 5a). The corresponding reduction potential for $\mathrm{O}_{2}$ to $2 \mathrm{H}_{2} \mathrm{O}$ is $+820 \mathrm{mV}$. So, if there would be a route for transfer of electrons from NADH to $\mathrm{O}_{2}$ the electrons would fall through a potential drop of $1.14 \mathrm{~V}$ which translates to an equilibrium constant, by Nernst equation analysis, of about $10^{38}$ (a factor of 10 in $\mathrm{K}_{\mathrm{eq}}$ for every $30 \mathrm{mV}$ of potential difference) (Figure 2b).

This is the basis for why aerobic metabolism has such a high energy yield. Each passage of two electrons down the mitochondrial membrane respiratory chain to $\mathrm{O}_{2}$ leads to enough protons flowing back into the mitochondria through ATP synthase machinery to make $\sim 2.5$ ATPs. ${ }^{10}$ The corresponding flow of electrons from $\mathrm{FADH}_{2}$ to $\mathrm{O}_{2}$ yields $~ 1.5$ ATPs per electron pair (Figure 3). Passage of the 24 electrons from $10 \mathrm{NADH}$ and $2 \mathrm{FADH}_{2}$ to $\mathrm{O}_{2}$ yields 28 ATPs from the conversion of two pyruvates to $6 \mathrm{CO}_{2}$ molecules. 
Additional facets of $\mathrm{NAD}^{+} / \mathrm{NADH}$ reactivity and utilization affect the workings of cellular metabolism. First is the observation that NADH and NADPH are restricted to two electron transfer steps. Hydride transfer but not hydrogen atom transfer $\left(\mathrm{H}^{\bullet}\right)$ is observed. ${ }^{8}$ The one electron pathway, generating a pyridinyl radical, is too high in energy (reduction potential in the $-600 \mathrm{mV}$ range), and is out of range of biological reagents ${ }^{38}$ and does not demonstrably occur in metabolism. Because both the $\mathrm{Fe}^{3+}$ cytochromes in the mitochondrial respiratory chain and $\mathrm{O}_{2}$ itself are obligate one electron acceptors there is a mechanistic incompatibility with the thermodynamic propensity for electrons to flow from NADH to cytochromes to $\mathrm{O}_{2}$.

A key consequence of the restriction to two electron redox routes is that $\mathrm{NAD}(\mathrm{P}) \mathrm{H}$ is not readily autoxidized by $\mathrm{O}_{2}$, despite the favorable $10^{38}$ equilibrium. Thus, $\mathrm{NAD}(\mathrm{P}) \mathrm{H}$ joins ATP as a chemical invention in nature where thermodynamic activation has been built in to a scaffold that is kinetically stable in cellulo. In turn this kinetic stability makes NADH and NADPH ideal packets of diffusable two electron transfer currency, via thermodynamically favorable transfer of a hydride group, for hundreds of cellular reactions.

\subsection{Nicotinamides and Flavins}

The question arises of how electrons get from NADH to cytochromes and then to $\mathrm{O}_{2}$. One or more two electron/one electron step down electron transfer molecules must intervene. ${ }^{39}$ That molecule is the other common redox coenzyme in cellular metabolism: the coenzyme forms, FMN and FAD, of riboflavin (Figure 5b). The planar tricyclic ring system of flavins can accept one electron or two electrons at a time, to yield the semiquinone radical or the two electron reduced dihydroflavin. Because the unpaired electron can be delocalized and thereby stabilized through the tricyclic ring system, the energy is lowered, the radical is stabilized, and is kinetically accessible in cellular metabolism.

Thus, flavins are the intermediary metabolites between $\mathrm{NAD}(\mathrm{P}) \mathrm{H}$ and obligate one electron acceptors, including both $\mathrm{Fe}^{3+}$ heme and nonheme centers in acceptor proteins and also $\mathrm{O}_{2}$ itself (in oxygenase catalysis). A canonical pattern of electron flow for passage of electrons to the respiratory chain and $\mathrm{O}_{2}$ is schematized in Figure 3 and Figure $5 b .{ }^{40}$

A corollary to the one electron reactivity of flavins and the autoxidizability of $\mathrm{FMNH}_{2}$ and $\mathrm{FADH}_{2}$ forms (half times for reoxidation by dissolved oxygen $(\sim 0.24 \mathrm{mM})$ less than a second), is that, unlike $\mathrm{NAD}(\mathrm{P}) \mathrm{H}$, they are not suited to function as freely diffusing electron transfer packets in cells, and they do not. FAD and FMN are tightly bound to respective apoproteins, and the $\mathrm{FMNH}_{2}$ and $\mathrm{FADH}_{2}$ states typically even more tightly bound, to avoid adventitious autoxidation and interruption of electron flow to specific partner acceptors. ${ }^{39}$ For this reason, flavins, unlike the more air stable NAD $(\mathrm{P}) \mathrm{H}$ and $\mathrm{NAD}(\mathrm{P})^{+}$, do not serve as freely diffusing substrates in cells. Instead they function as bound coenzymes. They are chemically more versatile than the nicotinamides but physically more restricted.

As with ATP, the negatively charged phosphate groups in $\mathrm{NAD}^{+}$and the additional one in $\mathrm{NADP}^{+}$provide electrostatic barriers to passage of nicotinamides across organelle membranes, in particular between cytoplasm (site of glycolysis and NADH production from GAPDH action) and mitochondria. As noted below, in section 10, transporters for malate, along with malate dehydrogenases in both cytoplasm and mitochondria, are one way of 
moving reducing equivalents (hydride ion transfers between the malate and oxaloacetate diacid substrates) between organelles (See Figure 17).

\subsection{Differential Role for NADPH vs NADH}

The extra phosphoryl group at the $2^{\prime}$-OH of the ribose moiety of the $2^{\prime}, 5^{\prime}$-ADP portion of $\mathrm{NADP}(\mathrm{H})$ (Figure 1) allows differential recognition from $\mathrm{NAD}(\mathrm{H})$ by cellular dehydrogenases and so allows specialization of function. In particular NADPH, generated in the cytoplasm of cells via the pentose phosphate pathway of glucose flux (Figure 3), ${ }^{41}$ serves as the hydride donor in the enoyl reductase step of each cycle of fatty acid biosynthesis, reducing the $\mathrm{CH}=\mathrm{CH}$ group to the bis-methylene $\mathrm{CH}_{2}-\mathrm{CH}_{2}$ group representing the fully reduced acyl chain (see Figure 6c). NADPH is also the reductant, utilized by glutathione reductases, for converting the oxidized, disulfide form of the tripeptide glutathione back to the thiol form in reduced glutathione (GSH) (Figure 3). ${ }^{42}$ In turn GSH is used by a family of glutathione S-transferases and peroxidases to detoxify electrophilic xenobiotic molecules and also toxic partially reduced oxygen molecules (superoxide, hydrogen peroxide) in cells.

The concentration of NADPH in cells is thought to be around $10 \%$ the total concentration of $\mathrm{NAD}^{+} / \mathrm{NADH}$, which would put it around $100 \mu \mathrm{M}\left(\sim 2 \times 10^{8}\right.$ molecules/human cell $)$. In contrast to $\mathrm{NAD}^{+} / \mathrm{NADH}$ where the oxidized form is predominant, the NADPH/NADP ${ }^{+}$ ratio can be as high as 20 to $200 / 1 .^{31-33}$ This is consistent with significant flux through the pentose phosphate cycle to generate the reduced form of this coenzyme and its utilization to drive the kinds of metabolic reactions noted in the preceding paragraph. Additional sources of NADPH can be malic enzyme action, ${ }^{43,44}$ mitochondrial IDH2, ${ }^{45} \mathrm{NAD}^{+}$kinases that convert $\mathrm{NAD}^{+}$to $\mathrm{NADP}^{+}$frameworks, ${ }^{46}$ and transhydrogenase equilibration of hydride transfer between $\mathrm{NADH}$ and $\mathrm{NADP}^{+.47}$

\subsection{Nonredox Biology of NAD+: ADP-Ribosyl Rransfers}

In addition to the thermodynamic activation of the NADH oxidation state to deliver a hydride ion to cosubstrate carbonyl groups as it rearomatizes to $\mathrm{NAD}^{+}$, the $\mathrm{NAD}^{+}$oxidation state is also thermodynamically activated for a different type of nonredox group transfer. That is ADP-ribosyl transfer. ${ }^{12,48}$ As shown in Figure 5c, the cosubstrate nucleophiles could be an internal nucleophile or water in $\mathrm{NAD}^{+}$cyclohydrolases or, in a chemically unlikely step, acyl groups on protein deacylases in the family of enzymes known as sirtuins. ${ }^{49,50}$ This ADP-ribosyl transfer capacity is available in $\mathrm{NAD}^{+}$but not $\mathrm{NADH}$ because the cationic pyridinium ring is a low energy leaving group while the dihydroaromatic ring in NADH is not. Because $\mathrm{NAD}^{+}$, not $\mathrm{NADH}$, is the predominant redox state in cells, $\mathrm{NAD}^{+}$is readily available for ADP-ribosyl transfers.

The most celebrated of the sirtuins remove acetyl groups from lysine residues in the $\mathrm{N}$ terminal tails of histones, cleaving an $\mathrm{NAD}^{+}$molecule in each catalytic cycle as the acetyl group is transiently stored on the ADP-ribosyl moiety of $\mathrm{NAD}^{+}$during net hydrolysis..$^{51,52}$ These $\mathrm{NAD}^{+}$-dependent histone deacetylases, more generally acting as protein deacetylases, are involved in transcriptional control and have been interpreted as directly connecting NAD

+ levels to patterns of gene expression. ${ }^{53,54}$ Other sirtuins have been demonstrated to remove 
negatively charged malonyl groups, succinyl groups, and longer chain acyl groups from proteins in different cellular compartments. ${ }^{55,56}$

A third set of ADP ribosyl transfers occurs in the nucleus under the catalytic agency of a family of poly-ADP-ribosyl polymerases (PARPs). They are activated during DNA damage and stress situations and the PARPs build chains of anionic ADP-ribose polymers (PARs) tethered to specific proteins. ${ }^{57}$ PARP isoenzymes have become targets of clinically effective inhibitors in cancer therapies. ${ }^{58}$ PARP-1 is the most active of 17 isozymes (half of which are PARPs, half monoADP ribosyl transferases), can make branched PAR chains that range from a few residues long up to $\sim 240$ ADPR residues ${ }^{59}$ PAR chains built on four kinds of protein side chains (glu asp lys arg), can be cleaved to yield free PAR molecules by action of PAR glycohydrolases that generate ADP ribose monomers and the unmodified protein products. ${ }^{60,61}$ The dynamics of PAR chain build up and breakdown can use up substantial fractions of cytoplasmic $\mathrm{NAD}^{+}$pools in cells; in turn insufficient cytoplasmic $\mathrm{NAD}^{+}$can lead to cessation of glyceraldehyde-3-P dehydrogenase-mediated carbon flux and blockade of glycolysis. ${ }^{62}$ The flux of cellular NAD ${ }^{+}$down these ADP ribosyl transfer pathways in higher eukaryotic cells can be substantial, ${ }^{5}$ suggestive of their metabolic importance.

An intramolecular variant of ADP ribosyl transfer occurs in the enzymatic formation of cyclic ADP ribose by the protein $\mathrm{CD} 38,{ }^{63}$ a second messenger for mobilization of intracellular calcium stores, where $\mathrm{N}_{3}$ of the adenine ring of $\mathrm{NAD}^{+}$is the kinetically competent nucleophile as free nicotinamide is released (Figure 5c).

One last comment about $\mathrm{NAD}^{+} / \mathrm{NADH}$ involves the anticipated turnover of this metabolite in cells. Given that $\sim 2.5$ ATPs are formed for each pair of electrons sent by an NADH molecule down the respiratory chain and that $\sim 80 \mathrm{~kg}$ of ATP (MW $=554 \mathrm{Da}$ ) are turned over in a day per adult male human, ${ }^{20}$ about $30 \mathrm{~kg}$ of NADH (MW $=664 \mathrm{Da}$ ) must be generated and funneled to $\mathrm{O}_{2}$ every day. A substantial fraction of the electron equivalents in NADH in times of energy surfeit must exit the mitochondria by the high capacity malate shuttle noted above and in section 10 to drive cytoplasmic electron transfer metabolism (e.g. lactate dehydrogenase action in aerobic glycolysis noted in a subsequent section).

\section{Acetyl-CoA}

\subsection{The Molecular Basis of the Utility of Acetyl-CoA}

The third of the "big three" molecules to arise from the central catabolic pathway of cytoplasmic glycolysis and then mitochondrial oxidative decarboxylation of pyruvate is acetyl-CoA. ${ }^{6}$ This is the vehicle by which the remaining two carbons from pyruvate get converted to $\mathrm{CO}_{2}$ in the tricarboxylate cycle. Acetyl-CoA is also generated during fatty acid catabolism as will be noted below.

At least as interesting in terms of roles in metabolism, acetyl-CoA powers two central anabolic pathways: fatty acid biosynthesis and isoprenoid biogenesis, including all the steroid scaffolds. ${ }^{6,64}$ The acetyl group is also used in a plethora of posttranslational modifications of proteins, among them the enzymatic acetylation of histone tails in chromatin, with attendant control of transcriptional activation of genes. ${ }^{65}$ 
This central metabolite has two parts: (a) the coenzyme A moiety that serves both as recognition module for many enzymes and crucially provides the terminal nucleophilic thiol group, and (b) the acetyl moiety that is attached to the thiol in acyl thioester linkage (Figure 6a). The acyl thioester group is the chemical basis for the utility of acetyl-CoA as a thermodynamically activated acetylating agent of cosubstrates. The $K_{\text {eq }}$ for hydrolysis to acetate and CoASH is $\sim 10^{6}$, the same favorable equilibrium as for ATP hydrolysis, a measure of the driving force that acetyl transfer provides for transfer to water oxygens (net hydrolysis) or to cosubstrate nucleophilic oxygen, nitrogen, and sulfur atoms.

Acetyl-CoA can also be generated enzymatically de novo from acetate, ATP and free coenzyme A in a two step process (Figure 6b). ${ }^{66-68}$ This involves attack of the acetate carboxylate group on a-P of Mg-ATP to yield acetyl-AMP. This mixed acyl phosphoric anhydride is thermodynamically activated but kinetically unstable in cellular milieus. ${ }^{8}$ It can be captured by the thiol of CoASH to yield acetyl-CoA and AMP via a committed enzyme, with a $K_{\text {eq }}$ for this step close to 300 (Figure 2c). The accumulation of the activated acyl thioester has been driven by the net hydrolysis of ATP to AMP and $\mathrm{PP}_{\mathrm{i}}$ but now the acyl thioester is much more stable than the acyl-AMP (hours for acetyl-CoA vs seconds for acetyl-AMP at physiologic $\mathrm{pH}$ and temperature) and is usable as a diffusible source of acetyl group transfers. We note the importance of this path for acetate to acetyl-CoA in tumor metabolism in a subsequent section. ${ }^{69}$

While acetyl-CoA is the prototypic, ubiquitously utilized acyl-CoA in many branches of primary metabolism, the combined kinetic stability/thermodynamic activation as an acyl transfer agent applies to other acyl-CoA metabolites as well and underlies their functions. Among them are malonyl-CoA (first committed step in fatty acid biogenesis-noted below), succinyl-CoA in the tricarboxylate cycle, and long chain fatty acyl-CoAs such as myristoyl $\left(\mathrm{C}_{14}\right)$ - and palmitoyl $\left(\mathrm{C}_{16}\right)$-CoAs used in beta oxidation to release acetyl-CoA units in fatty acid catabolism as well as in protein posttranslational protein acylations.

The acyl thioester strategy is also employed to generate intermediates in some key enzymes of primary metabolism. One example is in the NADH-forming step during glyceraldehyde-3-P dehydrogenase (GAPDH) action when a 3-P-glyceryl-S-Cys enzyme thioester is generated during NADH formation. A second set of widely distributed examples are the $\boldsymbol{\gamma}$-glutamyl- $S$-enzyme thioester intermediates generated during glutaminase actions ${ }^{70}$ : nascent $\mathrm{NH}_{3}$ is released to be used as nucleophilic amination cosubstrate in many contexts of nucleotide and amino acid metabolism. ${ }^{71}$

There has been speculation that earliest organisms may have evolved without phosphorus, at low abundance in the earth's crust, and that acyl thioester chemistry may have been seen more central for metabolic acylation and C-C bond formations (see next section 4.2) ${ }^{72}$ than in contemporary organisms. In such scenarios it is not clear when and how the switch to phosphate-containing metabolites eventually would have become dominant in contemporary and retrieved fossil organisms. 


\subsection{Acetyl-CoA Doubly Activated in Anabolic Fatty Acid and Steroid Biogenesis}

The chemical logic and protein machinery of fatty acid biosynthesis and steroidogenesis reveal that acetyl thioesters are actually doubly reactive metabolites, electrophilic at $\mathrm{C}_{1}$ of the acetyl group and nucleophilic at $\mathrm{C}_{2}$ of the acetyl group (Figure 6a). ${ }^{9}$ Both features come into play in each pathway.

Fatty acid biosynthesis involves iterative thioclaisen condensation chemistry for $\mathrm{C}-\mathrm{C}$ bond formation in each chain elongation step. Acetyl-CoA is first carboxylated to 2S-malonylCoA by the biotin-dependent multisubunit acetyl-CoA carboxylase, the gatekeeper enzyme for carbon flux into fatty acids for energy storage (Figure 6c). The malonyl-CoA can undergo transfer to the terminal thiol of acyl carrier protein domains in fatty acid synthase and undergo irreversible decarboxylation to the $\mathrm{C}_{2}$ acetyl-CoA carbanion, stabilized by delocalization of the negative charge into the thioester carbonyl. This thioester enolate/ carbanion equivalent is the attacking nucleophile on the elongating upstream acyl thioester chain, yielding a two-carbon elongated $\beta$-keto acyl thioester enzyme.

In every catalytic cycle of fatty acid synthase, this nascent $\beta$-keto acyl group undergoes four electron reduction. Both pairs of electrons come in from NADPH, the first reducing the $\beta$ keto to $\beta$-hydroxyl and the second transferring a hydride and a proton to reduce the enoyl-S$\mathrm{ACP}$. The net effect of the condensation and four electron reduction is chain elongation by $\mathrm{CH}_{2}-\mathrm{CH}_{2}$ unit. Two points to note: the thioclaisen condensation followed by four electron reduction occurs 7 or 8 times before release of the $\mathrm{C}_{16}$ and $\mathrm{C}_{18}$ fatty acids. In the case of the $\mathrm{C}_{16}$ palmitate, 28 electrons have been dumped in from NADPH (14 equivalents), emphasizing that fatty acids are molecules with stored electrons/reducing equivalents that can be called on when cells need energy reserves mobilized. The second point is that the source of all the electrons are the reduced nicotinamide coenzyme.

What goes up can come down in terms of fatty acid metabolism. In mobilization of the stored energy, the first step is transfer of the acyl chain from triglyceride to the thiol of coenzyme A by acyl transferases, acting as acyl-CoA synthetases. Enzymatic breakdown of long chain acyl-CoAs to acetyl-CoA units to send to the TCA cycle for catabolic energy production of ATP, the underlying chemical logic is the reverse of fatty acid synthase with the following distinctions (Figure 6c). Fatty acid $\beta$-oxidation typically occurs in mitochondria (although long chain fatty acids can be processed in peroxisomes) where the acetyl-CoA products can be funneled directly into the TCA cycle. The thioclaisen cleavages are carried out on soluble acyl-CoAs rather than acyl carrier proteins, allowing differentiation of the anabolic and catabolic arms of fatty acid metabolism. In each cycle where a $\mathrm{CH}_{2} \mathrm{CH}_{2}$ of the fatty acyl chain is converted to the $\mathrm{CH}_{2} \mathrm{CO}$-moiety that undergoes thiolytic cleavage and release as acetyl-CoA, the four electrons that are removed end up in $\mathrm{NADH}$ (not NADPH) and in $\mathrm{FADH}_{2}$-enzyme molecules rather than two molecules of NADPH.

Reoxidation of NADH and $\mathrm{FADH}_{2}$ by passage of the four electrons out to the respiratory chain complex I (NADH) and complex II $\left(\mathrm{FADH}_{2}\right)$ would yield 4 ATP molecules along with each acetyl-CoA released. Eight cycles of $\beta$-oxidation for complete degradation of palmitylCoA would thus yield 32 ATP equivalents and eight acetyl-CoA product molecules. If all 
eight acetyl-CoAs were then processed to two $\mathrm{CO}_{2}$ molecules via TCA action that would eventually yield 9 ATP and one GTP for each of eight turns of the cycle for another 80 ATPs (actually 72 ATPs and 8 GTPs). The total number of electrons removed from palmitoyl-CoA and sent down to oxygen are 96 electrons removed as 24 molecules of $\mathrm{O}_{2}$ get reduced to 48 molecules of water. These numbers emphasize the energy storage functions of long chain fatty acids in cellular metabolism.

As noted in the paragraphs above, the relevant nicotinamide donor recognized by both the keto acyl-ACP and enoyl-ACP reductases in fatty acid synthesis is NADPH not NADH. NADPH is generated largely through cytoplasmic flux of glucose-6-P into the pentose phosphate pathway (noted below) (Figure 3). The first step in the pathway is NADP+_ mediated oxidation of $\mathrm{C}_{1}$ of glucose-6-P from aldehyde to carboxylate oxidation state as NADPH is formed. Subsequent enzymes in this pathway equilibrate sugar scaffolds through actions of transketolase and transaldolase, ${ }^{73}$ generating inter alia D-ribose-5-P which is a crucial building block for both purine and pyrimidine nucleotide monomers on the way to RNA and DNA biosynthesis. As noted above, NADPH is also the key reductant for oxidized glutathione by the enzyme glutathione reductase which keeps levels of the glutathione-SH form at high cellular concentrations to act as a protective scavenging metabolite.

The double-headed, orthogonal reactivity of the acetyl moiety of acetyl-CoA is further emphasized in the first two reactions of isoprenoid biosynthetic pathways. Thiolase catalyzes condensation of one acetyl-CoA as the $\mathrm{C}_{2}$ carbanion with a second acetyl-CoA molecule offering up $\mathrm{C}_{1}$ as the electrophile to yield the anticipated acetoacetyl-CoA: the same kind of C-C bond formation seen in fatty acid synthase (Figure 7a). The next enzyme takes a third molecule of acetyl-CoA and condenses it with acetoacetyl-CoA to form a branched chain six-carbon hydroxymethylglutaryl-CoA (HMG-CoA). In this reaction, the acetyl-CoA substrate is again used as a $\mathrm{C}_{2}$ carbanion equivalent, attacking the $\mathrm{C}_{3}$ ketone of acetoacetyl-CoA, building a new $\mathrm{C}-\mathrm{C}$ bond in the branched framework.

To emphasize how NADPH and ATP, the other two central metabolites noted above, then mediate onward flux, HMG-CoA is reduced by two equivalents of NADPH to the corresponding alcohol mevalonate. Now ATP is used three consecutive times, all in phosphoryl transfers generating the mevalonate-PP metabolite at the primary alcohol before the third ATP phosphorylates the tertiary alcohol. ${ }^{22}$ That last phosphorylation sets up a facile decarboxylation and loss of $\mathrm{P}_{\mathrm{i}}$ to yield $\Delta^{3}$-isopentenyl-PP (Figure 7a) (see section 6 below).

Acetyl-CoA undergoes the same kind of $\mathrm{C}-\mathrm{C}$ bond formation in the first step of the TCA cycle, carried out by citrate synthase: the $\mathrm{C}_{2}$ carbanion/thioester enolate is generated at the enzyme's active site and added into the $\mathrm{C}_{2}$ ketone of cosubstrate oxaloacetate (Figure $7 \mathrm{~b}$ ). The nascent citryl-CoA is hydrolyzed to citrate, making the condensation and C-C bond formation irreversible. ( $K_{\mathrm{eq}}=10^{5}$ for citryl-CoA hydrolysis). The TCA cycle then proceeds from this tricarboxylate to undergo a set of dehydration and rehydration to isocitrate and then two oxidative decarboxylations on the way to succinyl-CoA, half way through the cycle. 
In these reactions involving acetyl-CoA and other acyl-CoA molecules, Nature chose thioesters over the more available oxoesters because of the difference in orbital overlap of the carbonyl with adjacent sulfur vs oxygen atom. The corresponding acetyl-oxoesters would be 100 to 1000 -fold less effective in activation of both the $C_{1}$ and $C_{2}$ of the acetyl moiety. ${ }^{4}$

\subsection{Aerobic and Microaerophilic Glycolysis and Multiple Routes to Acetyl-CoA Pools}

There are several examples of cells, including transformed cells, ${ }^{74} \mathrm{~T}$ cells undergoing activation ${ }^{75}$, and pluripotent stem cells, ${ }^{76,77}$ that practice aerobic glycolysis because the TCA cycle is not fully active for purposes of ATP synthesis. Thus, they do not oxidize glucose completely, and electrons do not get put into the mitochondrial respiratory chain effectively (Figure 8). In that state, the buildup of NADH could stop glycolysis by running out of cytoplasmic $\mathrm{NAD}^{+}$. The safety valve in aerobic glycolysis is to reduce the pyruvate to lactate, dumping the electrons from NADH as L-lactate which is excretable. Each regenerated $\mathrm{NAD}^{+}$can now permit another glucose molecule to go through the ten enzyme glycolytic pathway to pyruvate. In this state, the activity of the $\mathrm{NAD}^{+}$-dependent L-lactate dehydrogenase is a crucial catalyst, and its expression levels can be elevated. ${ }^{74}$

Canonically, acetyl-CoA is generated largely from the pyruvate dehydrogenase reaction in mitochondria when glucose is the predominant fuel. In times of energy deficits acetyl-CoA units are obtained by fatty acid oxidation noted earlier. Depending on the energy needs of a given cell and the location of distinct subcellular pools of acetyl-CoA, distinct fates for this acetyl thioester substrate are possible. When the two acetyl carbons feed into the first step of the tricarboxylate cycle, eight electron oxidation ensues, all the way to two $\mathrm{CO}_{2}$ molecules. Three NADH and one $\mathrm{FADH}_{2}$-enzyme are the intermediate loci for capture and storage of the four pairs of electrons that have been removed. They can, between them, give rise to 9 ATP if all eight electrons get funneled down the respiratory chain rather than being used for other forms of cellular metabolic work. Alternatively, if the cell has enough ATP and NADH for all its needs, the acetyl-CoA can be used to build fatty acids and isoprenoid scaffolds in the cytoplasm as noted.

Recent studies have also indicated that $\mathrm{T}$ cell activation involves metabolic reprogramming to rely more on aerobic glycolysis, with overproduction of the L-lactate dehydrogenase $A$ form tetramer as the key enzyme for regeneration of $\mathrm{NAD}^{+}$as noted above while pyruvate is reduced to lactate ${ }^{75}$ Less reliance on the TCA cycle for energy allows more release of citrate from the mitochondria and availability to the cytoplasmic ATP-dependent citrate lyase (Figure 7b). This enzyme generates the cytoplasmic acetyl-CoA that is utilized for fatty acid biogenesis as well as histone acetylations, subsequent gene activation and transcription to drive the generation of the proteomic cellular profile (e.g. cytokines) and altered small molecule metabolites that comprise the activated state of the $\mathrm{T}$ cell subset. ${ }^{75}$

A fourth route to acetyl-CoA (to go along with pyruvate dehydrogenase, fatty acyl-CoA thiolase, and ATP citrate lyase) is via the action of the ATP-dependent acetate-activating acetyl-CoA synthetase enzymes found in the cell cytoplasm and nucleus, and mitochondria (Figure 6b). This can be a consequential flux in some tumor cells that are either in hypoxic microenvironments and/or are practicing the aerobic glycolysis pattern noted above. ${ }^{69,78}$ The 
free acetate required as substrate may arise from enzymatic hydrolysis of acetylated histones (halftime of acetylation estimated at 2-3 minutes, ${ }^{69,79}$ and other acetylated proteins and small metabolites).

\subsection{Differentiation of Stem Cells: Switch from Glycolysis vs Respiration}

Given the energy yield in ATP equivalents from (a) glycolysis vs (b) the combination of glycolysis, the tricarboxylate cycle and electron transport down the respiratory chain to molecular oxygen favors path (b) by $32 / 2=16$ fold, one might anticipate all higher eukaryotic cells would run the latter program whenever possible. However, paradoxically, a hallmark of many cancer cells as noted above is a switch to glycolysis over glycolysis plus the TCA cycle, even in the presence of ample oxygen, the famous "Warburg effect". 80 More recently it has become clear that pluripotent stem cells also are tilted toward glycolytic metabolism. ${ }^{76,81}$ As they move down differentiation pathways, they reprogram metabolism and make more use of the TCA cycle and the respiratory chain. Less of the cellular energy flux comes from glycolysis. (Figure 8). The reverse is true as iPS (induced pluripotent stem) cells are dedifferentiated back towards more primitive lineages: they begin to rely more on aerobic glycolysis than aerobic respiration. In both directions, the reprogramming of metabolism can be directed by selective gene transcriptional programs.

Although pluripotent stem cells are typically smaller, it is not obvious they have fewer mitochondria per cell volume than larger, differentiated cells. Those mitochondria may be less functional, e.g. immature in terms of enzyme or substructure complements, and may be more uncoupled with respect to electron flow to oxygen than fully mature mitochondria in differentiated cells, due to higher expressions of uncoupling proteins ${ }^{76,82}$. Pyruvate dehydrogenase is phosphorylated by PDH knase and is less active so less pyruvate may enter the mitochondria. ${ }^{76}$ Instead, it is rerouted to lactate as high levels of tetrameric LDH A isoform are expressed. The NADH generated during glycolytic action of GAPDH is converted back to $\mathrm{NAD}^{+}$as pyruvate is rerouted reductively to excretable L-lactate (Figure 8). Thus, continual regeneration of $\mathrm{NAD}^{+}$allows for flux of glucose to pyruvate (and then lactate). Although only a net four electrons are taken out of glucose during its net conversion to two molecules of lactate, a high glycolytic flux appears to suffice to power stem cells. The TCA cycle runs at enough of a level to yield scaffolds for nitrogen-containing amino acids ${ }^{83}$ and sufficient citrate, which presumably accumulates and can be transported to the cytoplasm as a source of acetyl-CoA.

A presumably higher reliance on mitochondria for energy/ATP in differentiating normal cells compared to highly proliferating tumor cells generates the metabolic reprogramming that allows higher numbers of functionally and structurally mature mitochondria to make more NADH (TCA cycle) and thereby more ATP (electron transport chain).

In stem cells that sit normally in hypoxic niches, e.g. hematopoietic stem cells in bone marrow microenvironments, mesenchymal stem cells, and neuronal stem cells, the hypoxic response allows non-hydroxylated HIF1a (see next section) to be long-lived as a key transcription factor to turn on a suite of genes. Among them is the above noted pyruvate dehydrogenase kinase ${ }^{76,77}$ that sends pyruvate dehydrogenase into an inactive state (Figure 8). Among the net effects is shutting down pyruvate entry into mitochondria (by mass 
action) and turning off acetyl-CoA production therein. In one sense the switch back and forth, between glycolysis predominating or the full glycolysis/TCA cycle/mitochondrial respiratory chain predominating, is how cells can fare on different diets of NADH, ATP and acetyl-CoA levels (both in the presence of glutamine as nitrogen source). Cancer or stem cells under hypoxic conditions or that exhibit anaerobic glycolysis may have induced glucose uptake, mediated by HIF1-mediated upregulation of the GLUT1 transporter to help compensate for the reduced yield of ATP from each glucose metabolized. ${ }^{84}$

\section{Carbamoyl Phosphate, Related Acyl Phosphates, and Glutamine}

Carbamoyl phosphate, the mixed anhydride of carbamic acid and phosphoric acid, can be viewed as one of the anchor metabolites of nitrogen metabolism, acting both anabolically in pyrimidine biogenesis and catabolically in urea synthesis as a carbamoyl donor. $\mathrm{The}^{-} \mathrm{NH}_{2}$ moiety of carbamoyl-P derives from nascent ammonia which is kept at low concentrations in cellulo because it is adventitiously reactive as a nucleophilic amine. The great bulk of cellular ammonia derives from the carboxamido group of glutamine by action of glutaminase enzymatic domains that release free $\mathrm{NH}_{3}$ only in the glutaminase active site microenvironments. The nascent ammonia is efficiently captured by cosubstrates before unwanted release into the general cellular milieu. ${ }^{85,86}$

Although glutamine is the kinetically stable carrier and donor of ammonia for most anabolic steps in nitrogen assimilation, it is not typically thought of as thermodynamically activated analogous to the title molecules in this review. However, it, along with glutamate (available from glutaminase action) and aspartate, is also an anchor molecule for biosynthetic nitrogen metabolism. Further, the biosynthetic enzyme that traps ammonia and stores it as glutamine, glutamine synthetase, spends an ATP to sequester $\mathrm{NH}_{3}$, a measure that the Gln $\gamma$ carboxamide is uphill from the Glu $\gamma$-carboxylate.

\subsection{Carbamoyl- and Related Acyl-Ps}

Carbamoyl phosphate (CAP) plays a key role in two pathways in mammalian nitrogen metabolism: (1) in the urea cycle for safe excretion of nitrogen atoms in nonnucleophilic form and (2) in pyrimidine biosynthesis. CAP is a mixed anhydride between carbamic acid and phosphoric acid (Figure 9A), termed an acyl phosphate, and has the characteristic thermodynamic activation of such anhydrides for group transfer of either the phosphoryl group or the carbamoyl group to cosubstrate nucleophiles. It may be that such acyl phosphate anhydride structures were early inventions of thermodynamically activated scaffolds that could last long enough in aqueous media to begin to power steps in metabolic pathways. They tie back intimately to ATP as a generating metabolite.

In analogy to acetyl-CoA as a doubly reactive metabolite, so are acyl phosphates. As mixed anhydrides they are subject to capture by nucleophiles, both at the electrophilic acyl carbonyl group or at the elctrophilic phosphorus atom. The regiochemistry of acyl vs phosphoryl transfers to cosubstrate nucleophiles are determined by the specific enzyme catalysts, as noted in several examples below. 
Two biosynthetic enzymes, carbamoyl phosphate synthetases I and II, that utilize carbamoyl$\mathrm{P}$ as donor function in two quite different arms of nitrogen metabolism but use the same group transfer chemical logic. ${ }^{87,88}$ Both have glutaminase domains that hydrolyze Gln to Glu and $\mathrm{NH}_{3}$ to provide the nascent ammonia required for reaction with carbonic acid to generate sufficient carbamic acid in the active site to attack the $\gamma$-phosphoryl group of cosubstrate Mg-ATP (Figure 9A). The two synthetases also sit in different cellular compartments, cytoplasmic for the synthetase that funnels carbamoyl groups into RNA and DNA building blocks, vs mitochondrial for the synthetase that channels excess nitrogen into urea as an excretable end metabolite. The two synthetases are also regulated by different activator and inhibitor small molecules to modulate nitrogen flux anabolically and catabolically. ${ }^{89-92}$

In terms of chemical logic for one carbon unit activation, two related acyl phosphates are also metabolites that fit the reactivity pattern (Figure 9b). One is the acyl phosphate of formic acid, formyl phosphate. ${ }^{93}$ A second is the mixed anhydride of carbonic acid and phosphoric acid, termed carboxy phosphate (Figure 9b) that is an intermediate in the conversion of acetyl-CoA to malonyl-CoA at the start of fatty acid biosynthesis. (It undergoes phosphoryl transfer in the back direction and carbonic acid transfer in the front direction of biotinyl enzymes). Both these acyl-Ps are also formed from ATP as intermediates in formylation and carboxylation steps in purine biogenesis. Two additional acyl-Ps, glycyl-P and CAIR-P, are likewise generated from ATP in two additional steps of purine biosynthesis (Figure 9b). Thus, this acyl-P logic is utilized four successive times to generate acyl groups as electrophilic fragments in construction of two of the four bases in RNA and DNA.

The related two carbon acyl phosphate, acetyl-phosphate, is produced by bacterial acetate kinase and then reacted with CoASH via phosphotransacetylase catalysis to produce the hydrolytically more stable acetyl-CoA. All these acyl phosphate metabolites arise by enzyme-directed attack of a carboxylate oxygen on the electrophilic $\gamma$-P group of Mg-ATP, releasing Mg-ADP and the mixed anhydride product. The enzyme acetyl-CoA synthetase imposes a different regiospecificity on the acetate carboxylate such that it is positioned to attack the a-P of ATP to generate acetyl-AMP. Acyl phosphates are on the border of sufficient kinetic stability to be useful diffusible, primary metabolites in cells while acylAMPs seem to have given way to acyl thioesters, with no loss in thermodynamic group transfer potential while gaining aqueous kinetic stability.

Perhaps one might have anticipated cells would utilize carbamoyl-S-CoA as a preferred carbamoyl donor rather than carbamoyl-P but that path is not evident in contemporary organisms. This thermodynamically activated acyl phosphate has just enough kinetic stability to be able to diffuse to and be used by enzymes for carbamoyl transfers ( $\mathrm{t}_{1 / 2}$ at physiological $\mathrm{pH}$ and $37^{\circ} \mathrm{C}$ is $\sim 5$ minutes).${ }^{94}$ Analogously as noted earlier, in the energygenerating and capture steps of glycolysis, glyceraldehyde-3-P dehydrogenase (GAPDH) generates a 3-phosphoglyceryl-S-enzyme thermodynamically activated thioester and then releases it via attack from inorganic phosphate to produce 1,3-diphosphoglycerate with a newly formed acyl phosphate linkage. That acyl-P is harvested in the next enzymatic step by 
3-phosphoglycerate kinase, converting ADP to ATP by phosphoryl transfer from the mixed anhydride.

\subsection{Carbamoyl Transferases}

Aspartate carbamoyltransferase (aspartate to $\mathrm{N}$-carbamoyl aspartate) $\mathrm{N}$-acylates the amino group of aspartate in the first committed step of pyrimidine biosynthesis that leads on to uridine and cytidine RNA and DNA building blocks (Figure 9a). The second enzyme example, ornithine carbamoyltransferase, has a more pedestrian but still essential cellular function, in the urea cycle, to enable safe excretion of excess nitrogen in an unreactive, nonucleophilic form (Figure 9a). The chemistry in each case is attack by a nucleophilic amino group (Asp or Orn) on the activated carbamoyl carbonyl to form a tetrahedral intermediate which can decompose in the front directon with loss of phosphate. ${ }^{95}$ The accumulation of the $\mathrm{N}$-carbamoylated end products is driven by the favorable thermodynamics of capture of the mixed carbamoyl-phosphoric anhydride on the carbonyl group by the cosubstrate amines.

\subsection{Glutamine, Glutamate, ATP and the Management of $\mathrm{NH}_{3}$ Levels}

We noted in the prior section that management of $\mathrm{NH}_{3} / \mathrm{NH}_{4}{ }^{+}$levels is critical to the nitrogen cellular economy. This is a key concern given the potentially promiscuous behavior of the free $\mathrm{NH}_{3}$ form as an unwanted nucleophile. Two ATP-utilizing routes are employed to capture free $\mathrm{NH}_{3}$ (Figures 9a and 10a). We noted the action of the carbamoyl phosphate synthases (CAPS) in the previous section, which ultimately pass the $\mathrm{NH}_{3}$ into pyrimidine scaffolds or excrete it as urea.

The second catalyst is glutamine synthetase, connecting acyl phosphate to amide formation and the logic of the previous section. In this enzyme active site the $\gamma$-carboxylate of glutamate attacks the $\gamma$-P of ATP to produce $\gamma$-glutamyl-P as a transient intermediate (Figure 10a). Attack on this acyl phosphoric anhydride (on the carbonyl group not the the phosphoryl group) by cosubstrate $\mathrm{NH}_{3}$ generates the stable amide linkage in glutamine. ${ }^{96}$ The product glutamine is then the diffusible metabolite that can release $\mathrm{NH}_{3}$ in the active site of various glutaminases. From this perspective, one of the key attributes of glutamine is a "just in time" or latent source of ammonia in restricted microenvironments of specific enzyme active sites. To emphasize the convergent logic of ATP, acyl-Ps, glutamine, and nascent ammonia at another stage of purine biosyntheses we note the enzymatic conversion of 5-phospho-ribose-1-pyrophosphate (PRPP) to 5-P-ribosyl-1-amine at the start of purine biosynthesis. ${ }^{26}$

\subsection{Glutamine as a Nitrogen and Carbon Source}

Pluripotent stem cells need glucose and glutamine to survive under culture conditions..$^{97,98}$ Glucose functions as an energy source for aerobic glycolysis (noted above) with insufficient flux through the TCA cycle to power respiration. Glutamine is taken up by a dedicated cell membrane transporter and then imported via a transport protein into the mitochondria where it can sequentially give up its two nitrogens as ammonia, under the action first of glutaminase and then the $\mathrm{NAD}^{+}$-dependent glutamate dehydrogenase (generating an equivalent of NADH in the process) (Figure 8 and 10b). Either the released $\mathrm{NH}_{3}$ or the 
initial glutamine, acting as a latent carrier of ammonia provide the nitrogen atoms for both amino acids and the building blocks for RNA and DNA synthesis. ${ }^{78,99,100}$

The a-ketoglutarate arising from the tandem action of glutaminase and glutamate dehydrogenase can feed into the TCA cycle at the level of the a-ketoglutarate dehydrogenase complex, bypassing the block in aconitase and isocitrate dehydrogenase. The second half of the TCA cycle (ketoglutarate to oxalacetate) removes six electrons (as three hydride equivalents), providing $2 \mathrm{NADH}$ and one $\mathrm{FADH}_{2}$, capable of yielding 6.5 ATPs through coupling to the respiratory chain. This route of glutamine catabolism has been observed in many cancer cell lines growing in culture. ${ }^{101,102}$ Moreover, glutamine is a significant carbon source in small intestine and kidney metabolic flux. ${ }^{103}$ For ammonia generation in the kidney during starvation, glutamine is converted to a-ketoglutarate, whose carbons can subsequently be used for gluconeogenesis in concert with ammoniagenesis. However, it is not clear that glutamine is an equivalent major carbon source for tumors in vivo, as opposed to in culture dishes. ${ }^{78,99,104}$

An alternative metabolic fate exists for the mitochondrial glutamate, available from glutaminase hydrolytic action. ${ }^{97}$ Rather than be oxidized by glutamate dehydrogenase to the imino-glutamate that then hydrolyzes to ammonia and a-ketoglutarate, glutamate can be transaminated directly to a-ketoglutarate while oxaloacetate and pyruvate can be reductively aminated to aspartate and alanine by their respective transaminases (Figure 10b). This route avoids release of free $\mathrm{NH}_{3}$ by directly transferring the amino moiety between keto acid frameworks.

A brief aside about the transaminases found in mitochondria and cytoplasm of many cell types. All those enzymes utilize the aldehyde form of vitamin $\mathrm{B}_{6}$, pyridoxal-P (PLP), as tightly bound coenzyme to move the amino group between a-keto acid backbones. Indeed, PLP is the signature coenzyme for almost every metabolic transamination, decarboxylation, epimerization, and aldol cleavage in the manipulation of amino groups during biosynthesis of amino acids. ${ }^{73}$ In its tight binding to the apo forms of its constituent enzymes, PLP has functional analogies to the FMN and FAD coenzymes noted in an earlier section. By virtue of the high affinity specific protein binding constants, neither flavins nor PLP are appreciably free in cells, for good reasons. The dihydroflavins would be futilely autoxidized in fractions of seconds while the aldehyde group of PLP would be adventitiously reactive for condensation with any amine-containing metabolite. ${ }^{12,39}$

Glutamine is also the primary nitrogen donor in proliferating cells. ${ }^{105}$ As cells exit quiescence and reenter the cell cycle they have increased energy needs and nitrogen requirements to gear up for growth and proliferation. Glutamate dehydrogenase, glutamine synthetase, glutaminase and the cadre of transaminases move the amino group nitrogen atoms through anabolic and catabolic pathways that incorporate (nucleotides, RNA, DNA, protein biosynthesis) or excrete them, while cooperating to generate enough a-ketoglutarate to run the TCA cycle in times of need. 


\subsection{Redox Currency for Nitrogen Metabolism}

$\mathrm{NAD}(\mathrm{H})$ and $\mathrm{NADP}(\mathrm{H})$ both play a key role as hydride donors/hydride acceptors in the reversible interconversion of glutamate and a-ketoglutarate as some glutamate dehydrogenases can use one form or the other of the nicotinamides as electron currency. The ready reversibility in cellulo of glutamate dehydrogenase enables this enzyme to balance flux between tricarboxylate cycle and energy metabolism vs amino acid metabolic pathways. Glutamate and glutamine levels can reach $\mathrm{mM}$ concentration or higher, depending on the cell type, ${ }^{105-108}$ some $5-10$ fold higher than other proteinogenic amino acids, in keeping with their roles as nodal point metabolites.

\section{Isopentenyl-PP Isomers and Head to Tail Prenyl Transfers}

\subsection{The Molecular Basis of the Utility of Isopentenyl-PP}

Section 2.3 noted how the $\mathrm{C}_{5}$ framework of $\Delta^{3}$-isopentenyl-PP arises from tandem condensation of three acetyl-CoA molecules by the initial enzymes of isoprenoid pathways. The next enzyme in the pathway isomerizes the double bond from the 3- to the 2-position, generating useful quantities of both the original $\Delta^{3}$-isomer and the $\Delta^{2}$-IPP (Figure 11a). Each of these regioisomeric IPPs has a central and complementary role in building up isoprenoid frameworks. ${ }^{9}$

The $\Delta^{2}$-isomer is a ready source of a five-carbon allyl cation equivalent through $\mathrm{C}_{1}$-OPP bond cleavage at enzyme active sites. The $\mathrm{C}-\mathrm{O}$ bond cleaves with low energy because the resultant $\mathrm{C}_{1}$ carbocation is stabilized by delocalization of the positive charge at $\mathrm{C}_{3}$, the definition of a resonance-stabilized allyl cation. In turn, the $\Delta^{3}$-IPP can offer up the $\pi$ electrons of its double bond as nucleophile to attack the allyl cation. The result is a head to tail alkylation event: alkylation of the terminal carbon of the $\Delta^{3}$-IPP by the allyl cation derived from the $\Delta^{2}$-IPP. Loss of a proton to quench the nascent product cation yields the $\mathrm{C}_{10}$ product geranyl-PP that is specifically a $\Delta^{2}$-prenyl-PP (Figure 11a). So it can function as the source of an electrophilic $\mathrm{C}_{10}$ carbocation in a subsequent round with the $\Delta^{3}$-IPP.

We note explicitly that the carbon nucleophile used by prenyl transferases is a terminal $\mathrm{C}=\mathrm{C}$ double bond, specifically the $\pi$ electrons. Double bonds are used only rarely as carbon nucleophiles in metabolism, another notable case being the formation of cyclopropane fatty acids from $\Delta^{9}$ olefins with SAM (vide infra) as the $\mathrm{C}_{1}\left(\mathrm{CH}_{2}\right)$ donor. ${ }^{109}$

A second head to tail chain elongation by a five-carbon unit generates the $\mathrm{C}_{15}$ farnesyl-PP (Figure 11a). This type of five carbon head to tail chain elongation process can be repeated in cells to accumulate different length prenyl-PP products, some with Z-olefin (cis) geometries in place of the $E$-geometries (trans) shown. Thus, seven elongations would generate a $\mathrm{C}_{40}$ species (for electron transfer quinones), 10 would yield the $\mathrm{C}_{55}$ bactoprenol$\mathrm{PP}$ in bacterial cell wall assembly, and 21 elongations would yield the $\mathrm{C}_{110}$ dolichol-PP that is the oligosaccharide carrier in $\mathrm{N}$-glycoprotein assembly. ${ }^{110}$

The $\Delta^{2}$ - and $\Delta^{3}$-IPP isomers are building blocks for some 50,000 known isoprenoid metabolites, most of them isolated historically from plant sources. ${ }^{9}$ As such, they may be the most widely used building blocks in all of metabolism. It is the $\Delta^{2}$-IPP isomer specifically 
that is the facile donor of the electrophilic five carbon prenyl group. In contrast to acetylCoA which is the premier biological acyldonor, $\Delta^{2}$-IPP and longer congeners such as farnesyl-PP and geranylgeranyl-PP are alkyl donors. They can undergo both head to tail and as noted below, head to head alkylations, and can be captured by other nucleophiles, including thiol side chains of cysteine residues in proteins. ${ }^{111}$

\subsection{Farnesyl-PP and Geranyl-PP: Head to Head Prenyl Transfers}

One of the most remarkable attributes of some enzymes that act on the $\mathrm{C}_{15}$ and $\mathrm{C}_{20}$ length $\Delta^{2}$-prenyl-PPs (farnesyl- and geranylgeranyl-PP) is their ability to catalyze head to head rather than head to tail self-alkylations (Figure 11a). Squalene synthase converts two molecules of farnesyl-PP to the linear $\mathrm{C}_{30}$ hexaenoic hydrocarbon squalene. ${ }^{112}$

Correspondingly, phytoene synthase in plants converts two molecules of geranylgeranyl-PP to the $\mathrm{C}_{40}$ olefin phytoene, which has nine double bonds. ${ }^{113}$ The mechanisms of these head to head conversions have been worked out and shown to proceed through cyclopropanecontaining intermediates that rearrange to the $\mathrm{C}_{1}-\mathrm{C}_{1}$ coupled products (Figure 11a) (summarized in ${ }^{9}$ ).

Although beyond the scope of this presentation, this is another manifestation of how the allyl- and rearranged carbocation reaction manifolds open up novel metabolic pathway options by producing rearranged scaffolds. After generating squalene, organisms then go on to morph it from a linear hexaene to the tetracyclic framework of sterols. Animals epoxidize squalene at the 2,3-double bond and then cyclize it to lanosterol (Figure 11b). Plants instead make variant polycyclic scaffolds, including $\beta$-amyrin. ${ }^{114}$ Thousands of steroid variants have been found between plant and animal kingdoms, reflecting both differential quenching of sequential cationic intermediates in the cyclization process and extensive posttranslational oxygenative maturation steps.

\section{S-Adenosyl Methionine: Sulfonium Ion Activated for Group Transfers}

$S$-adenosylmethionine (SAM) may be the most widely used metabolite/coenzyme for group transfer reactions in cells after ATP. It is formed from ATP and L-methionine by an unusual attack of the methionine sulfur, at the oxidation state of sulfide, on the $\mathrm{C}_{5^{\prime}}$ carbon of the ribose ring of ATP, a net adenosyl transfer (Figure 4d). ${ }^{115}$ During the reaction, the nascent triphosphate is hydrolyzed to $\mathrm{PP}_{\mathrm{i}}$ and $\mathrm{P}_{\mathrm{i}}$ before release, reflecting a $10^{5}$ coupling in the direction of SAM accumulation. SAM is unusual in containing a positively charged trivalent sulfur, a sulfonium ion group. This is the structural basis of its thermodynamic activation as a group transfer agent. On the other hand, the concentration of SAM in cells, in the range of $10 \mu \mathrm{M}$ is a minute percentage $(\sim 1-3 \%)$ of the ATP concentration, ${ }^{116}$ reflecting diversion of a small fraction of the ATP pool. The kinetic stability is adequate for its biologic roles but nonenzymatic epimerization at the trivalent sulfur will produce a biologically inactive SAM diastereomer ${ }^{117}$ and it can fragment nonenzymatically to methylthioadenosine and homoserine lactone. At a nominal concentration of about $2 \times 10^{7}$ molecules of SAM/human cell and its high utilization for the kinds of alkyl transfers elaborated below, there is a premium on metabolic regeneration of the SAM metabolic pool (e.g. from $S$ - 
adenosyhomocysteine following methyl transfer) to ensure sufficient capacity for its multiple roles in small molecule and protein metabolism.

In principle, any of the three substituents at the sulfur of SAM are activated for group transfer to a cosubstrate nucleophile, with consequent quenching of the positive charge on sulfur as it reverts to a divalent state (Figure 12a). ${ }^{109}$ As depicted in Figure 12b one can observe transfer of the aminobutyryl group in formation of the modified tRNA base wybutosine, ${ }^{118}$ or aminopropyl transfer to putrescine after SAM decarboxylase action, yielding the $\mathrm{C}_{7}$ triamine spermidine. One can also observe transfer of the ribose substituent in formation of queuosine, another modified base in tRNA. ${ }^{119,120}$

However, far and away it is the transfer of the one carbon methyl substituent to cosubstrate nucleophiles that defines SAM in cellular metabolism. All three of the bond cleavages in Figure 12a are alkyl transfers, with the methyl transfer a $\mathrm{C}_{1}$ group transfer. It is of interest to compare the chemical logic and enzymatic machinery of these $\mathrm{C}_{1}$ alkyl transfers vs the $\mathrm{C}_{5}$ alkyl transfers from isopentenyl-PP above. Each involves an electron deficient carbon species: one carbon or five carbon alkyl group in flight but the chemical nature of the activation in the starting material SAM vs $\Delta^{2}$-IPP is dramatically different.

Almost all of the perhaps tens to hundreds of millions of methyl transfers per cell cycle involve transfer of a $\left[\mathrm{CH}_{3}{ }^{+}\right]$equivalent to a nucleophilic oxygen, nitrogen, sulfur, or carbon atom. In the wybutosine example above, four such methyl transfers have occurred (Figure 12b). ${ }^{9}$ Methyl transfers in neurotransmitter metabolism include $N$-methylation of noradrenaline to adrenaline, and deactivating catechol to $O$-methyl catechol transformations. Methyl transfers to $\mathrm{C}_{5}$ of cytosine residues in DNA involve net C-methylation of an isoamide carbon nucleophile in an enzyme-DNA covalent adduct intermediate (Figure 12c). 121

Among the most studied methyl transfers in recent decades have been the suite of lysine side chain methylations in histone tails in chromatin (Figure 18a). ${ }^{122,123}$ Strictly speaking, this is SAM acting as substrate for protein posttranslational modifications rather than primary small molecule metabolism, but these are quantitatively important in terms of SAM consumption. ${ }^{124}$ There may be 500 million histones per human cell and up to 10 methyl groups on Lys side chains of $\mathrm{H} 3$ and $\mathrm{H} 4$ at steady state, emphasizing the large flux of methyl transfers down this pathway (Prof N. Kelleher, personal communication). Along with the orthogonal histone acetylations noted earlier these methyl marks are thought to signal differing states of transcriptionally active chromatin. Here is a case where metabolomics of SAM affects transcriptomics, then proteomics, and presumably a broader reach of metabolomics throughout the cell. One recent study has indicated in Drosophila that increased activity of glycine $\mathrm{N}$-methyltransferase, generating sarcosine, extends lifespan. ${ }^{125}$ It is unlikely this is an effect of rising sarcosine levels; rather it is a net decrease in SAM concentration. SAM-dependent methylations in other posttranslational modifications of proteins are further examined in section 11.

A second metabolic pathway that is a significant sink for methyl group transfers from cellular SAM is the phospholipid biosynthetic enzyme carrying out the first of three $\mathrm{N}$ - 
methylation steps as phosphatidylethanolamine (PE) is converted to phosphatidylcholine (PC), both bulk phospholipid components of cell membranes (Figure 12d). ${ }^{126}$ Studies have suggested the histone methylations and membrane PE methylations may be important components/sinks in regulation of cellular fluxes of SAM to the reaction product $S$ adenosylhomocysteine to facilitate transsulfuration and the subsequent synthesis of cysteine and glutathione from methionine and SAM. ${ }^{126}$ The amount of PE in E. coli cells is estimated around $2 \times 10^{7}$ molecules. ${ }^{13}$ In a eukaryotic cell with a thousand-fold larger volume, if there would be $10^{9}$ to $10^{10} \mathrm{PE}$ molecules and $30 \%$ undergo $1-3$ methylations to yield phosphatidylcholine, this could be a massive drain on the SAM concentrations in cells.

\section{Glucose-6-P, Glucose-1-P and UDP-Glucose}

As glucose enters cells, the first chemical event is ATP-dependent phosphorylation of glucose at $\mathrm{C}_{6}$, driven by the $10^{5}$ equilibrium kick as ATP is fragmented to ADP so essentially all glucose molecules are trapped as the impermeant phosphomonoesters. Three metabolic fates await glucose-6-phosphate (glucose-6-P) (Figure 13).

\subsection{Glycolysis: Three ATP-dependent sugar kinases}

Glucose-6-P can be processed down the ten enzyme glycolytic pathway and then the TCA cycle noted above as the key energy-generating route in cell metabolism. The hexokinase/ glucokinase reaction is effectively irreversible under all physiologic conditions. The ATPdependent conversion of fructose-6-P to the fructose-1,6-diphosphate and ADP is also effectively irreversible under physiologic conditions. The third kinase in glycolysis, pyruvate kinase, actually runs in the ATP-generating direction from phosphoenolpyruvate, but can be reversed under glucoeneogenesis conditions in hepatocytes ${ }^{127}$ and other tissues.

\subsection{Pentose-P Pathway: NADPH Generation}

A second route for flux of glucose-6-P is the pentose phosphate pathway, with the NADP ${ }^{+}$ specific gatekeeper enzyme oxidizing $\mathrm{C}_{1}$ by two electrons to the 6-P-gluconolactone scaffold and NADPH. ${ }^{41}$ Hydrolytic ring opening by a lactonase presents the 6-P-gluconate for a second $\mathrm{NADP}^{+}$-reducing oxidoreductase. This enzyme is similar in logic and mechanism to the oxidation/decarboxylation path of isocitrate dehydrogenase in the TCA cycle. Oxidation of the 3-OH of 6-P-gluconate to the ketone, with reduction of $\mathrm{NADP}^{+}$to NADPH transiently generates the 3-keto-6-P-gluconate which, as a $\beta$-keto acid, undergoes facile decarboxylation via the intermediate enolate to D-ribulose-5-P. This is an enzymatic isomerization away from D-ribose-5-P (Figure 13), the crucial building block for nucleotide biosynthesis. These five carbon phospho sugars give the pentose-P pathway its name.

The 5-P-ribulose and 5-P-ribose, keto and aldehyde sugar isomers respectively, can be processed by transketolases and transaldolases to transfer $\mathrm{C}_{2}$ and $\mathrm{C}_{3}$ fragments respectively to other sugar scaffolds to yield $\mathrm{C}_{4}$ to $\mathrm{C}_{6}$ scaffolds. Among these is the $\mathrm{C}_{4}$ erythrose-4-P, a central building block in plants and microbes that have the genes and enzymes for the shikimate pathway to phenylalanine, tyrosine, and a plethora of other shikimate-derived aromatic metabolites. 
Conversion of glucose-6-P to ribulose-5-P and $\mathrm{CO}_{2}$ in the first three enzymatic steps of the pentose phosphate pathway constitutes a four electron oxidation of the glucose framework. These four electrons, transferred as two hydride equivalents, are stored in two molecules of NADPH. This energy capture is the main route to cytoplasmic NADPH which we have noted above is the preferred donor of hydride ion in fatty acid biosynthesis, in HMG-CoA reduction, in glutathione reduction, and as detailed in a subsequent section, in two electron donation to cytochrome P450-dependent oxygenases that tailor sterol scaffolds in steroid hormone and vitamin D maturations.

\subsection{Glucose-1-P pathway: UDP-Glucose as the activated glucosyl donor}

The third potential significant flux of glucose carbon in anabolic pathways starts with its enzymatic isomerization by phosphoglucomutase to the $\mathrm{a}$-isomer of glucose-1-P (Figure 13). We note below that this glucose-1-P stereoisomer is the substrate for attack on UTP to give UDP-glucose. Thus ATP, NADPH, and UTP/UDP-glucose are intimately involved in directing the metabolic fluxes of intracellular glucose.

This seventh group transfer strategy is responsible for driving assembly of all intracellular and extracellular oligosaccharide, polysaccharides, lipopolysaccharides, proteoglycans, and $\mathrm{N}$ - and $O$-linked glycoproteins. ${ }^{9}$ The key building blocks are nucleoside diphospho sugars where the glycosyl residues are activated for capture at $\mathrm{C}_{1}$ by any of a large number of cellular nucleophiles. UDP-glucose is the paradigmatic activated building block in mammalian cells but ADP-glucose is the monomer for starch in plants, reflecting utilization of both pyrimidine and purine triphosphates as glycosyl donors (GDP-mannose and CDPparatose are additional examples of metabolic sugar donors, indicating all four common nucleoside triphosphates in cells are ultimate energy sources for sugar-based biopolymer assembly).

Focusing on UDP-glucose as prime example, UTP is attacked at a-P by one of the phosphate oxygens of glucose- $\mathrm{a}-1-\mathrm{P}$ in a nucleotidyl transfer mediated by the gatekeeper enzyme UDP-glucose pyrophosphorylase/UTP-glucose-1-phosphate uridylyltransferase to produce UDP-glucose and $\mathrm{PP}_{\mathrm{i}}$ (Figure 13). The cleavage of a pyrophosphoric anhydride bond between $\mathrm{a}-\mathrm{P}$ and $\beta-\mathrm{P}$ indicates expenditure of energy, expressed as a push on the equilibrium in the forward direction. The resultant UDP-glucose is activated for glucosyl transfer at $\mathrm{C}_{1}$. UDP-glucose is likely synthesized in the cytoplasm and then can be transported into the lumen of the endoplasmic reticulum, ${ }^{128}$ consistent with the $O$ - and $N$ glycosylation of proteins transiting through the intracellular secretory vesicle systems.

Inspection of the potential transition state with early $\mathrm{C}_{1}-\mathrm{O}$ bond breakage indicates that the developing positive charge at $\mathrm{C}_{1}$ is delocalized into the oxygen bridging to $\mathrm{C}_{5}$, an oxocarbonium ion that is kinetically accessible in the active sites of thousands of glycosyl transferases. Capture at $\mathrm{C}_{1}$, for example by the oxygen atom at $\mathrm{C}_{4}$ of a glucosyl moiety from an elongating starch chain can occur from the front side to give glucosyl-a-1,4-glucose $\mathrm{n}_{\mathrm{n}}$ or from the back side to a growing cellulose chain $\left(\beta-1,4\right.$-glucose $\left.e_{n}\right)$ to give glucosyl- $\beta-1,4-$ glucose $_{n}$ depending on whether starch synthase or cellulose synthase is the catalyst (Figure 13). Iteration of these transfers hundreds of times or more builds up starch, glycogen, and 
cellulose, as three examples of polysaccharides with energy storage or mechanical functions for cells.

In a different set of metabolic intersections the assembly of the tetradecasaccharyl-dolchol as the starting point for all $\mathrm{N}$-glycoprotein glycosylation events uses equivalent logic via glycosyl transferase action on NDP-hexose building blocks attached to the long chain isoprenyl dolichol-P. ${ }^{129}$ The universal reliance on NDP-hexoses as glycosyl group donors to a wide range of cosubstrate nucleophiles ensures that essentially every glycosyl residue in biology is regiospecifically connected to its neighboring $\mathrm{O}, \mathrm{N}, \mathrm{S}$, or $\mathrm{C}$ atom through $\mathrm{C}_{1}$.

It is worth noting that the ADP-ribosyl transfers from $\mathrm{NAD}^{+}$and the glycosyl transfers from UDP-glucose have a similar underlying chemical logic from the point of view of the groups undergoing transfer. In each transition state an electron deficient $\mathrm{C}_{1}$ oxocarbonium ion (glucosyl vs ADP ribosyl) is attacked by a nucleophilic cosusbstrate atom to achieve glycosylation of the nucleophile. From the point of view of the leaving groups, one is UDP, the other is nicotinamide, the strategies are distinct and presumably represent convergent evolution to arrive at thermodynamically activated glucosyl/ribosyl moieties embedded in the kinetically stable scaffolds of $\mathrm{NAD}^{+}$and UDP glucose.

\subsection{5-Phosphoribose-1-pyrophosphate (PRPP) as activated phosphoribosyl donor}

While glucose is the most central hexose in metabolism, D-ribose is the corresponding pentose, given it is the core scaffold in the nucleotides that make up all RNA species and, after conversion to the 2 -deoxyribose at the deoxynucleotide diphosphate level, the corresponding scaffold in DNAs. We noted above in section 8.2 that the pentose-P pathway generates 5-P-ribose from glucose-6-P but it is the 5-P-ribose-1-PP (PRPP) that is the functional ortholog to UDP-glucose.

As noted in Figure 14A both UDP-glucose and PRPP have sugars bearing a pyrophosphate group at $\mathrm{C}_{1}$ that functions as a low energy leaving group. PRPP like UDP-glucose is both thermodynamically activated $\left(\mathrm{K}_{\mathrm{eq}} \text { for hydrolysis } \sim 3500\right)^{26}$ and sufficiently stable kinetically to function, in this case as a phosphoribosylating agent for a set of cellular amine nucleophiles. While UDP-glucose is assembled by nucleotidyl transfer to glucose-1-P, PRPP is generated enzymatically by a rare pyrophosphokinase (PRPP synthetase, see section 2.3) catalyzing attack of the $\mathrm{C}_{1}-\mathrm{OH}$ of the $\mathrm{a}$-anomer of 5-P-ribose on $\beta$-P of Mg-ATP (Figure 4C). One might have anticipated that UDP-ribose would have been the UDP-glucose equivalent and indeed UDP-ribose is a known microbial metabolite for ribosyl transfer in antibiotic biosynthetic pathways. ${ }^{9}$ It may be that evolution to PRPP was an early event that allowed generation of membrane impermeant anionic nucleotide monophosphates rather than neutral nucleosides that could have diffused out of cells.

In contrast to UDP-glucose and related NDP-hexoses that function largely in oligosaccharide chain elongations, PRPP is used predominantly in nitrogen metabolic pathways. These include de novo purine and pyrimidine biosynthesis, salvage pathways for all free nucleobases, an early step in $\mathrm{NAD}^{+}$biosynthesis, and in the production of both histidine and tryptophan (Figure 14b) ${ }^{26}$ In all these cases one can formulate the mechanism as an early cleavage of the $\mathrm{C}_{1}$-OPP linkage to an oxocarbonium ion-like transition state, akin 
to that featured for UDP-glucose (Figure 14a). All amine captures result in inversion of stereochemistry at $\mathrm{C}_{1}$ of the P-ribosyl moiety, generating $\beta$ stereochemistry.

In de novo purine biosynthesis, the amine nucleophile is nascent $\mathrm{NH}_{3}$, generated in the enzyme active site by controlled hydrolysis of glutamine, to yield P-ribosyl-1-amine as the first committed step in the pathway (Figure 9b). By contrast, in pyrimidine assembly we noted the condensation of carbamoyl-P and aspartate as the starting reaction (Figure 9a). Subsequently, $\mathrm{N}_{1}$ of orotate is the nucleophile attacking PRPP to yield the nucleotide orotidine-5-P, a decarboxylation away from UMP. This is also the reaction type for all salvage reactions to scavenge free nucleobases at $\mathrm{N}_{1}$ and return them to nucleotide monophosphates.

One of the routes to NAD ${ }^{+}$involves nicotinate coupling to PRPP as shown in Figure 14b, with the pyridine nitrogen as nucleophile. The pathways to histidine and tryptophan are among the more complex of the proteinogenic amino acids (Figure 14b). The start of the histidine pathway involves the rare attack of $\mathrm{N}_{3}$ of ATP on $\mathrm{C}_{1}$ of PRPP while tryptophan biosynthesis involves $\mathrm{N}$-phosphoribosylation of anthranilate before opening of the ribose on the way to indole glycerol-P. Clearly PRPP provides a crucial link between ribose and nitrogen metabolism.

\section{9. $\mathrm{O}_{2}$ : Thermodynamically Activated, Kinetically Stable Inorganic Molecule to Power Eukaryotic Metabolism}

\subsection{Realizing the Thermodynamic Benefit of $\mathrm{O}_{2}$ as Terminal Electron Acceptor: From TCA Cycle to Cytochrome Oxidase}

The respiratory chain membrane proteins embedded in the inner mitochondrial membrane are iron and copper-based redox components that mediate the transfer of electrons one at a time through a series of controlled potential drops, finally to the terminal redox protein cytochrome oxidase (Figure 3) ${ }^{73}$ Cytochrome oxidase, with two heme iron atoms and two copper atoms can store four electrons and then transfer them to $\mathrm{O}_{2}$ molecules, one at a time without loss of any of the formal intermediates (superoxide, peroxide, hydroxyl radical), to reduce them to two molecules of water each. Coenzyme Q quinones are lipid soluble mobile 2/1 step down electron transfer molecules that work upstream of the B and C cytochrome subtypes. Each of the cytochromes in the respiratory chain has a different $\mathrm{Fe}^{3}$ to $\mathrm{Fe}^{2}$ one electron reduction potential, based on variations in the heme macrocycle and/or the apoprotein environment. This enables the heme proteins to function as way stations ordered by relative alignments and their redox potentials. The cytochrome-filled respiratory chain is a one electron conduit all the way to $\mathrm{O}_{2}$ (Figure 3).

NADH transfers electrons to a 4-subunit protein mitochondrial membrane complex known historically as complex I, ${ }^{130}$ that acts functionally as an NADH dehydrogenase (Figure 3). Electrons flow two at a time as a hydride ion to bound FMN and then one at a time to ironsulfur clusters before connecting to the cytochrome gauntlet. Correspondingly, the reduced form $\left(\mathrm{E}-\mathrm{FADH}_{2}\right)$ of succinate dehydrogenase, generated during TCA cycle, feeds electrons 
into the multiprotein complex II way stations in the mitochondrial membrane respiratory chain.

Compared to the $\mathrm{E}^{\mathrm{o}}$, for electron transfer in the $\mathrm{NADH} / \mathrm{NAD}^{+}$couple of $-340 \mathrm{mV}$ under physiologic conditions and $\mathrm{FAD} / \mathrm{FADH}_{2}$ of $-210 \mathrm{mV}$, (although tight protein binding can move the midpoint of the potentials) various cytochrome midpoint potentials $\left(\mathrm{Fe}^{3}\right.$ to $\left.\mathrm{Fe}^{2}\right)$ range from $-100 \mathrm{mV}$ to $+500 \mathrm{mV}$ for the terminal cytochrome oxidase while the reduction potential for the $\mathrm{O}_{2}$ to $2 \mathrm{H}_{2} \mathrm{O}$ conversion is $+0.82 \mathrm{~V} .{ }^{10}$ Electrons passing from $\mathrm{NAD}(\mathrm{P}) \mathrm{H}$ to $\mathrm{O}_{2}$ thus fall through a potential drop of $(0.34+0.82)=1.16 \mathrm{~V}$., indicating a $\mathrm{K}_{\mathrm{eq}} \sim 10^{38}$ for oxidation of $\mathrm{NADH}$ and reduction of $\mathrm{O}_{2}$ enabled by the respiratory chain components (Figure 2b). This is one measure that $\mathrm{O}_{2}$ reduction is immensely thermodynamically favored, provided kinetic barriers to one electron transfer steps can be overcome.

\subsection{Iron-Based Oxygenases Reductively Activate $\mathrm{O}_{2}$ To Oxygenate Lipophilic Metabolites}

It is estimated that $~ 95 \%$ of reductive dioxygen metabolism in higher eukaryotes is via the mitochondrial respiratory chains noted above. The remaining $5 \%$ of $\mathrm{O}_{2}$ metabolism is again reductive, by a net two electrons in oxidase mode or by a net four electrons in oxygenase mode. ${ }^{9,39} \mathrm{O}_{2}$ is a substrate for hundreds of oxygenases that act in secondary metabolic pathways in microbes and plants to build complex natural product scaffolds. ${ }^{9}$ Those oxygenases often tailor hydrophobic nascent scaffolds to build in both functional group chemistry and to provide hydrophilic/hydrophobic balance to the product framework. Perhaps this logic is best exemplified in maturation of taxadiene into taxol, the microtubuledisrupting antitumor drug. The $\mathrm{C}_{20}$ hydrocarbon framework of taxadiene undergoes eight oxygenations on the way to taxol. ${ }^{9}$

In contrast, few of the primary metabolic pathways in higher eukaryotes, including humans, employ oxygenase-mediated chemistry extensively. While flavin-based oxidases are used in some amine oxidase pathways, ${ }^{39}$ the great bulk of the mammalian oxygenases are irondependent, generating high valent oxoiron intermediates, in both heme (Figure 15a) and nonheme frameworks (Figure 15b), to carry out radical-based oxygenations of cosubstrates. A suite of heme-containing cytochrome P450 family oxygenases work on steroid frameworks as noted below. Two related sets of nonheme iron oxygenases carry out consequential oxygenative demethylations of histones and DNA and are noted in section 11 subsequently.

\subsubsection{Steroid Oxygenations: Lanosterol to Estrone: Oxygenative Metabolism} at its Most Extensive-Of particular note are the conversions of the initial $\mathrm{C}_{30}$ tetracyclic framework of lanosterol on to $\mathrm{C}_{27}$ cholesterol, then the set of $\mathrm{C}_{21}$ adrenal hormones, and finally the $\mathrm{C}_{19}$ androgen and $\mathrm{C}_{18}$ estrogen frameworks of the sex hormones (Figure 11b). From lanosterol to cholesterol three angular methyl groups are carved out oxidatively by monooxygenases which collectively activate and reduce nine molecules of $\mathrm{O}_{2}$ in that process.

Cholesterol in adrenal glands is subject to removal of the seven carbon isovaleryl side chain by action of three cytochrome $\mathrm{P} 450$ oxygenases. Then a cytochrome $\mathrm{P} 450$ type of $\mathrm{C}_{17,20}$ lyase removes the residual acetyl group and converts the $\mathrm{C}_{21}$ steroid to a $\mathrm{C}_{19}$ androgen 
androstenedione. Finally, the remarkable enzyme aromatase oxygenatively removes the angular $\mathrm{C}$ methyl group of the $\mathrm{A}$ ring, aromatizing it to give the $\mathrm{C}_{18}$ estradiol. From lanosterol to estradiol, 12 carbons are carved out of the initial tetracyclic framework via action of some 6 oxygenases reducing 17 molecules of $\mathrm{O}_{2}$ (Figure 11b).

We have noted the thermodynamic reduction potential of $\mathrm{O}_{2}$ in an earlier section. In the monooxygenase reactions summarized here NADPH is the typical electron donor to bound FAD or FMN in the oxygenase multi-enzyme complex. The FAD acts in its unique mode as 2/1 step down electron switch, accepting a hydride two electron packet from NADPH and then reoxidizing by one electron paths $\left(\mathrm{FADH}_{2}\right.$ to $\mathrm{FADH} \bullet$ to $\left.\mathrm{FAD}\right)$ to feed electrons one at a time to iron centers, either directly to the cytochrome cofactor of the P450 oxygenases or via intermediacy of an iron-sulfur cluster electron transfer protein.

9.2.2 Vitamin D and Prostaglandin Oxygenative Metabolism-The metabolic precursor to Vitamin D is 7-dehydrocholesterol which undergoes a sequential set of rearrangements to give the vitamin D framework Sequential vitamin D3 hydroxylations by cytochrome $\mathrm{P} 450$ monooxygenases in two different tissues, liver and kidney, produce the trihydroxy end metabolite calcitriol. These transformations can be viewed as part of the chemical logic of hydroxylation of steroid family members to achieve distinctive biological functions.

A third example of heme protein-based oxygenation occurs in the arachidonate to prostaglandin pathway of lipid hormones, involving formation of allylic hydroperoxides and cyclic endoperoxides, effected by a pair of cyclooxygenase isozymes (Figure 15b). The oxygenative modifications of steroid and fatty acid substrate frameworks are late stage events in the respective pathways and may represent recent evolutionary additions to the metabolic repertoires in contrast to oxygen-independent core metabolic transformations.

\subsection{Mononuclear Nonheme Iron Oxygenases for Methyl Cytosine Demethylation}

The second major family of iron-based monooxygenases do not use a heme cofactor but instead rely on two His and one Asp or Glu side chain carboxylate as ligands to the active site $\mathrm{Fe}^{(\mathrm{II})}$ (Figure 15c). Typically this oxygenase superfamily requires a-ketoglutarate as oxidizable cosubstrate to generate the high valent $\mathrm{Fe}^{(\mathrm{IV})}=\mathrm{O}$ active oxygen transfer species. Removal of the $\mathrm{CH}_{3}$ group from 5-Me-cytosine residues in DNA occurs oxygenatively, by a family of TET nonheme mononuclear oxygenases (Figure 15d). ${ }^{131,132}$ The mechanism is akin to the oxygenative demethylation of Me-Lys side chains in histones summarized in section 11. Cytidine demethylation in DNA occurs after egg fertilization, in embryogenesis, and in some cancer cells.

The initial product from 5-methylcytosine residues is the corresponding 5hydroxymethylcytosine residue. Unlike the $\mathrm{N}-\mathrm{CH}_{2} \mathrm{OH}$ nascent products from histone $\mathrm{N}$ methyl oxygenations which are spontaneously hydrolytically labile, the $\mathrm{C}-\mathrm{CH}_{2} \mathrm{OH}$ linkage is chemically stable. Thus, net dealkylaton of cytosine residues in DNA requires two more sequential TET family oxygenation events (logic akin to the sequential triple oxygenations in lanosterol $\mathrm{C}_{4}$ and $\mathrm{C}_{14}$ demethylations in section 9.2.1), via 5-formyl-cytosine and 5carboxy-cytosine products before ultimate loss of $\mathrm{CO}_{2}$ (Figure 15d). ${ }^{133}$ 
In all monooxygenases the substrate undergoing hydroxylation is oxidized by two electrons while the $\mathrm{O}_{2}$ molecule is reduced by four electrons. (Figure 15). Thus, there always needs to be a second substrate that gives up two electrons for the reaction to balance. For all the P450 oxygenases, that cosubstrate is NADPH (less frequently NADH), tying NADPH electron currency availability to these biosynthetic oxygenations (Figure 15a). For the nonheme Jumonji and TET family oxygenases the cosubstrate undergoing co-oxidation is not NADPH but instead a-ketoglutarate, a TCA cycle intermediate that allows regulation of the two types of iron-based oxygenases by metabolic state (Figure 15c). As will be noted below the mutant forms of isocitrate dehydrogenase lead to $R$-2-hydroxyglutarate alternate product molecules that can shut down the a-ketoglutarate-dependent histone and DNA demethylases.

It is possible that this sequestration of oxygenase chemistry into the restricted sets of pathways, notably in steroid hormone maturation and on macromolecular protein and DNA substrates, reflects late evolution of these catalytic capacities. All the other primary metabolic pathways (glycolysis, TCA cycle, pentose phosphate pathway, fatty acid synthesis, purine and pyrimidine biosynthesis, protein and nucleic acid macromolecular syntheses) had arisen in anaerobic organisms before planetary oxygenation levels rose. Second, it may be that one should think of steroidogenesis, vitamin D maturation, and carotene and vitamin A formation as secondary metabolism, not primary metabolism in that same evolutionary sense. ${ }^{134}$

\subsection{From IDH-1 Mutations to Blockade of Histone and DNA Oxygenative Demethylases}

Perhaps the most significant example that has refocused attention on perturbations in primary metabolism that are relevant to human diseases, e.g. in gliomas, acute myeloid leukemias, and other tumors, are the mutations in the one of the three isoenzyme forms of isocitrate dehydrogenase, IDH-1. ${ }^{135}$ IDH-1 is cytoplasmic while IDH-2 and IDH-3 are mitochondrial; the latter functions in the TCA cycle. IDH- 1 and IDH-2 use $\mathrm{NADP}^{+}$as cosubstrate ${ }^{136}$ while IDH-3, the classic tricarboxylate cycle participant, uses $\mathrm{NAD}^{+}$and generates NADH as product. Possible functions for cytoplasmic IDH-1 are to provide aketoglutarate as cofactor for the class of oxygenases noted above that function to oxygenatively demethylate $\mathrm{N}-\mathrm{Me}_{1-3}-$ Lys histone tails in chromatin and also to hydroxylate 5 -methylcytosine residues in DNA, ${ }^{135}$ and to supply an additional source of NADPH.

The mutations in IDH-1 (R132H, R132C) that are oncogenic reroute the flux of isocitrate such that the nascent $a$-ketoglutarate and NADPH products are not released as usual but instead held long enough for the bound NADPH to reduce the ketone to $R$-2-

hydroxyglutarate (Figure 16). ${ }^{137}$ This alternative hydroxyglutarate product, as opposed to normal a-ketoglutarate product, can rise to 100 -fold higher concentrations in glioma vs normal cells. ${ }^{135,137}$ The hydroxyglutarate can then act as a competitive inhibitor of $a-$ ketoglutarate, with particular import in blockade of a-ketoglutarate-dependent mononuclear, nonheme iron oxygenases in the histone demethylase class and the oxygenative conversion of 5-methylcytosines in DNA for loss as $\mathrm{CO}_{2}$. It is now clear that 2-hydroxyglutarate is produced even in normal cells, especially under hypoxia. ${ }^{138,139} \mathrm{IDH}$ mutants produce $R-2$ hydroxyglutarate while $S$-2-hydroxyglutarate can come from action of L-lactate 
dehydrogenase and malate dehydrogenase on a-ketoglutarate. Both 2-HG isomers can act as inhibitors of a-ketoglutarate-dependent oxygenases.

2-Hydroxyglutarate therefore qualifies as an oncometabolite. ${ }^{135}$ Blockade of these demethylases leads to elevated levels of methylated histones and aberrant regulation of gene transcription that can promote unrestrained cell growth. This novel metabolite can be detected at low levels by mass spectrometry, in principle allowing classification of tumors with IDH mutations. ${ }^{140}$ Medicinal chemistry programs are underway that have defined inhibitors specific to the mutant forms of IDH-1 ${ }^{141,142}$ and would have promise as antitumor agents in such disease states. The IDH-1 mutation story links altered NAD(P)H redox metabolism to reductive activation of $\mathrm{O}_{2}$, and SAM modification of proteins and DNA.

Molecular oxygen is a wild card metabolite. Higher eukaryotes unlock its thermodynamic potential to undergo four electron reduction and make a good living energetically. They practice substrate hydroxylation chemistry judiciously, in hypoxia, in macromolecule demethylations, and in the steroid hormone maturation pathways. Yet, they still have had to evolve enzymatic and nonenzymatic defenses against toxic partially reduced oxygen metabolites, emphasizing how oxygen reductive metabolism has its intrinsic dangers.

The dioxygen molecule joins the other seven thermodynamically activated molecules of this chapter as companion molecule that can power multiple metabolic steps. A gaseous, inorganic, biogenerated metabolite, $\mathrm{O}_{2}$ offers itself as a dramatic energy sink to organisms that can feed in electrons one at a time. The mechanistic incompatibility between two electron-only $\mathrm{NADH}$ and one electron-only $\mathrm{O}_{2}$ reactivity could be viewed as the main boundary condition for aerobic life and an energy tie-in between glycolysis, the pentose phosphate pathway, the TCA cycle and the respiratory chain components.

\section{Spatial Integration of Metabolism: Pools of Key Metabolites}

Most metabolic pathways are compartmentalized within cells, although some have steps with involvement of more than one organelle and a rare subset, such as vitamin D maturation, involve both kidney and liver oxygenative metabolism to get to the final active calcitriol metabolite. ${ }^{134}$ For passage of metabolites between cytoplasm and nucleus, e.g. SAM, acetyl-CoA, or ATP to enable chromatin methylation and acetylation and for DNA replication and RNA transcription (to name just a few nuclear events), it is likely that nuclear pores are sufficiently large to permit passive diffusion of these low molecular weight central metabolites.

On the other hand, diffusional passage of charged molecules between mitochondria and cytoplasm does not occur and has required the expression and membrane insertion of families of transport proteins. The most well-studied group may be the ATP-ADP translocases (Figure 17) which allow export of mitochondrial ATP down its concentration gradient to the cytoplasm (we have noted 5 mitochondrial NADHs generated for each cytoplasmic NADH during glycolysis). ${ }^{143}$ In turn ADP is countertransported from cytoplasm to mitochondria, required for continuing synthesis of ATP during respiration. 
The amount of ATP in a $70 \mathrm{~kg}$ human has been estimated at $\sim 50 \mathrm{~g}$, with about $10^{9}$ molecules/cell, ${ }^{20}$ most of it generated in mitochondria. The turnover of ATP molecules by the two types of side chain cleavages has been suggested to be $\sim 0.3 \mathrm{sec}^{-1}$. Kornberg suggested that up to $80 \mathrm{~kg}$ of ATP is cycled every day, indicating both dramatic utilization of ATP to power metabolism and a need for robust transport of ATP out and ADP into mitochondria. Most cells have nucleoside diphosphokinase enzymes that convert UDP, CDP, GDP back to the nucleotide triphosphates as ATP is converted to ADP. In turn adenylate kinase will take two ADPs to ATP and AMP reversibly for equilibration of mono-, di-, and triphosphate pools.

Mitochondrial membranes typically also have monocarboxylate transporters, dicarboxylate transporters and tricarboxylate transporters (Figure 17), the latter moving citrate back and forth. ${ }^{73}$ The passage of citrate by this transporter is one device for moving acetyl units back and forth between mitochondrial and cytoplasmic CoA-SH stores. Mitochondrial acetyl$\mathrm{CoA}$, generated either from pyruvate dehydrogenase action or fatty acid $\beta$-oxidation enzymes can react with oxaloacetate, as noted in an earlier section under agency of the first enzyme in the TCA cycle, citrate synthase. After catalyzed hydrolysis of nascent citryl-CoA to citrate and free Co-ASH to ensure accumulation of the tricarboxylate, the citrate can be carried across the mitochondrial membranes to the cytoplasm by the tricarboxylate transporter.

There it can be cleaved by the enzyme ATP citrate lyase, into oxaloacetate and acetyl-CoA as ATP is cleaved to ADP and $\mathrm{P}_{\mathrm{i}}{ }^{144}$ The ATP cleavage pattern is consistent with logic that yields citryl phosphate as early intermediate, then the more kinetically stable citryl-CoA, before retroaldol cleavage to yield acetyl-CoA (Figure 7b). The ATP cosubstrate is used to produce the thermodynamically activated acetyl thioester product. These acetyl-CoA molecules in the cytoplasm then undergo carboxylation to malonyl-CoA and are funneled into fatty acid biosynthesis. Acetyl groups can also move between mitochondria and cytoplasm by transfer of the acetyl group to carnitine, passage of acetyl carnitine via its transporter, and recapture of the acetyl group by cytoplasmic or mitochondrial CoASH. ${ }^{145}$

Moving redox equivalents of NADH between mitochondria and cytoplasm is also indirect. It can involve glycerol-3-P transporters in adipose tissue or malate shuttling via dicarboxylate transporters in liver and muscle cells. ${ }^{146}$ The transport of malate from cytoplasm to mitochondria is functionally equivalent to transport of a hydride to $\mathrm{NAD}^{+}$in different cell compartments. Cytoplasmic oxaloacetate (e.g. from ATP citrate lyase action, vide supra) is reduced to L-malate by malate dehydrogenase using cytoplasmic NADH as reducing agent. Malate is transported selectively into mitochondria and then oxidized by mitochondrial malate dehydrogenease (enzyme six of the TCA cycle) back to oxaloacetate as $\mathrm{NAD}^{+}$is reduced to NADH. De facto, this is the equivalent of moving two electrons into the mitochondrial pool of $\mathrm{NAD}^{+}$. Mitochondrial oxaloacetate is not a solute for the malate transporter. It can be transaminated to L-aspartate which is a substrate for a dicarboxy amino acid transporter. Once in the cytoplasm, L-Asp is transaminated back to oxaloacetate (Figure 17). 
One further example involves transfer of SAM between nucleus (DNA, RNA, and chromatin protein methylations), cytoplasm, and mitochondria (biotin and lipoamide assembly in acetyl-CoA carboxylase and the lipoamide acyl transferase components of pyruvate dehydrgenase and ketoglutarate dehydrogenase complexes) ${ }^{120}$. Passage between nucleus and cytoplasm is perhaps via free diffusion while it is now clear that there is a transporter that moves SAM into mitochondria and the demethylated SAH product back out into the cytoplasm for hydrolysis, ${ }^{147}$ to keep SAH at concentrations below its inhibition constant (Figure 17). These four examples emphasize the value of inter-organelle shuttles and the range of strategies cells have developed to make these central group transfer metabolites available in the subcellular locales needed for specific pathways. Their inter-organelle passage allows integration of the moment to moment needs for the seven kinds of reactions that these molecules engage in for their particular group transfers and displacement of otherwise unfavorable equilibria.

\section{Intersection and Convergence of the Posttranslational Modification Universe with Small Molecule Metabolism}

In one canonical view metabolism is generally concerned with the conversion of low molecular weight molecules in cells, with more than 2000 such metabolites identified to date. On the other hand, much of the ATP spent in anabolic pathways is to build macromolecules: replication of DNA, transcription of RNA, ribosomal assembly of thousands of proteins in any cell cycle. Admittedly, these are assembled from low molecular weight metabolites noted earlier as the essential building blocks that get incorporated into linear condensed biopolymers.

The subset of proteins with catalytic activity (i.e. enzymes) are the proximal agents responsible for metabolism in the sense that they carry out the directed flux of the low molecular weight metabolites into and through the multiple pathways in different organelles of the cell. Although there are only 20,000 genes in the human genomes there may be millions of protein variants, some from RNA splicing but most from posttranslational modification (PTM) of protein side chains. ${ }^{12}$ The many PTMs control/modulate protein localization, protein catalytic activity and substrate recognition, and protein lifetimes among other features. The same key six group transfer metabolites (absent carbamoyl-P) we have highlighted as central players in driving metabolic pathways of low molecular weight molecules are the ones used most frequently in protein PTMs (Figure 18). ${ }^{12,148}$ These protein modifications occur separately or in combinations.

The most common single PTM is phosphorylation of Ser, Thr, and Tyr side chains by ATPdependent protein kinases. Tens- to hundreds of thousands of phospho variants of proteins may be formed transiently in human cells by the $>500$ members encoded in human kinomes. Many proteins can be phosphorylated at multiple residues, by single or multiple kinases. The fraction of a given protein subject to modification can depend on location within the cell (distinct pools) and the activity of the PTM enzymes. Hundreds to thousands of fractional molecular protein variants can be created and then returned to starting pools by protein phosphatases. ${ }^{149}$ Just as the concentrations of low molecular weight metabolites can vary 
from moment to moment and be subject to readjustment, so too can the composition of posttranslationally modified proteins.

The next sections detail a subset of the interplay of different varieties of PTMs from the central cast of thermodynamically activated low molecular weight group transfer donors.

\subsection{Interplay between Acetyl-CoA and SAM in Histone Tail Modifications}

The $\mathrm{N}_{6}$ side chain amino group of Lys residues in the N-terminal tails of both Histone $\mathrm{H} 3$ and $\mathrm{H} 4$ in chromosomes are famously subject to either acetylation or competing methylation. Acetylation involves acetyl-CoA as donor via action of a set of histone acetyltransferases while the histone methyltransferase families use SAM as donor of one, two, or three methyl groups at some of the same lysine residues. The potential combinatorial patterns are numerous and allow for titration of transcriptional activity across chromosome regions. Replacement of acetyl groups by methyl groups requires prior removal of the acetyl moiety as acetate by families of hydrolytic histone deacetylases as well as $\mathrm{NAD}^{+}$-dependent sirtuins. By contrast replacement of methyl groups on lysine side chains is oxygenative not hydrolytic, as noted above in the mononuclear oxygenase section, reflecting the differential chemical lability of $N$-acyl vs $N$-alkyl groups. The one carbon methyl group is removed as formaldehyde, a reactive and potentially toxic one carbon metabolite, as shown in Figure 18a. The fractional stoichiometry of acetylations and methylations on $\mathrm{H} 3$ and $\mathrm{H} 4$ can be substantial given perhaps 500 million histones per cell. Therefore there is a large flux of acetyl and methyl groups committed to these PTMs.

\subsection{Hypoxic Response}

A metabolically notable set of oxygenations of a specific protein are at the heart of the hypoxic response of eukaryotic tissues. These are hydroxylations of Pro and Asn side chains on the hypoxia inducible factor HIF1a transcription factor protein subunit. We note explicitly that these hydroxyproline and hydroxyasparagine residues occur in the realm of posttranslational modification of proteins rather than on classical small molecule metabolites discussed in section 9. Also these are catalyzed by mononuclear nonheme iron oxygenases, requiring a-ketoglutarate as an oxidizable cosubstrate. ${ }^{9}$ Both the nonheme and heme-based oxygenases generate high valent oxoiron species as the radical-initiating catalysts and follow similar chemical logic in delivering one of the two oxygen atoms from $\mathrm{O}_{2}$ to a formally unactivated carbon center on the substrate.

Using $\mathrm{O}_{2}$-consuming oxygenases as the direct hypoxia sensors is an elegantly simple route to monitor $\left[\mathrm{O}_{2}\right]$ in cells. At low $\mathrm{pO}_{2}$ the oxygenases cannot run, the HIF subunit is not hydroxylated. In this state it is not a substrate for a second posttranslational modification, side chain lysine ubiquitylation, and so persists and can function as a transcription factor, activating hundreds of genes which set in motion the hypoxic response. ${ }^{150}$ When HIF1a is hydroxylated posttranslationally, then it is a robust substrate for ubiquitylation and rapid degradation by the proteasome. The HIF1a subunit does not accumulate and so the hypoxia program does not run. It is tautologic that the HIF oxygenases would be a late stage acquisition once ambient $\mathrm{O}_{2}$ levels had risen to sustain aerobic organism metabolism and the 
rich variety of protein posttranslational modifications which carry much of the signaling flux and communication logic in cells.

11.2.1 Histone Demethylations are Oxygen-Consuming-A second set of oxygenases, again in the nonheme mononuclear iron superfamily as in the HIF example above, are the catalysts that carry out demethylation reactions of the lysine side chains of histone protein $\mathrm{H} 3$ and $\mathrm{H} 4 .{ }^{151}$

The Jumonji family reductively activate $\mathrm{O}_{2}$ at the expense of a-ketoglutarate oxidative decarboxylation to produce the $\mathrm{Fe}^{\mathrm{IV}}=\mathrm{O}$ actve site oxidant that can deliver an $\mathrm{OH} \bullet$ equivalent to the methyl groups on $\mathrm{Me}_{1}, \mathrm{Me}_{2}$, and $\mathrm{Me}_{3}$ forms of N-Me-Lys side chains in histones $\mathrm{H} 3$ and H4 (Figure 18a). Unlike acetyl groups of Lys side chains of histones, the $\mathrm{N}$-methyl groups are not removable by hydrolysis. Only oxidative routes can undo the alkylations. The nascent $N$-hydroxymethyl products can then unravel spontaneously in aqueous solutions to the amine and an equivalent of formaldehyde (Figure 18A). Three such sequential oxygenations are required to take an $\mathrm{N}-\mathrm{Me}_{3}$-Lys side chain back to the $\mathrm{Lys}-\mathrm{NH}_{2}$ while generating three equivalents of formaldehyde. Given the abundance of histones in cells $\left(\sim 5 \times 10^{6}\right.$ molecules) and a steady state methylation stoichiometry that could be anywhere from 1-10 methyl groups per nucleosome, the oxygenative demethylation capacity in cells may be highly robust. In passing, it is known that half-lives of histone acetylations are shorter than histone methylations, ${ }^{79,152,153}$ perhaps correlating with the chemical ease of hydrolysis and a larger set of deacetylases.

\subsection{Interplay between Prenyl Transfers and Methyl Transfers in changing cellular address of proteins as in the small family of conditional GTPases}

Proteins can also be alkylated with farnesyl or geranylgeranyl isoprenoid groups on cysteine thiolates. These $\mathrm{C}_{15}$ or $\mathrm{C}_{20}$ hydrophobic prenyl groups can target such proteins to membrane microenvironments.

One such protein class that undergoes these prenylations are the family of small GTPases, whose hydrolysis activity is both slow and conditional. ${ }^{154}$ Among them are Ras and Rho subfamily GTPases which hydrolyze GTP in the service of some coupled cellular activity. The $\mathrm{k}_{\text {cat }}$ for GTP hydrolysis, can be less than $1 \mathrm{~min}^{-1}$, and be accelerated by partner GTPase activating proteins (GAPs) and GDP exchange factor proteins (GEFs: release of GDP is typically rate-limiting in a catalytic cycle), reflecting the contextual conditionality of the presence of partner proteins and specific protein substrates (e.g. vesicle proteins). GTP hydrolysis is providing its usual thermodynamic role of driving coupled equilibria in the cell, in this family often for cellular work in cargo transport. ${ }^{155}$

A closer examination of the posttranslational processing of proteins such as Ras and Rho isoforms reveals three distinct types of modifications (Figure 18b): (1) prenylation of one or more Cys thiolate atoms near the C-terminus; (2) proteolysis just downstream of the prenylated Cys residue and then (3) SAM-dependent methylation of the new C-terminus to create a methyl ester, quenching the carboxylate negative charge and further facilitating relocation of modified Ras from cytosol to membrane surfaces. ${ }^{12}$ The availability of SAM 
and farnesyl-PP (Ras, Rho) and geranylgeranyl-PP (Rho) are both critical for full maturation of these small GTPases.

\subsection{SAM and ATP as Interactive PTMs}

A third example of interaction between two of the central group transfer metabolites in protein posttranslational modifications occurs in a related $C$-terminal carboxylate methylation of the catalytic subunit of protein phosphatase $2 A .{ }^{156-158}$ The catalytic subunit of PP2A assembles on a scaffold partner protein and can interact with regulatory B subunits that can affect subcellular localization and choice of specific P-Ser- and P-Thr-containing proteins as substrates. The activity of the PP2A catalytic subunit can be significantly altered by action of a leucine $C$-terminal methyltransferase which covers the $C$-terminal carboxylate charge in forming the $O$-methyl ester, the same chemistry as in Ras and Rho. This methyl substitutent can be removed hydrolytically, as methanol, by a partner carboxylesterase, enabling reversible control of PP2A activity. ${ }^{159}$

This SAM/ATP interaction logic is reprised in a recent case study on autophagy and growth control in yeast. ${ }^{124}$ SAM inhibits autophagy and promotes cell growth in a manner dependent on the methyltransferase that modifies PP2A. The aforementioned carboxymethylation of PP2A was observed to be highly sensitive to intracellular methionine and SAM levels, thereby enabling PP2A to function as a metabolically-regulated phosphatase. As such, protein phosphorylation status can be adjusted in tune with the availability of SAM. Thus, a tandem pair of PTM enzymes, guided by the availability of ATP and SAM as group transfer cosubstrates, are part of the sensory and chemical logic for control of survival responses in yeast and perhaps higher eukaryotic cells.

\subsection{NAD+ and Acetyl-CoA Opposing Regulation of Pentose Phosphate Pathway Flux by Posttranslational Modification of Glucose-6-P Dehydrogenase}

A cogent example of how posttranslational modification covalent chemistry can modulate flux through a primary metabolic pathway is provided by the regulation of glucose-6-P dehydrogenase activity. As noted earlier, this is the gatekeeper enzyme into the pentose phosphate pathway, controlling the major source of NADPH for reductive steps in fatty acid and sterol biosynthesis e.g. HMG-CoA reductase and squalene synthase reactions) as well as ribose-5-P for nucleotide assembly and erythrose-4-P for aromatic amino acid formation.

When glycolytic flux is high in cells, the pentose-P pathway flux is often low, with little diversion of glucose-6-P. ${ }^{160}$ A variety of mechanisms regulate G-6-P dehydrogenase activity, including subunit dimerization stabilized by binding of a structural $\mathrm{NADP}^{+}$molecule at the dimer interface. The side chain of lysine 403 is positioned at the dimer interface and it can be covalently acetylated from acetyl-CoA in a posttranslational acetyltransferase reaction (Figure 18c). ${ }^{160}$ This covers the positive charge on the $\mathrm{N}_{6}$ amino group and may also provide steric hindrance that prevents dimerization and leads to inactive dehydrogenase monomers. This is a molecular route to keeping the pentose-P pathway flux dialed down, with the reduction depending on the mole fraction of subunits acetylated.

Reversal of the Lys403 side chain acetylation is effected by the NAD ${ }^{+}$-dependent Sir2 cytoplasmic deacetylase (Figure 18c), noted earlier in the section on nonredox functions of 
$\mathrm{NAD}^{+}$. Sir2 activity is elevated in cells during oxidative stress and the increased activity leads to deacetylation and activation of the FOXOA3 transcription factor and also the increases in activity of G-6-P dehydrogenase. In turn more NADPH is produced, powering glutathione reductase and the downstream glutathione peroxidase to destroy problematic peroxides. The use of Sir2 rather than an $\mathrm{NAD}^{+}$-independent deacetylase links $\mathrm{NAD}^{+}$, NADPH, acetyl-CoA levels and flux through the pentose-P pathway by balancing the posttranslational acetylation state of the gatekeeper enzyme in the pathway.

\subsection{Multiple Posttranslational Modifications of Rho GTPase: Utilization of ATP, NAD+, UDP glucose, GeranylgeranyI-PP, SAM, and Indirectly Acetyl-CoA}

The Rho subfamily of small GTPases can serve as protein poster child for five of the six group transfer metabolites central jointly to metabolism and protein posttranslational modifications. ${ }^{161,162}$ In addition to the C-terminal geranylgeranylation $\left(\mathrm{Cys}_{190}\right)$ and $\mathrm{O}$ methylation of the newly exposed C-terminal carboxylate (utilization of $\mathrm{C}_{20}$ prenyl-PP and SAM, as for Ras in Figure 18b above), Rho can suffer three other types of posttranslational modifications. UDP-glucose can donate its glucosyl moiety to the side chain- $\mathrm{OH}$ of $\mathrm{Thr}_{37}$ with abrogation of GTPase activity (Figure 18d) (summarized in ${ }^{12}$ ). NAD ${ }^{+}$can donate its ADP-ribosyl group to the side chain amide moiety of $\mathrm{Asn}_{41}$.

The fifth modification, phosphorylation, can occur on Rho itself to target it for subsequent polyubiquitylation and destruction by the proteasome but also can involve self phosphorylation of Rho-associated kinase by ATP. ${ }^{162}$ Phosphoryl transfer controls lifetime of Rho as catalyst and this two-step process of phosphorylation and polyubiquitylation is a common motif for marking short lived proteins in cells.

Finally, the sixth group transfer metabolite, acetyl-CoA, is used to acetylate the RhoAspecific GEF partner protein, completing the full panoply of group transfers and exemplifying extensive combinatorial diversification of proteomes ${ }^{163}$. The extent to which any given Rho protein molecule in a cellular population has multiple modifications is not well quantitated nor is the net activity of such multiply-modified Rho species wellevaluated.

\subsection{Nonenzymatic Reactions of Thermodynamically Activated Metabolites?}

One consequence of the combination of thermodynamic activation of the eight metabolites coupled to kinetic stability in physiologic conditions, is that they circulate in cells as diffusible intermediates with useful half lives. This raises the possibility of unintended, nonenzymatic group transfers to cellular macromolecules leading to spurious covalent modifications.

In principle, any of the seven organic activated metabolites and the sole inorganic activated molecule $\mathrm{O}_{2}$ could be susceptible to uncontrolled reactions. There is little evidence that ATP and congeneric NTPs, dNTPs engage in nonenzymatic phosphorylations or nucleotidylations of proteins in phosphoproteomic analyses. Likewise, there seems to be little uncatalyzed liability to isopentenyl-PP as alkylating agent. SAM, the premier biologic methylating reagent could transfer any of the three substituents on the sulfonium cation to cellular nucleophiles but this potential reactivity does not appear to be notably problematic 
in cells. Nor are spurious glycosylations of proteins from NDP-sugars reported to be responsible for random glycosylations. (In contrast, hyperglycemic levels of blood glucose levels modify red cell hemoglobin to give the signature glycosylated hemoglobin A1C in diabetics). ${ }^{164}$

Activated acyl groups are more of a problem. Of the three molecular species, acyl-AMPs, acyl-Ps, acyl-S-CoAs, all are equally activated thermodynamically. But, the acyl-AMPs and acyl-Ps are at much lower concentrations in cellular metabolism and so nonenzymatic acylation/phosphorylations are likely to be of minor incidence and consequence. Not so for some of the predominant acyl-CoAs.

Acyl-CoAs such as acetyl-, malonyl- and succinyl-CoAs are at higher local concentrations in cells. Thousands of proteins can be acetylated as detected by mass spectrometry, albeit the mole fraction and regiochemistry of such species are often uncertain. ${ }^{165,166}$ Many proteins are also found to be succinylated, malonylated, propionylated, and crotonylated. It is possible that a majority of such acylated proteins form nonenzymatically, as whether there exist specific acyltranferases other than acetyltransferases is not clear. ${ }^{64,167,168}$ Acylated proteins may be especially abundant in the mitochondria where there is thought to be a higher $\mathrm{pH}$ and concentration of acetyl-CoA and succinyl-CoA that could enhance rates of nonenzymatic acyl transfer, ${ }^{169,170}$ most commonly to protein lysine residues. Consistent with this idea, several sirtuins are dedicated to the mitochondria as protein deacylases, $55,171-173$ perhaps in a clean up role.

The eighth activated metabolite $\mathrm{O}_{2}$ offers a distinct nonenzymatic liability from the above organic molecules. Nonenzymatic group transfer is not a problem. Rather it is adventitious one electron reduction to superoxide, for example in the presence of inorganic ferrous irons that can set off reactive oxygen species (ROS) cascades. ${ }^{174}$ There is a vast literature on ROS chemistry and biology for oxidation of lipids, proteins, and nucleic acids, illustrating that $\mathrm{O}_{2}$ is probably the most liable to nonenzymatic reactivity and cellular component modifications.

\subsection{Convergent Chemical Logic and Reactivity}

Many of the chemical modifications that occur up at the protein levels thus mirror the kinds of phosphorylations, acetylations, glycosyl transfers, acylations and alkylations that occur down on the ground in primary metabolism. They may reflect an evolutionary expansion of the chemical reactivity built into this set of six group transfer molecules from low molecular weight modifications of metabolites to macromolecular modifications. The convergence of the same kinds of transformations emphasize a core chemical inventory and the utility of ATP, NADH, acetyl-CoA, SAM, IPP and longer homologs, and UDP-glucose in both the low molecular weight and the parallel protein PTM metabolic universes. It is not yet clear how many kinases, acetyl transferases or methyl transferases can carry out group transfers to both low molecular weight and protein substrates. Those that do so tend to have vastly different catalytic throughputs. On the other hand the phosphoinositol kinases and microbial aminoglycoside kinases $^{175}$ are clearly related structurally and evolutionarily to protein kinase families. Regulation of intracellular location and activity of PTM-modified enzymes by the seven group transfer cellular reagents can clearly alter the small molecule metabolome. 


\section{CONCLUDING REMARKS}

The systems biology approaches to the study of metabolism, under the rubric of metabolomics, have revived metabolism as a contemporary scientific activity. Interpretable connection of changes of metabolites to phenotypes is much more likely when perturbations in hundreds of metabolites can be measured simultaneously by mass spectrometry vs the classical approach of one metabolite at a time. Whatever the number of simultaneous measurements that can be made, it is helpful to have molecular insights into the logical framework that unites a small set of molecules that serve as nodal points for driving and integrating key pathways.

Of the eight small molecules highlighted in this review, all can be captured under the rubric of chemical stability in cellular conditions but readily activatable for thermodynamically favorable reactions by specific catalysts. Seven are organic molecules poised to carry out chemical work in metabolism, by displacement of coupled equilibria. The eighth, $\mathrm{O}_{2}$, reacting by one electron reaction manifolds only, serves mostly as a thermodynamically favored electron sink but can also be reductively activated as oxygen transfer agent in lateevolving metabolic pathways.

ATP and NADH are central metabolic players in terms of energy harvesting and energy storage. Both can be accumulated in glycolysis as two molecules of pyruvate are produced and this ancient pathway is independent of $\mathrm{O}_{2}$. So is the tricarboxylate cycle where acetyl$\mathrm{CoA}$, the third prime time energy-rich metabolite, is oxidized to two molecules of $\mathrm{CO}_{2}$ and the eight electrons stored as three $\mathrm{NADH}$ and one $\mathrm{FADH}_{2}$, available for driving dozens of coupled redox transformations. The intersection of phosphoryl group and acyl group chemistry is central in several primary metabolic pathways, exemplified by the diverse roles of carbamoyl-P in both anabolic and catabolic nitrogen metabolism.

When $\mathrm{O}_{2}$ is introduced into the metabolic equations, the electrons that have been captured in NADH can flow via the one electron respiratory chain to carry out the remarkable four electron reduction of $\mathrm{O}_{2}$ to $2 \mathrm{H}_{2} \mathrm{O}$ with a 16-fold increase in ATP yield. This dramatic jump in ATP production is one compelling measure of the thermodynamic activation of $\mathrm{O}_{2}$, achievable under the right chemical circumstances. The transfer of electrons from NADPH to $\mathrm{O}_{2}$ via $2 / 1$ step down flavin chemistry has enabled organisms to unlock the oxygenation potential of $\mathrm{O}_{2}$ via high valent oxoiron species, to carry out dramatic oxygenations of unactivated carbon centers. This $\mathrm{NADPH} / \mathrm{O}_{2}$ interplay enables exquisite regiospecific conversion of hydrophobic to hydrophilic metabolite scaffolds and also provides the only obvious route to removal of methyl groups from proteins and DNA.

Inspection of the structures of NADH, the coenzyme A portion of acyl-CoAs, NDP-hexoses, and SAM reveal a common utilization of the AMP/NMP moiety over and over again as the structural (and perhaps evolutionary) foundation on which the specific group transfer moieties have become grafted. But the business end of the seven molecules is distinct and reveals that organisms have collected a customized set of organic (acyl phosphates, acyl thioesters, dihydropyridines, alkyl sulfoniums, allyl cation precursors, glycosyl oxocarbonium ion precursors) and inorganic (phosphoric anhydrides, dioxygen) functional 
groups to carry out specific chemistries. These functional groups get spent on their own and in sequential, combinatorial action to power the primary metabolic pathways of life.

It is likely that most metabolomic studies of metabolite perturbations, be they genetic or pharmacologic, are reflecting the interconnected nodal points at which these seven central metabolites traffic in cells. The controlled reactivity of the group transfer molecules highlighted in this review spill over from small molecule metabolism to macromolecular decoration, in enzymes, glycoproteins, regulatory proteins, RNA, and DNA, emphasizing the logical and metabolic continuity of their use.

Gene content directly determines encoded protein content, via mRNA intermediacy, but the 2000 (known) small molecule metabolites in cells and tissues are not directly encoded in DNA. To be sure the transformation of one set of metabolites into others is mediated by proteins with specific encoded catalytic activities and that includes the enzymes that build these seven group transfer metabolites. But the coalescence of catalytic machineries to stitch these small molecule scaffolds together to bring the palette of described chemistries to bear is a remarkable bottom up achievement to enable the chemistry of life, balancing the top down information in the genes themselves.

\section{Acknowledgments}

Related work in our labs are supported by NIH (1R35GM118056 to YT and R01GM094314 and R01CA185169 to BPT) and the David and Lucile Packard Fellowship to YT and BPT.

\section{LITERATURE CITED}

1. Frolkis A, Knox C, Lim E, Jewison T, Law V, Hau DD, Liu P, Gautam B, Ly S, Guo AC, et al. SMPDB: the small molecule pathway database. Nucleic Acids Res. 2010; 38:D480-487. [PubMed: 19948758]

2. Patti GJ, Yanes O, Siuzdak G. Innovation: Metabolomics: the apogee of the omics trilogy. Nat Rev Mol Cell Biol. 2012; 13:263-269. [PubMed: 22436749]

3. Hackett SR, Zanotelli VR, Xu W, Goya J, Park JO, Perlman DH, Gibney PA, Botstein D, Storey JD, Rabinowitz JD. Systems-level analysis of mechanisms regulating yeast metabolic flux. Science. 2016; 354:aaf2786. [PubMed: 27789812]

4. Jencks, WP. Catalysis in chemistry and enzymology. Dover Publications; 1987.

5. Canto C, Menzies KJ, Auwerx J. NAD(+) metabolism and the control of energy homeostasis: a balancing act between mitochondria and the nucleus. Cell Metab. 2015; 22:31-53. [PubMed: 26118927]

6. Pietrocola F, Galluzzi L, Bravo-San Pedro JM, Madeo F, Kroemer G. Acetyl coenzyme A: a central metabolite and second messenger. Cell Metab. 2015; 21:805-821. [PubMed: 26039447]

7. Westheimer FH. Why nature chose phosphates. Science. 1987; 235:1173-1178. [PubMed: 2434996]

8. Walsh, CT. Enzymatic reaction mechanisms. W.H. Freeman; San Francisco: 1979.

9. Walsh, CT., Tang, Y. Natural product biosynthesis: chemical logic and enzymatic machinery. Royal Society of Chemistry; London: 2017.

10. Nelson, D., Cox, M. Lehninger Principles of Biochemsitry. 6. W.H. Freeman \& Co; Ny NY: 2013. 11. Gilbert W. Origin of life: the RNA world. Nature. 1986; 319:618.

12. Walsh, CT. Posttrtanslational modification of proteins: expanding nature's inventory. Roberts and Co; Colorado: 2005.

13. Milo R, Jorgensen P, Moran U, Weber G, Springer M. BioNumbers--the database of key numbers in molecular and cell biology. Nucleic Acids Res. 2010; 38:D750-753. [PubMed: 19854939] 
14. Krupenie PH. The spectrum of molecular oxygen. J Phys Chem Ref Data. 1972; 1:423-534.

15. Wood PM. What is the Nernst equation. Trends Biochem Sci. 1985; 10:106-107.

16. Rich PR. The molecular machinery of Keilin's respiratory chain. Biochem Soc Trans. 2003; 31:1095-1105. [PubMed: 14641005]

17. Knowles JR. Enzyme-catalyzed phosphoryl transfer reactions. Annu Rev Biochem. 1980; 49:877919. [PubMed: 6250450]

18. Gajewski E, Steckler DK, Goldberg RN. Thermodynamics of the hydrolysis of ATP to ADP. J Biol Chem. 1986; 261:12733-12737. [PubMed: 3528161]

19. Beis I, Newsholme EA. The contents of adenine nucleotides, phosphagens and some glycolytic intermediates in resting muscles from vertebrates and invertebrates. Biochem J. 1975; 152:23-32. [PubMed: 1212224]

20. Kornberg, A. For the love of enzymes: odyssey of a biochemist. First Harvard University Press; 1989.

21. Wakil SJ, Stoops JK, Joshi VC. Fatty acid synthesis and its regulation. Annu Rev Biochem. 1983; 52:537-579. [PubMed: 6137188]

22. Miziorko HM. Enzymes of the mevalonate pathway of isoprenoid biosynthesis. Arch Biochem Biophys. 2011; 505:131-143. [PubMed: 20932952]

23. Valiev M, Kawai R, Adams JA, Weare JH. The role of the putative catalytic base in the phosphoryl transfer reaction in a protein kinase: first-principles calculations. J Am Chem Soc. 2003; 125:9926-9927. [PubMed: 12914447]

24. Carman GM, Han GS. Roles of phosphatidate phosphatase enzymes in lipid metabolism. Trends Biochem Sci. 2006; 31:694-699. [PubMed: 17079146]

25. Miller GA Jr, Rosenzweig S, Switzer RL. Oxygen-18 studies of the mechanism of pyrophosphoryl group transfer catalyzed by phosphoribosylpyrophosphate synthetase. Arch Biochem Biophys. 1975; 171:732-736. [PubMed: 173242]

26. Hove-Jensen B, Andersen KR, Kilstrup M, Martinussen J, Switzer RL, Willemoes M. Phosphoribosyl diphosphate (PRPP): biosynthesis, enzymology, utilization, and metabolic significance. Microbiol Mol Biol Rev. 2017; 81

27. Sheppard DE, Penrod JT, Bobik T, Kofoid E, Roth JR. Evidence that a B12-adenosyl transferase is encoded within the ethanolamine operon of Salmonella enterica. J Bacteriol. 2004; 186:76357644. [PubMed: 15516577]

28. Mera PE, Escalante-Semerena JC. Multiple roles of ATP:cob(I)alamin adenosyltransferases in the conversion of B12 to coenzyme B12. Appl Microbiol Biotechnol. 2010; 88:41-48. [PubMed: 20677021]

29. Imai S, Guarente L. NAD+ and sirtuins in aging and disease. Trends Cell Biol. 2014; 24:464-471. [PubMed: 24786309]

30. Mouchiroud L, Houtkooper RH, Auwerx J. NAD(+) metabolism: a therapeutic target for agerelated metabolic disease. Crit Rev Biochem Mol Biol. 2013; 48:397-408. [PubMed: 23742622]

31. Veech RL, Guynn R, Veloso D. The time-course of the effects of ethanol on the redox and phosphorylation states of rat liver. Biochem J. 1972; 127:387-397. [PubMed: 4342558]

32. Casazza JP, Veech RL. The content of pentose-cycle intermediates in liver in starved, fed ad libitum and meal-fed rats. Biochem J. 1986; 236:635-641. [PubMed: 3790084]

33. Curtis, W., Kemper, M., Miller, A., Pawlosky, R., King, MT., Veech, RL. Ketogenic Diet and Metabolic Therapy. Masino, SA., editor. Oxford University Press; 2016.

34. Bucher T, Brauser B, Conze A, Klein F, Langguth O, Sies H. State of oxidation-reduction and state of binding in the cytosolic NADH-system as disclosed by equilibration with extracellular lactatepyruvate in hemoglobin-free perfused rat liver. Eur J Biochem. 1972; 27:301-317. [PubMed: 4340564]

35. Nakahata Y, Sahar S, Astarita G, Kaluzova M, Sassone-Corsi P. Circadian control of the NAD+ salvage pathway by CLOCK-SIRT1. Science. 2009; 324:654-657. [PubMed: 19286518]

36. Ramsey KM, Yoshino J, Brace CS, Abrassart D, Kobayashi Y, Marcheva B, Hong HK, Chong JL, Buhr ED, Lee C, et al. Circadian clock feedback cycle through NAMPT-mediated NAD+ biosynthesis. Science. 2009; 324:651-654. [PubMed: 19299583] 
37. Asher G, Reinke H, Altmeyer M, Gutierrez-Arcelus M, Hottiger MO, Schibler U. Poly(ADPribose) polymerase 1 participates in the phase entrainment of circadian clocks to feeding. Cell. 2010; 142:943-953. [PubMed: 20832105]

38. Alberty RA. Standard apparent reduction potentials of biochemical half reactions and thermodynamic data on the species involved. Biophys Chem. 2004; 111:115-122. [PubMed: 15381309]

39. Walsh CT, Wencewicz TA. Flavoenzymes: versatile catalysts in biosynthetic pathways. Nat Prod Rep. 2013; 30:175-200. [PubMed: 23051833]

40. Hand SC, Menze MA, Borcar A, Patil Y, Covi JA, Reynolds JA, Toner M. Metabolic restructuring during energy-limited states: insights from Artemia franciscana embryos and other animals. J Insect Physiol. 2011; 57:584-594. [PubMed: 21335009]

41. Kruger NJ, von Schaewen A. The oxidative pentose phosphate pathway: structure and organisation. Curr Opin Plant Biol. 2003; 6:236-246. [PubMed: 12753973]

42. Berkholz DS, Faber HR, Savvides SN, Karplus PA. Catalytic cycle of human glutathione reductase near 1 A resolution. J Mol Biol. 2008; 382:371-384. [PubMed: 18638483]

43. Moreadith RW, Lehninger AL. The pathways of glutamate and glutamine oxidation by tumor cell mitochondria. Role of mitochondrial NAD(P)+-dependent malic enzyme. J Biol Chem. 1984; 259:6215-6221. [PubMed: 6144677]

44. Ochoa S, Mehler A, Kornberg A. Reversible oxidative decarboxylation of malic acid. J Biol Chem. 1947; 167:871. [PubMed: 20287922]

45. Jo SH, Son MK, Koh HJ, Lee SM, Song IH, Kim YO, Lee YS, Jeong KS, Kim WB, Park JW, et al. Control of mitochondrial redox balance and cellular defense against oxidative damage by mitochondrial NADP+-dependent isocitrate dehydrogenase. J Biol Chem. 2001; 276:1616816176. [PubMed: 11278619]

46. Magni G, Orsomando G, Raffaelli G. Structural and functional properties of NAD kinase, a key enzyme in NADP biosynthesis. Mini Rev Med Chem. 2006; 6:739-746. [PubMed: 16842123]

47. Jackson JB. Proton translocation by transhydrogenase. FEBS Lett. 2003; 555:176-177. [PubMed: 14630339]

48. Ueda K, Hayaishi O. ADP-ribosylation. Annu Rev Biochem. 1985; 54:73-100. [PubMed: 3927821]

49. Avalos JL, Boeke JD, Wolberger C. Structural basis for the mechanism and regulation of Sir2 enzymes. Mol Cell. 2004; 13:639-648. [PubMed: 15023335]

50. Sauve AA, Celic I, Avalos J, Deng H, Boeke JD, Schramm VL. Chemistry of gene silencing: the mechanism of NAD+-dependent deacetylation reactions. Biochemistry. 2001; 40:15456-15463. [PubMed: 11747420]

51. Hawse WF, Hoff KG, Fatkins DG, Daines A, Zubkova OV, Schramm VL, Zheng W, Wolberger C. Structural insights into intermediate steps in the Sir2 deacetylation reaction. Structure. 2008; 16:1368-1377. [PubMed: 18786399]

52. Suave AA. Sirtuin chemical mechanisms. Biochmib Biophys Acta. 2010; 1804:1591-1603.

53. Houtkooper RH, Pirinen E, Auwerx J. Sirtuins as regulators of metabolism and healthspan. Nat Rev Mol Cell Biol. 2002; 13:225-238.

54. Imai S, Armstrong CM, Kaeberlein M, Guarente L. Transcriptional silencing and longevity protein Sir2 is an NAD-dependent histone deacetylase. Nature. 2000; 403:795-800. [PubMed: 10693811]

55. Du J, Zhou Y, Su X, Yu JJ, Khan S, Jiang H, Kim J, Woo J, Kim JH, Choi BH, et al. Sirt5 is a NAD-dependent protein lysine demalonylase and desuccinylase. Science. 2011; 334:806-809. [PubMed: 22076378]

56. Jiang H, Khan S, Wang Y, Charron G, He B, Sebastian C, Du J, Kim R, Ge E, Mostoslavsky R, et al. SIRT6 regulates TNF-alpha secretion through hydrolysis of long-chain fatty acyl lysine. Nature. 2013; 496:110-113. [PubMed: 23552949]

57. Isabelle M, Moreel X, Gagne JP, Rouleau M, Ethier C, Gagne P, Hendzel MJ, Poirier GG. Investigation of PARP-1, PARP-2, and PARG interactomes by affinity-purification mass spectrometry. Proteome Sci. 2010; 8:22-35. [PubMed: 20388209]

58. Livraghi L, Garber JE. PARP inhibitors in the management of breast cancer: current data and future prospects. BMC Med. 2015; 13:188. [PubMed: 26268938] 
59. Leung AK. Poly(ADP-ribose): an organizer of cellular architecture. J Cell Biol. 2014; 205:613619. [PubMed: 24914234]

60. Hatakeyama K, Nemoto Y, Ueda K, Hayaishi O. Purification and characterization of poly(ADPribose) glycohydrolase. Different modes of action on large and small poly(ADP-ribose). J Biol Chem. 1986; 261:14902-14911. [PubMed: 3771556]

61. Lin W, Ame JC, Aboul-Ela N, Jacobson EL, Jacobson MK. Isolation and characterization of the cDNA encoding bovine poly(ADP-ribose) glycohydrolase. J Biol Chem. 1997; 272:11895-11901. [PubMed: 9115250]

62. Luo X, Kraus WL. On PAR with PARP: cellular stress signaling through poly(ADP-ribose) and PARP-1. Genes Dev. 2012; 26:417-432. [PubMed: 22391446]

63. Howard M, Grimaldi JC, Bazan JF, Lund FE, Santos-Argumedo L, Parkhouse RM, Walseth TF, Lee HC. Formation and hydrolysis of cyclic ADP-ribose catalyzed by lymphocyte antigen CD38. Science. 1993; 262:1056-1059. [PubMed: 8235624]

64. Shi L, Tu BP. Acetyl-CoA and the regulation of metabolism: mechanisms and consequences. Curr Opin Cell Biol. 2015; 33:125-131. [PubMed: 25703630]

65. Lee KK, Workman JL. Histone acetyltransferase complexes: one size doesn't fit all. Nat Rev Mol Cell Biol. 2007; 8:284-295. [PubMed: 17380162]

66. Berg P. Acyl adenylates; an enzymatic mechanism of acetate activation. J Biol Chem. 1956; 222:991-1013. [PubMed: 13367067]

67. Jones ME, Lipmann F, Hilz H, Lynen F. On the enzymatic mechanism of Coenzyme A acetylation with adenosine triphosphate and acetate. J Am Chem Soc. 1953; 75:3285-3286.

68. Lipmann F, Tuttle LC. The detection of activated carboxyl groups with hydroxylamine as interceptor. J Biol Chem. 1945; 161:415-416. [PubMed: 21005751]

69. Comerford SA, Huang Z, Du X, Wang Y, Cai L, Witkiewicz AK, Walters H, Tantawy MN, Fu A, Manning HC, et al. Acetate dependence of tumors. Cell. 2014; 159:1591-1602. [PubMed: 25525877]

70. Hashizume R, Maki Y, Mizutani K, Takahashi N, Matsubara H, Sugita A, Sato K, Yamaguchi S, Mikami B. Crystal structures of protein glutaminase and its pro forms converted into enzymesubstrate complex. J Biol Chem. 2011; 286:38691-38702. [PubMed: 21926168]

71. Hewagama A, Guy HI, Vickrey JF, Evans DR. Functional linkage between the glutaminase and synthetase domains of carbamoyl-phosphate synthetase. Role of serine 44 in carbamoyl-phosphate synthetase-aspartate carbamoyltransferase-dihydroorotase (cad). J Biol Chem. 1999; 274:2824028245. [PubMed: 10497179]

72. Goldford JE, Hartman H, Smith TF, Segre D. Remnants of an ancient metabolism without phosphate. Cell. 2017; 168:1126-1134. e1129. [PubMed: 28262353]

73. Berg, JM., Tymoczko, JL., Stryer, L. Biochemistry. 5. W.H. Freeman; New York: 2002.

74. Boudreau A, Purkey HE, Hitz A, Robarge K, Peterson D, Labadie S, Kwong M, Hong R, Gao M, Del Nagro C, et al. Metabolic plasticity underpins innate and acquired resistance to LDHA inhibition. Nat Chem Biol. 2016; 12:779-786. [PubMed: 27479743]

75. Peng M, Yin N, Chhangawala S, Xu K, Leslie CS, Li MO. Aerobic glycolysis promotes T helper 1 cell differentiation through an epigenetic mechanism. Science. 2016; 354:481-484. [PubMed: 27708054]

76. Zhang J, Nuebel E, Daley GQ, Koehler CM, Teitell MA. Metabolic regulation in pluripotent stem cells during reprogramming and self-renewal. Cell Stem Cell. 2012; 11:589-595. [PubMed: 23122286]

77. Ito K, Suda T. Metabolic requirements for the maintenance of self-renewing stem cells. Nat Rev Mol Cell Biol. 2014; 15:243-256. [PubMed: 24651542]

78. Mashimo T, Pichumani K, Vemireddy V, Hatanpaa KJ, Singh DK, Sirasanagandla S, Nannepaga S, Piccirillo SG, Kovacs Z, Foong C, et al. Acetate is a bioenergetic substrate for human glioblastoma and brain metastases. Cell. 2014; 159:1603-1614. [PubMed: 25525878]

79. Jackson V, Shires A, Chalkley R, Granner DK. Studies on highly metabolically active acetylation and phosphorylation of histones. J Biol Chem. 1975; 250:4856-4863. [PubMed: 168194]

80. Warburg O. On the origin of cancer cells. Science. 1956; 123:309-314. [PubMed: 13298683] 
81. Lunt SY, Vander Heiden MG. Aerobic glycolysis: meeting the metabolic requirements of cell proliferation. Annu Rev Cell Dev Biol. 2011; 27:441-464. [PubMed: 21985671]

82. Sieber MH, Thomsen MB, Spradling AC. Electron transport chain remodeling by GSK3 during oogenesis connects nutrient state to reproduction. Cell. 2016; 164:420-432. [PubMed: 26824655]

83. Chen J, Sutter BM, Shi L, Tu BP. GATOR1 regulates nitrogenic cataplerotic reactions of the mitochondrial TCA cycle. Nat Chem Biol. 2017; 13:1179-1186. [PubMed: 28920930]

84. Chen C, Pore N, Behrooz A, Ismail-Beigi F, Maity A. Regulation of glut1 mRNA by hypoxiainducible factor-1. Interaction between H-ras and hypoxia. J Biol Chem. 2001; 276:9519-9525. [PubMed: 11120745]

85. Guy HI, Rotgeri A, Evans DR. Activation by fusion of the glutaminase and synthetase subunits of Escherichia coli carbamyl-phosphate synthetase. J Biol Chem. 1997; 272:19913-19918. [PubMed: 9242657]

86. Wojcik M, Seidle HF, Bieganowski P, Brenner C. Glutamine-dependent NAD+ synthetase. How a two-domain, three-substrate enzyme avoids waste. J Biol Chem. 2006; 281:33395-33402. [PubMed: 16954203]

87. Thoden JB, Holden HM, Wesenberg G, Raushel FM, Rayment I. Structure of carbamoyl phosphate synthetase: a journey of 96 A from substrate to product. Biochemistry. 1997; 36:6305-6316. [PubMed: 9174345]

88. Thoden JB, Huang X, Raushel FM, Holden HM. Carbamoyl-phosphate synthetase. Creation of an escape route for ammonia. J Biol Chem. 2002; 277:39722-39727. [PubMed: 12130656]

89. Holden HM, Thoden JB, Raushel FM. Carbamoyl phosphate synthetase: an amazing biochemical odyssey from substrate to product. Cell Mol Life Sci. 1999; 56:507-522. [PubMed: 11212301]

90. Nakagawa T, Lomb DJ, Haigis MC, Guarente L. SIRT5 Deacetylates carbamoyl phosphate synthetase 1 and regulates the urea cycle. Cell. 2009; 137:560-570. [PubMed: 19410549]

91. Raushel FM, Thoden JB, Holden HM. The amidotransferase family of enzymes: molecular machines for the production and delivery of ammonia. Biochemistry. 1999; 38:7891-7899. [PubMed: 10387030]

92. Thoden JB, Huang X, Kim J, Raushel FM, Holden HM. Long-range allosteric transitions in carbamoyl phosphate synthetase. Protein Sci. 2004; 13:2398-2405. [PubMed: 15322282]

93. Marolewski A, Mattia KM, Warren MS, Benkovic SJ. Formyl phosphate: a proposed intermediate in the reaction catalyzed by Escherichia coli PurT GAR transformylase. Biochemistry. 1997; 36:6709-6716. [PubMed: 9184151]

94. Wang Q, Xia J, Guallar V, Krilov G, Kantrowitz ER. Mechanism of thermal decomposition of carbamoyl phosphate and its stabilization by aspartate and ornithine transcarbamoylases. Proc Natl Acad Sci U S A. 2008; 105:16918-16923. [PubMed: 18971327]

95. Murata LB, Schachman HK. Structural similarity between ornithine and aspartate transcarbamoylases of Escherichia coli: implications for domain switching. Protein Sci. 1996; 5:719-726. [PubMed: 8845762]

96. Issoglio FM, Campolo N, Zeida A, Grune T, Radi R, Estrin DA, Bartesaghi S. Exploring the catalytic mechanism of human glutamine synthetase by computer simulations. Biochemistry. 2016; 55:5907-5916.

97. Coloff JL, Murphy JP, Braun CR, Harris IS, Shelton LM, Kami K, Gygi SP, Selfors LM, Brugge JS. Differential glutamate metabolism in proliferating and quiescent mammary epithelial cells. Cell Metab. 2016; 23:867-880. [PubMed: 27133130]

98. Tohyama S, Fujita J, Hishiki T, Matsuura T, Hattori F, Ohno R, Kanazawa H, Seki T, Nakajima K, Kishino Y, et al. Glutamine Oxidation Is Indispensable for Survival of Human Pluripotent Stem Cells. Cell Metab. 2016; 23:663-674. [PubMed: 27050306]

99. Davidson SM, Papagiannakopoulos T, Olenchock BA, Heyman JE, Keibler MA, Luengo A, Bauer MR, Jha AK, O'Brien JP, Pierce KA, et al. Environment impacts the metabolic dependencies of Ras-driven non-small cell lung cancer. Cell Metab. 2016; 23:517-528. [PubMed: 26853747]

100. Spinelli JB, Yoon H, Ringel AE, Jeanfavre S, Clish CB, Haigis; MC. Metabolic recycling of ammonia via glutamate dehydrogenase supports breast cancer biomass. Science. 2017; doi: 10.1126/science.aam9305 
101. Wise DR, DeBerardinis RJ, Mancuso A, Sayed N, Zhang XY, Pfeiffer HK, Nissim I, Daikhin E, Yudkoff M, McMahon SB, et al. Myc regulates a transcriptional program that stimulates mitochondrial glutaminolysis and leads to glutamine addiction. Proc Natl Acad Sci U S A. 2008; 105:18782-18787. [PubMed: 19033189]

102. Reitzer LJ, Wice BM, Kennell D. Evidence that glutamine, not sugar, is the major energy source for cultured HeLa cells. J Biol Chem. 1979; 254:2669-2676. [PubMed: 429309]

103. Owen OE, Kalhan SC, Hanson RW. The key role of anaplerosis and cataplerosis for citric acid cycle function. J Biol Chem. 2002; 277:30409-30412. [PubMed: 12087111]

104. Marin-Valencia I, Yang C, Mashimo T, Cho S, Baek H, Yang XL, Rajagopalan KN, Maddie M, Vemireddy V, Zhao Z, et al. Analysis of tumor metabolism reveals mitochondrial glucose oxidation in genetically diverse human glioblastomas in the mouse brain in vivo. Cell Metab. 2012; 15:827-837. [PubMed: 22682223]

105. Zhang J, Pavlova NN, Thompson CB. Cancer cell metabolism: the essential role of the nonessential amino acid, glutamine. EMBO J. 2017; 36:1302-1315. [PubMed: 28420743]

106. Bennett BD, Kimball EH, Gao M, Osterhout R, Van Dien SJ, Rabinowitz JD. Absolute metabolite concentrations and implied enzyme active site occupancy in Escherichia coli. Nat Chem Biol. 2009; 5:593-599. [PubMed: 19561621]

107. Danbolt NC. Glutamate uptake. Prog Neurobiol. 2001; 65:1-105. [PubMed: 11369436]

108. Divino Filho JC, Hazel SJ, Furst P, Bergstrom J, Hall K. Glutamate concentration in plasma, erythrocyte and muscle in relation to plasma levels of insulin-like growth factor (IGF)-I, IGF binding protein-1 and insulin in patients on haemodialysis. J Endocrinol. 1998; 156:519-527. [PubMed: 9582509]

109. Fontecave M, Atta M, Mulliez E. S-adenosylmethionine: nothing goes to waste. Trends Biochem Sci. 2004; 29:243-249. [PubMed: 15130560]

110. Liang PH, Ko TP, Wang AH. Structure, mechanism and function of prenyltransferases. Eur J Biochem. 2002; 269:3339-3354. [PubMed: 12135472]

111. Wang M, Casey PJ. Protein prenylation: unique fats make their mark on biology. Nat Rev Mol Cell Biol. 2016; 17:110-122. [PubMed: 26790532]

112. Tansey TR, Shechter I. Squalene synthase: structure and regulation. Prog Nucleic Acid Res Mol Biol. 2001; 65:157-195. [PubMed: 11008488]

113. Burkhardt PK, Beyer P, Wunn J, Kloti A, Armstrong GA, Schledz M, von Lintig J, Potrykus I. Transgenic rice (Oryza sativa) endosperm expressing daffodil (Narcissus pseudonarcissus) phytoene synthase accumulates phytoene, a key intermediate of provitamin A biosynthesis. Plant J. 1997; 11:1071-1078. [PubMed: 9193076]

114. Abe I, Sankawa U, Ebizuka Y. Purification of 2,3-oxidosqualene:beta amyrin cyclase from pea seedlings. Chem Pharm Bull. 1989; 37:536-538.

115. Mato JM, Alvarez L, Ortiz P, Pajares MA. S-adenosylmethionine synthesis: molecular mechanisms and clinical implications. Pharmacol Ther. 1997; 73:265-280. [PubMed: 9175157]

116. German DC, Bloch CA, Kredich NM. Measurements of S-adenosylmethionine and Lhomocysteine metabolism in cultured human lymphoid cells. J Biol Chem. 1983; 258:1099711003. [PubMed: 6885808]

117. Gross A, Geresh S, Whitesides GM. Enzymatic synthesis of S-adenosyl-L-methionine from Lmethionine and ATP. Appl Biochem Biotechnol. 1983; 8:415-422. [PubMed: 6679195]

118. Perche-Letuvee P, Kathirvelu V, Berggren G, Clemancey M, Latour JM, Maurel V, Douki T, Armengaud J, Mulliez E, Fontecave M, et al. 4-Demethylwyosine synthase from Pyrococcus abyssi is a radical-S-adenosyl-L-methionine enzyme with an additional $[4 \mathrm{Fe}-4 \mathrm{~S}](+2)$ cluster that interacts with the pyruvate co-substrate. J Biol Chem. 2012; 287:41174-41185. [PubMed: 23043105]

119. Atta M, Mulliez E, Arragain S, Forouhar F, Hunt JF, Fontecave M. S-Adenosylmethioninedependent radical-based modification of biological macromolecules. Curr Opin Struct Biol. 2010; 20:684-692. [PubMed: 20951571]

120. Broderick JB, Duffus BR, Duschene KS, Shepard EM. Radical S-adenosylmethionine enzymes. Chem Rev. 2014; 114:4229-4317. [PubMed: 24476342] 
121. Vilkaitis G, Merkiene E, Serva S, Weinhold E, Klimasauskas S. The mechanism of DNA cytosine-5 methylation. Kinetic and mutational dissection of Hhai methyltransferase. J Biol Chem. 2001; 276:20924-20934. [PubMed: 11283006]

122. Martin C, Zhang Y. The diverse functions of histone lysine methylation. Nat Rev Mol Cell Biol. 2005; 6:838-849. [PubMed: 16261189]

123. Greer EL, Shi Y. Histone methylation: a dynamic mark in health, disease and inheritance. Nat Rev Genet. 2012; 13:343-357. [PubMed: 22473383]

124. Sutter BM, Wu X, Laxman S, Tu BP. Methionine inhibits autophagy and promotes growth by inducing the SAM-responsive methylation of PP2A. Cell. 2013; 154:403-415. [PubMed: 23870128]

125. Obata F, Miura M. Enhancing S-adenosyl-methionine catabolism extends Drosophila lifespan. Nat Commun. 2015; 6:8332. [PubMed: 26383889]

126. Ye C, Sutter BM, Wang Y, Kuang Z, Tu BP. A metabolic function for phospholipid and histone methylation. Mol Cell. 2017; 66:180-193. e188. [PubMed: 28366644]

127. Dobson GP, Hitchins S, Teague WE. Thermodynamics of thr pyruvate kinase reaction. J Biol Chem. 2002; 277:27176-27182. [PubMed: 11986306]

128. Csala M, Marcolongo P, Lizak B, Senesi S, Margittai E, Fulceri R, Magyar JE, Benedetti A, Banhegyi G. Transport and transporters in the endoplasmic reticulum. Biochim Biophys Acta. 2007; 1768:1325-1341. [PubMed: 17466261]

129. Bieberich E. Synthesis, processing, and function of N-glycans in N-glycoproteins. Adv Neurobiol. 2014; 9:47-70. [PubMed: 25151374]

130. Hirst J. Mitochondrial Complex I. Annu Rev Biochem. 2013; 82:551-575. [PubMed: 23527692]

131. Ito S, D'Alessio AC, Taranova OV, Hong K, Sowers LC, Zhang Y. Role of Tet proteins in $5 \mathrm{mC}$ to 5hmC conversion, ES-cell self-renewal and inner cell mass specification. Nature. 2010; 466:1129-1133. [PubMed: 20639862]

132. Tahiliani M, Koh KP, Shen Y, Pastor WA, Bandukwala H, Brudno Y, Agarwal S, Iyer LM, Liu DR, Aravind L, et al. Conversion of 5-methylcytosine to 5-hydroxymethylcytosine in mammalian DNA by MLL partner TET1. Science. 2009; 324:930-935. [PubMed: 19372391]

133. Shen L, Zhang Y. Enzymatic analysis of Tet proteins: key enzymes in the metabolism of DNA methylation. Methods Enzymol. 2012; 512:93-105. [PubMed: 22910204]

134. Bikle DD. Vitamin D metabolism, mechanism of action, and clinical applications. Chem Biol. 2014; 21:319-329. [PubMed: 24529992]

135. Losman JA, Kaelin WG. What a difference a hydroxyl makes: mutant IDH, R-2-hydroxyglutarate and cancer. Genes Dev. 2016; 27:836-852.

136. Dalziel K, Londesborough JC. The mechanisms of reductive carboxylation reactions. Carbon dioxide or bicarbonate as substrate of nicotinamide-adenine dinucleotide phosphate-linked isocitrate dehydrogenase and malic enzyme. Biochem J. 1968; 110:223-230. [PubMed: 4387225]

137. Dang L, White DW, Gross S, Bennett BD, Bittinger MA, Driggers EM, Fantin VR, Jang HG, Jin $\mathrm{S}$, Keenan MC, et al. Cancer-associated IDH1 mutations produce 2-hydroxyglutarate. Nature. 2009; 462:739-744. [PubMed: 19935646]

138. Intlekofer AM, Dematteo RG, Venneti S, Finley LW, Lu C, Judkins AR, Rustenburg AS, Grinaway PB, Chodera JD, Cross JR, et al. Hypoxia Induces production of L-2-hydroxyglutarate. Cell Metab. 2015; 22:304-311. [PubMed: 26212717]

139. Oldham WM, Clish CB, Yang Y, Loscalzo J. Hypoxia-mediated increases in L-2hydroxyglutarate coordinate the metabolic response to reductive stress. Cell Metab. 2015; 22:291-303. [PubMed: 26212716]

140. Santagata S, Eberlin LS, Norton I, Calligaris D, Feldman DR, Ide JL, Liu X, Wiley JS, Vestal $\mathrm{ML}$, Ramkissoon SH, et al. Intraoperative mass spectrometry mapping of an onco-metabolite to guide brain tumor surgery. Proc Natl Acad Sci U S A. 2014; 111:11121-11126. [PubMed: 24982150]

141. Wu F, Jiang H, Zheng B, Kogiso M, Yao Y, Zhou C, Li XN, Song Y. Inhibition of cancerassociated mutant isocitrate dehydrogenases by 2-yhiohydantoin compounds. J Med Chem. 2015; 58:6899-6908. [PubMed: 26280302] 
142. Dang L, Su SM. Isocitrate Dehydrogenase Mutation and (R)-2-Hydroxyglutarate: From Basic Discovery to Therapeutics Development. Annu Rev Biochem. 2017; 86:305-331. [PubMed: 28375741]

143. Klingenberg M. The ADP and ATP transport in mitochondria and its carrier. Biochim Biophys Acta. 2008; 1778:1978-2021. [PubMed: 18510943]

144. Fan F, Williams HJ, Boyer JG, Graham TL, Zhao H, Lehr R, Qi H, Schwartz B, Raushel FM, Meek TD. On the catalytic mechanism of human ATP citrate lyase. Biochemistry. 2012; 51:5198-5211. [PubMed: 22657152]

145. van Rossum HM, Kozak BU, Niemeijer MS, Duine HJ, Luttik MA, Boer VM, Kotter P, Daran JM, van Maris AJ, Pronk JT. Alternative reactions at the interface of glycolysis and citric acid cycle in Saccharomyces cerevisiae. FEMS Yeast Res. 2016; 16:fow017. [PubMed: 26895788]

146. Booty LM, King MS, Thangaratnarajah C, Majd H, James AM, Kunji ER, Murphy MP. The mitochondrial dicarboxylate and 2-oxoglutarate carriers do not transport glutathione. FEBS Lett. 2015; 589:621-628. [PubMed: 25637873]

147. Agrimi G, Di Noia MA, Marobbio CM, Fiermonte G, Lasorsa FM, Palmieri F. Identification of the human mitochondrial S-adenosylmethionine transporter: bacterial expression, reconstitution, functional characterization and tissue distribution. Biochem J. 2004; 379:183-190. [PubMed: 14674884]

148. Walsh CT, Garneau-Tsodikova S, Gatto GJ Jr. Protein posttranslational modifications: the chemistry of proteome diversifications. Angew Chem Int Ed. 2005; 44:7342-7372.

149. Shi Y. Serine/threonine phosphatases: mechanism through structure. Cell. 2009; 139:468-484. [PubMed: 19879837]

150. Simon MC. The hypoxia response pathways - hats off! N Engl J Med. 2016; 375:1687-1689. [PubMed: 27618882]

151. Martinez S, Hausinger RP. Catalytic mechanisms of Fe(II)- and 2-oxoglutarate-dependent oxygenases. J Biol Chem. 2015; 290:20702-20711. [PubMed: 26152721]

152. Waterborg JH. Dynamics of histone acetylation in Saccharomyces cerevisiae. Biochemistry. 2001; 40:2599-2605. [PubMed: 11327883]

153. Zee BM, Levin RS, DiMaggio PA, Garcia BA. Global turnover of histone post-translational modifications and variants in human cells. Epigenetics Chromatin. 2010; 3:22. [PubMed: 21134274]

154. Cherfils J, Zeghouf M. Regulation of small GTPases by GEFs, GAPs, and GDIs. Physiol Rev. 2013; 93:269-309. [PubMed: 23303910]

155. Mishra AK, Lambright DG. Invited review: small GTPases and their GAPs. Biopolymers. 2016; 105:431-448. [PubMed: 26972107]

156. Lee J, Stock J. Protein phosphatase 2 A catalytic subunit is methyl-esterified at its carboxyl terminus by a novel methyltransferase. J Biol Chem. 1993; 268:19192-19195. [PubMed: 8396127]

157. Xie H, Clarke S. Methyl esterification of C-terminal leucine residues in cytosolic 36-kDa polypeptides of bovine brain. A novel eucaryotic protein carboxyl methylation reaction. J Biol Chem. 1993; 268:13364-13371. [PubMed: 8514774]

158. Xie H, Clarke S. Protein phosphatase $2 \mathrm{~A}$ is reversibly modified by methyl esterification at its Cterminal leucine residue in bovine brain. J Biol Chem. 1994; 269:1981-1984. [PubMed: 8294450]

159. Lee J, Chen Y, Tolstykh T, Stock J. A specific protein carboxyl methylesterase that demethylates phosphoprotein phosphatase 2A in bovine brain. Proc Natl Acad Sci U S A. 1996; 93:60436047. [PubMed: 8650216]

160. Wang YP, Zhou LS, Zhao YZ, Wang SW, Chen LL, Liu LX, Ling ZQ, Hu FJ, Sun YP, Zhang JY, et al. Regulation of G6PD acetylation by SIRT2 and KAT9 modulates NADPH homeostasis and cell survival during oxidative stress. EMBO J. 2014; 33:1304-1320. [PubMed: 24769394]

161. Hodge RG, Ridley AJ. Regulating Rho GTPases and their regulators. Nat Rev Mol Cell Biol. 2016; 17:496-510. [PubMed: 27301673]

162. Visvikis O, Maddugoda MP, Lemichez E. Direct modifications of Rho proteins: deconstructing GTPase regulation. Biol Cell. 2010; 102:377-389. [PubMed: 20377524] 
163. Song EH, Oh W, Ulu A, Carr HS, Zuo Y, Frost JA. Acetylation of the RhoA GEF Net1A controls its subcellular localization and activity. J Cell Sci. 2015; 128:913-922. [PubMed: 25588829]

164. Anguizola J, Matsuda R, Barnaby OS, Hoy KS, Wa C, DeBolt E, Koke M, Hage DS. Review: Glycation of human serum albumin. Clin Chim Acta. 2013; 425:64-76. [PubMed: 23891854]

165. Choudhary C, Kumar C, Gnad F, Nielsen ML, Rehman M, Walther TC, Olsen JV, Mann M. Lysine acetylation targets protein complexes and co-regulates major cellular functions. Science. 2009; 325:834-840. [PubMed: 19608861]

166. Zhao S, Xu W, Jiang W, Yu W, Lin Y, Zhang T, Yao J, Zhou L, Zeng Y, Li H, et al. Regulation of cellular metabolism by protein lysine acetylation. Science. 2010; 327:1000-1004. [PubMed: 20167786]

167. Cai L, Tu BP. On acetyl-CoA as a gauge of cellular metabolic state. Cold Spring Harb Symp Quant Biol. 2011; 76:195-202. [PubMed: 21900151]

168. Wagner GR, Bhatt DP, O'Connell TM, Thompson JW, Dubois LG, Backos DS, Yang H, Mitchell GA, Ilkayeva OR, Stevens RD, et al. A class of reactive acyl-CoA species reveals the nonenzymatic origins of protein acylation. Cell Metab. 2017; 25:823-837. e828. [PubMed: 28380375]

169. Wagner GR, Hirschey MD. Nonenzymatic protein acylation as a carbon stress regulated by sirtuin deacylases. Mol Cell. 2014; 54:5-16. [PubMed: 24725594]

170. Weinert BT, Iesmantavicius V, Moustafa T, Scholz C, Wagner SA, Magnes C, Zechner R, Choudhary C. Acetylation dynamics and stoichiometry in Saccharomyces cerevisiae. Mol Syst Biol. 2014; 10:716. [PubMed: 24489116]

171. Ahn BH, Kim HS, Song S, Lee IH, Liu J, Vassilopoulos A, Deng CX, Finkel T. A role for the mitochondrial deacetylase Sirt3 in regulating energy homeostasis. Proc Natl Acad Sci U S A. 2008; 105:14447-14452. [PubMed: 18794531]

172. Hirschey MD, Shimazu T, Goetzman E, Jing E, Schwer B, Lombard DB, Grueter CA, Harris C, Biddinger S, Ilkayeva OR, et al. SIRT3 regulates mitochondrial fatty-acid oxidation by reversible enzyme deacetylation. Nature. 2010; 464:121-125. [PubMed: 20203611]

173. Lombard DB, Alt FW, Cheng HL, Bunkenborg J, Streeper RS, Mostoslavsky R, Kim J, Yancopoulos G, Valenzuela D, Murphy A, et al. Mammalian Sir2 homolog SIRT3 regulates global mitochondrial lysine acetylation. Mol Cell Biol. 2007; 27:8807-8814. [PubMed: 17923681]

174. Winterbourn CC. Toxicity of iron and hydrogen peroxide: the Fenton reaction. Toxicol Lett. 1995; 82-83:969-974.

175. Scheeff ED, Bourne PE. Structural evolution of the protein kinase-like superfamily. PLoS Comput Biol. 2005; 1:e49. [PubMed: 16244704]

\section{Biographies}

Christopher T. Walsh, born in 1944, studied biology at Harvard and completed his $\mathrm{PhD}$ in biochemistry under Fritz Lipmann at The Rockefeller University. From 1972 to 1987 he held a faculty position at MIT and later moved on to continue his work at Harvard Medical School. He served as Chair of the Department of Chemistry at MIT from 1978 to 1982 and of the Department of Biological Chemistry \& Molecular Pharmacology at Harvard Medical School from 1987 to 1995. In 2014, he was appointed a Consulting Professor of Chemistry at Stanford University and a member of the Stanford Institute for Chemistry, Engineering, and Medicine for Human Health (ChEM-H). His research interests focus on the molecular logic and enzymatic machinery of peptide-based natural product biosynthesis.

Benjamin P. Tu, born in 1977, attended State College Area High School (State College, PA) and received his undergraduate degree in Chemistry from Harvard University in 1998, where he worked in the laboratory of Dr. James C. Wang. He then received his Ph.D. in 
Biochemistry and Biophysics from the University of California, San Francisco in 2003 under the mentorship of Dr. Jonathan S. Weissman. He pursued postdoctoral training under the mentorship of Dr. Steven L. McKnight at UT Southwestern Medical Center in Dallas, Texas. He started his own lab in the Department of Biochemistry at UT Southwestern in 2007. His lab is interested in understanding how fundamental cellular processes are coordinated with metabolism and the metabolic state of the cell.

Yi Tang, born in 1976, attended State College Area High School (State College, PA) and received his undergraduate degree in Chemical Engineering and Material Science from Penn State University in 1997. He received his Ph.D. in Chemical Engineering from California Institute of Technology under the guidance of Prof. David A. Tirrell in 2002. After NIH postdoctoral training in Chemical Biology from Prof. Chaitan Khosla at Stanford University, he started his independent career at University of California Los Angeles in 2004. He is currently Professor in the Department of Chemical and Biomolecular Engineering at UCLA, and holds joint appointments in the Department of Chemistry and Biochemistry; and Department of Bioengineering. His lab is interested in identifying new enzymes from the biosynthetic pathways of polyketides, nonribosomal peptides, terpenoids, alkaloids and hybrid compounds. 


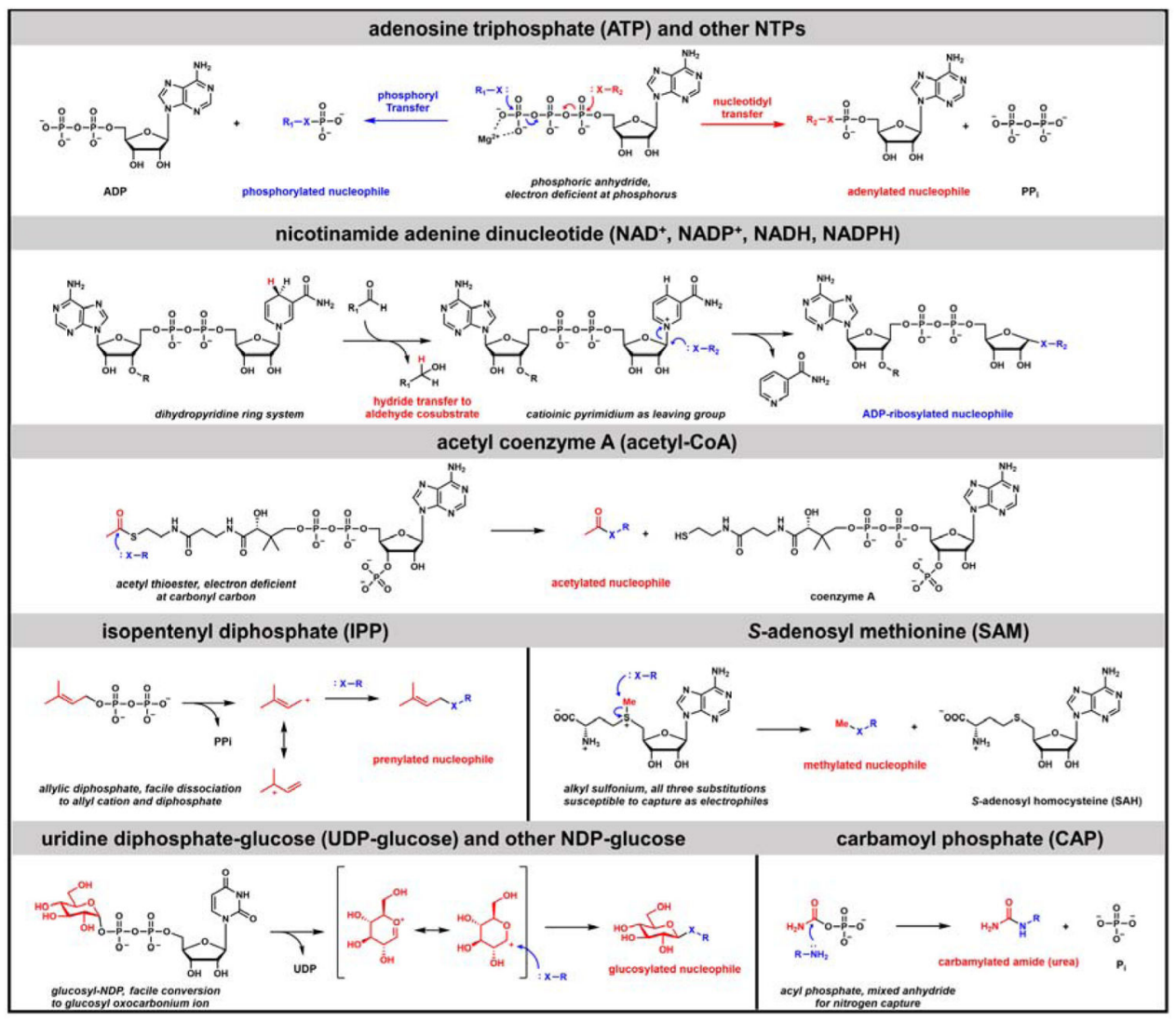

Figure 1.

Seven organic molecules that power cell metabolism: ATP and related Nucleoside Triphosphates (NTPs); oxidized $\left(\mathrm{NAD}^{+}, \mathrm{NADP}^{+}\right.$) and reduced (NADH, NADPH) nicotinamide adenine dinucleotides; acetyl-Coenzyme A; $\Delta^{2-}$ isopentenyl diphosphate (also known historically as isopentenyl pyrophosphate (IPP)); $S$-adenosyl methionine (SAM); Uridine-diphosphoglucose (UDP-glucose) and related NDP-hexoses; carbamoyl phosphate (CAP). 


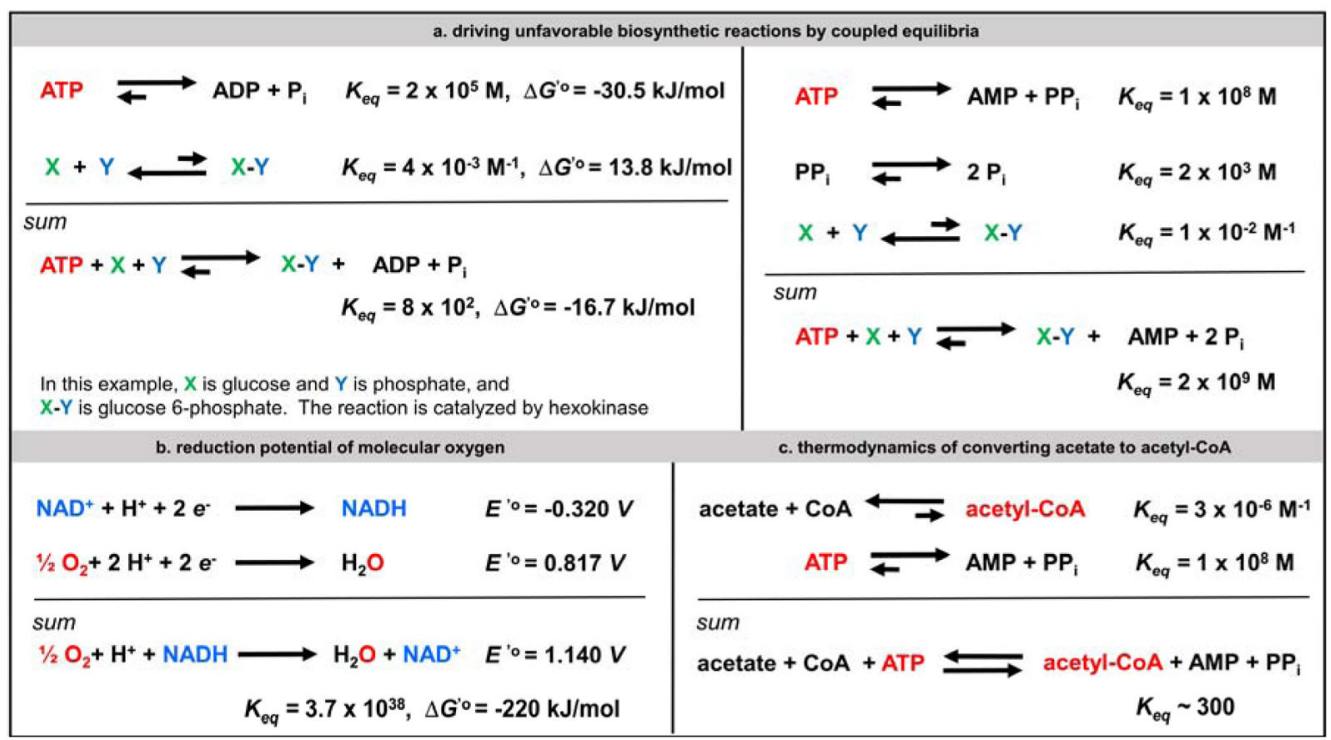

Figure 2.

Thermodynamics of coupled metabolic reactions: (a) driving unfavorable biosynthetic reactions by coupled equilibria involving phosphoryl or adenylyl (nucleotidtyl) transfers that fragment ATP; (b) the favorable thermodynamics for four electron reduction of $\mathrm{O}_{2}$ to $2 \mathrm{H}_{2} \mathrm{O}$ from $2 \mathrm{NADH}$ is revealed by the reduction potential difference. This equilibrium is silent about the kinetic barriers to reduction; (c) thermodynamics of coupled activation of acetate to acetyl-CoA as ATP is cleaved. 


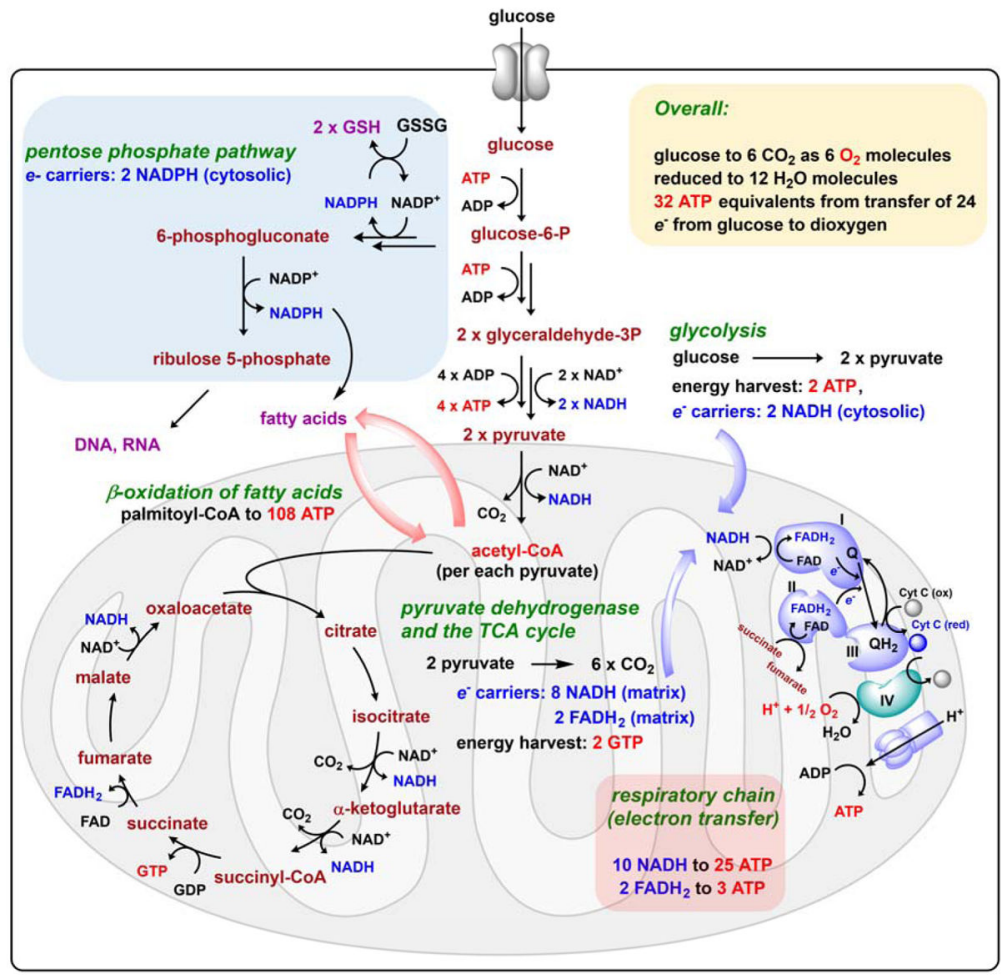

Figure 3.

An overview of cellular glucose metabolism. The coupled pathways of glycolysis, TCA cycle, and electron transport down the membrane respiratory chain summarize removal of 24 electrons from each glucose molecule and 30 ATP molecules accumulated for each four electron reduction of $\mathrm{O}_{2}$. A second major flux of glucose carbons is via the pentose phosphate pathway, yielding 2 equivalents of NADPH used for fatty acid biosynthesis and to make D-ribose-5-P for nucleic acid biosynthesis. The diagram also notes that complete oxidation of the predominant $\mathrm{C}_{16}$ fatty acyl-CoA, palmityl-CoA to 8 molecules of acetylCoA that are run through the TCA cycle and respiratory chain yields $\sim 108$ ATPs, emphasizing that saturated fatty acyl chains are energy storage molecules. 


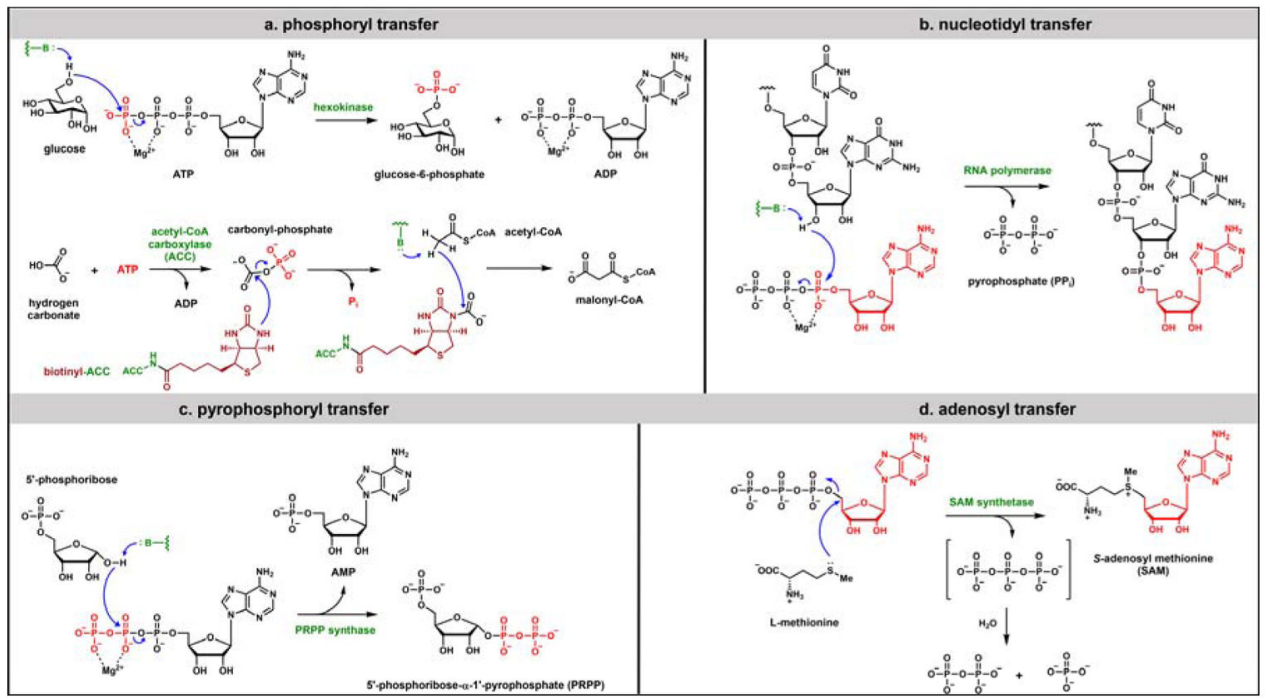

Figure 4.

Mechanistic Alternatives for ATP Side Chain Cleavage to Drive Coupled Equilibria: (a) phosphoryl transfer involves attack of cosubstrate nucleophile on electrophilic $\gamma$-phosphorus atom of Mg-ATP; (b) attack of cosubstrate nucleophile on a-P of Mg-ATP constitutes nucleotidyl (here adenylyl) transfer and is the common side chain cleavage mode in RNA, DNA, and protein biosynthesis; (c) Pyrophosphoryl transfer involves cosubstrate attack on the $\beta$-P of Mg-ATP and is relatively rare, although the formation of PRPP is central to purine biosynthesis; (d) The fourth mode of ATP side chain cleavage involves attack of cosubstrate nucleophile on $\mathrm{C}_{5}{ }^{\prime}$ of the ribose moiety of ATP and, while also a metabolically rare cleavage mode, is central to the formation of $S$-adenosyl methionine. 


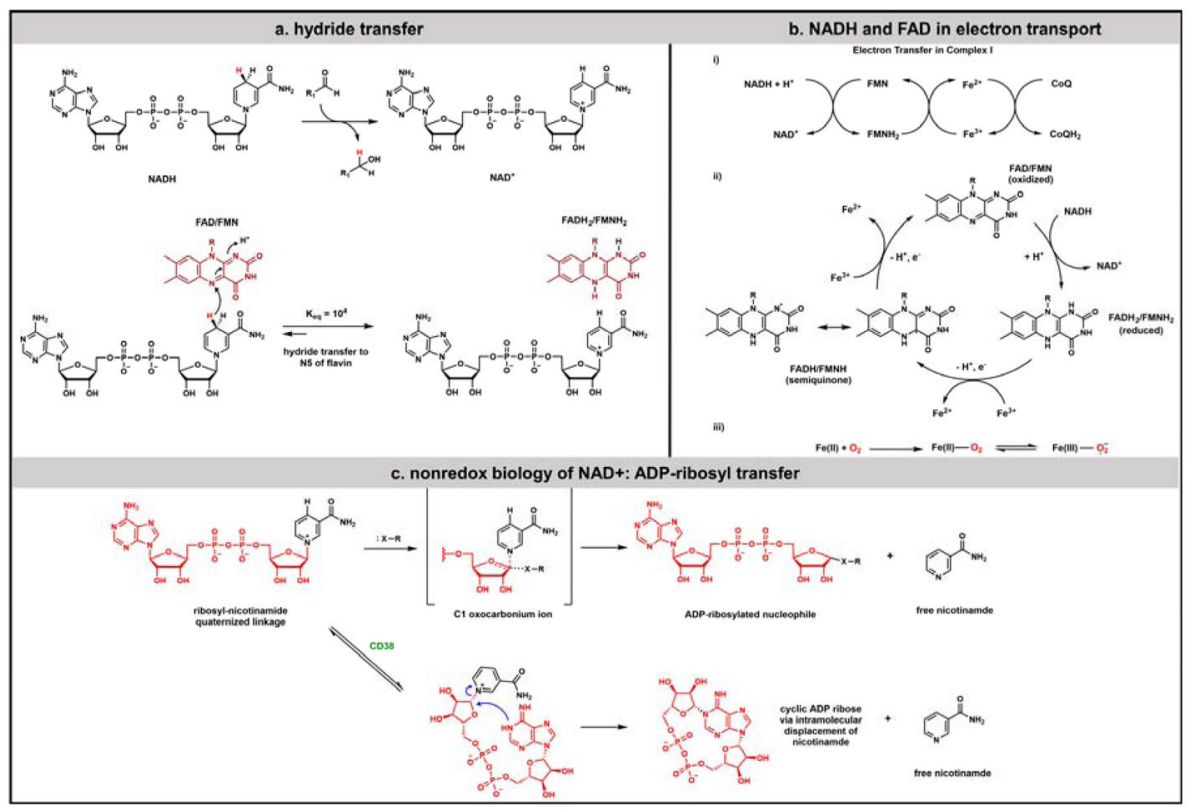

Figure 5.

Two modes of reactivity of oxidized nicotinamide coenzymes: (a) the most common role of $\mathrm{NAD}(\mathrm{P})^{+}$is as a hydride acceptor during cosubstrate oxidation to form NAD $(\mathrm{P}) \mathrm{H}$. In the back direction $\mathrm{NAD}(\mathrm{P}) \mathrm{H}$ is a thermodynamically activated hydride donor for cosubstrate reductions. (b) FAD has a special place in $\mathrm{NAD}(\mathrm{P}) \mathrm{H}$ biochemistry as a favored acceptor of a hydride to give $\mathrm{FADH}_{2}$. The dihydroflavin can subsequently be reoxidized either by a reverse of the two electron pathway or by two one electron steps. FAD (and FMN) thus functions as a 2 electron/1 electron step down redox transformer and interfaces between $\mathrm{NAD}(\mathrm{P}) \mathrm{H}$ and obligate one electron acceptors such as $\mathrm{O}_{2}$ and $\mathrm{Fe}^{3+}$ proteins; (c) Nonredox biology of $\mathrm{NAD}^{+}$involves ADP-ribosyl transfer to nucleophiles. These can be side chains on proteins or growing ADP-ribosyl chains. Also shown is the comparable intramolecular displacement on $\mathrm{NAD}^{+}$, creating cyclic ADP ribose. 


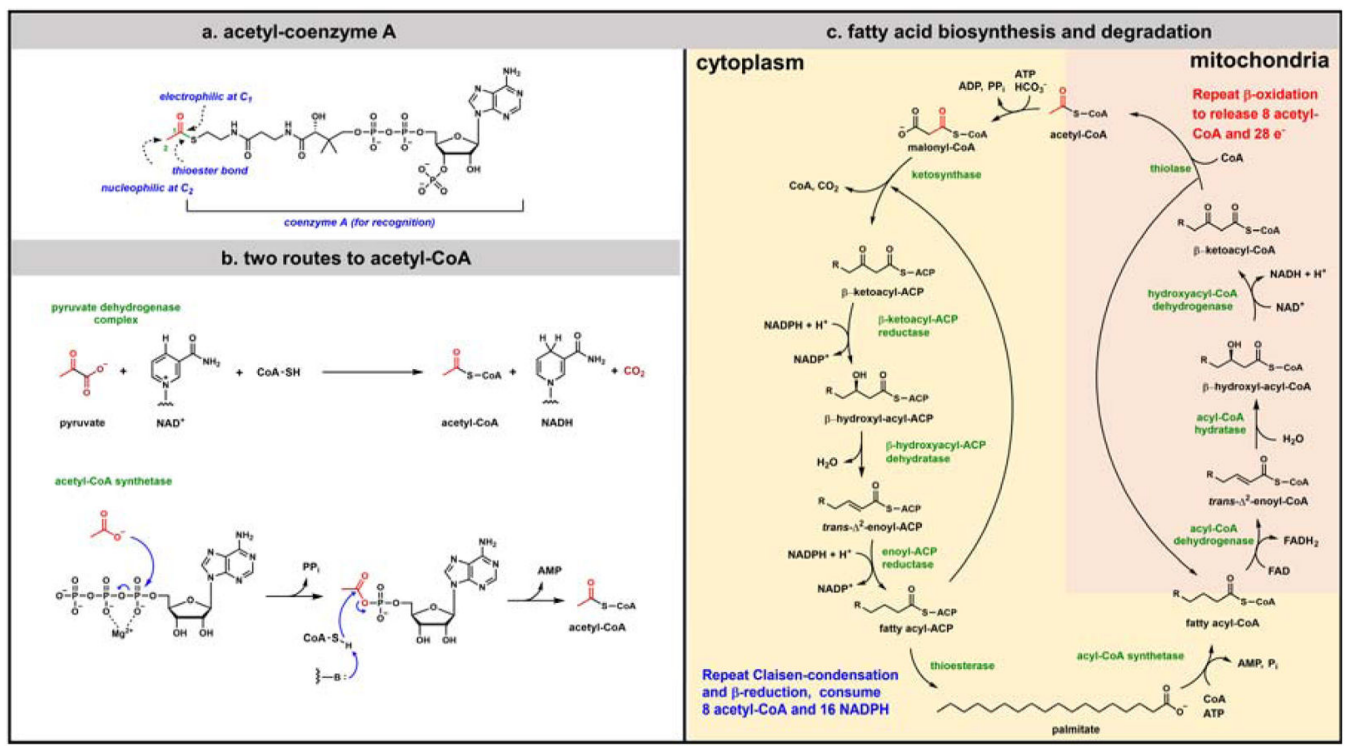

Figure 6.

Overview of Acetyl-CoA: (a) structure and chemical features of acetyl-CoA; (b) Two biosynthetic routes to acetyl-CoA involve (1) the oxidative decarboxylation of pyruvate to acetyl-CoA in the transition between glycolysis and TCA cycle catalyzed by the multisubunit pyruvate dehydrogenase; (2) the conversion of acetate back to acetyl-CoA by nucleotidyl transfer and acetyl-AMP intermediacy. (Free acetate in mammalian cells can arise by multiple routes including histone deacetylase action); (c) in times of energy excess, the utilization of acetyl-CoA carbons for fatty acid biosynthesis occurs in cell cytoplasm while the reverse steps occur during mitochondrial beta oxidation of fatty acids to generate acetyl-CoA molecules. 


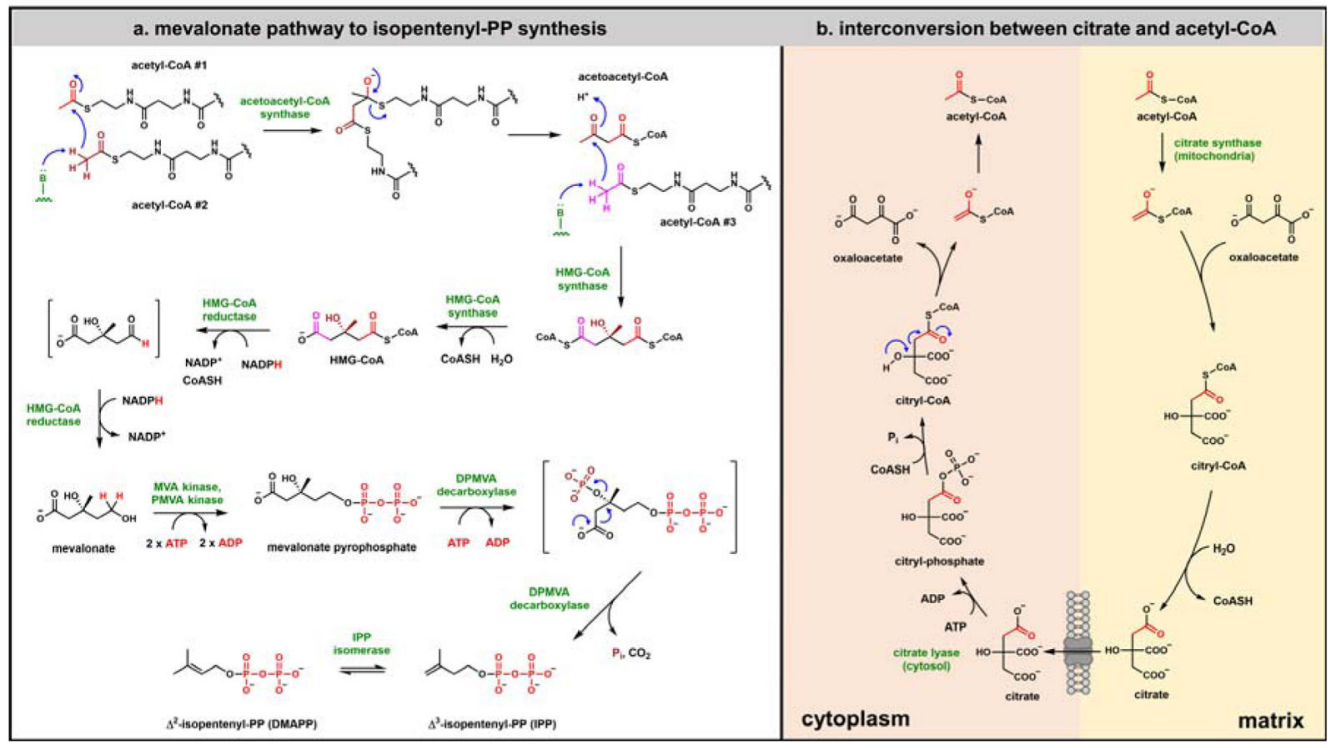

Figure 7.

Acetyl-CoA metabolism part two: (a) conversion of three molecules of acetyl-CoA to the $\Delta^{2}$ and $\Delta^{3}$ isomers of isopentenyl diphosphate (IPP) by the enzymes of the mevalonate pathway. Note the utilization of three molecules of ATP and two of NADPH as HMG-CoA is converted to $\Delta^{2}$-IPP; (b) acetyl-CoA and citrate can be interconverted by distinct enzymes in both cytoplasm and mitochondria and citrate can pass between the two compartments. Citryl-CoA is an intermediate common to both arms. 


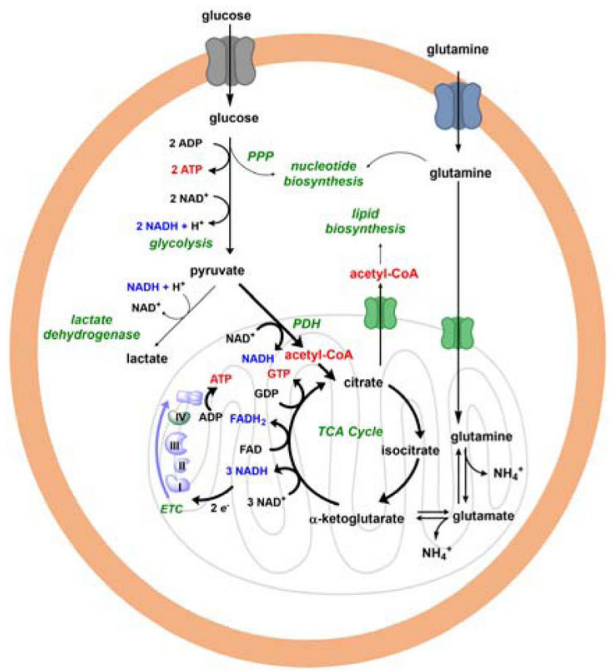

Normal/Differentiated cell

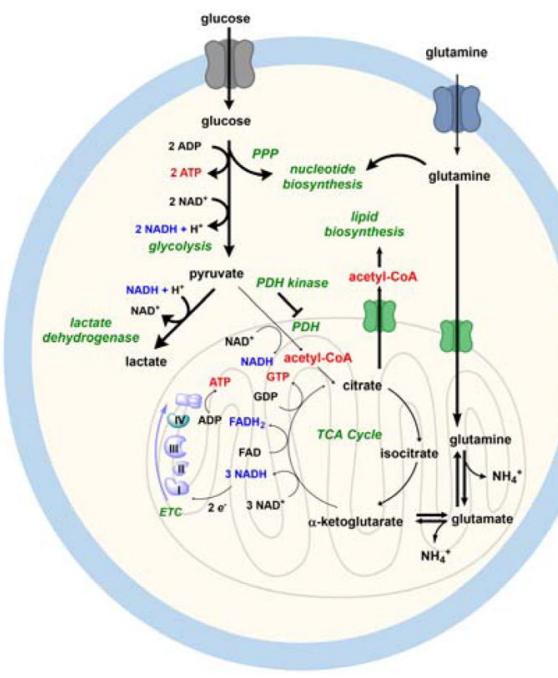

Proliferating/iPS cell

Figure 8.

Comparison of metabolic fluxes from glucose and glutamine in normal/differentiating cells which are depicted with a robust TCA cycle and electron transport system vs proliferating IPS cells. Thick arrows indicate a greater flux through steps compared to thin arrows. The right hand panel indicates less energetic flux through the TCA cycle and increased aerobic glycolysis. The ability to "dump" excess electrons and regenerate $\mathrm{NAD}^{+}$for glycolysis to continue depends substantially on high levels of lactate dehydrogenase, allowing reduction of pyruvate to lactate which can be excreted. 


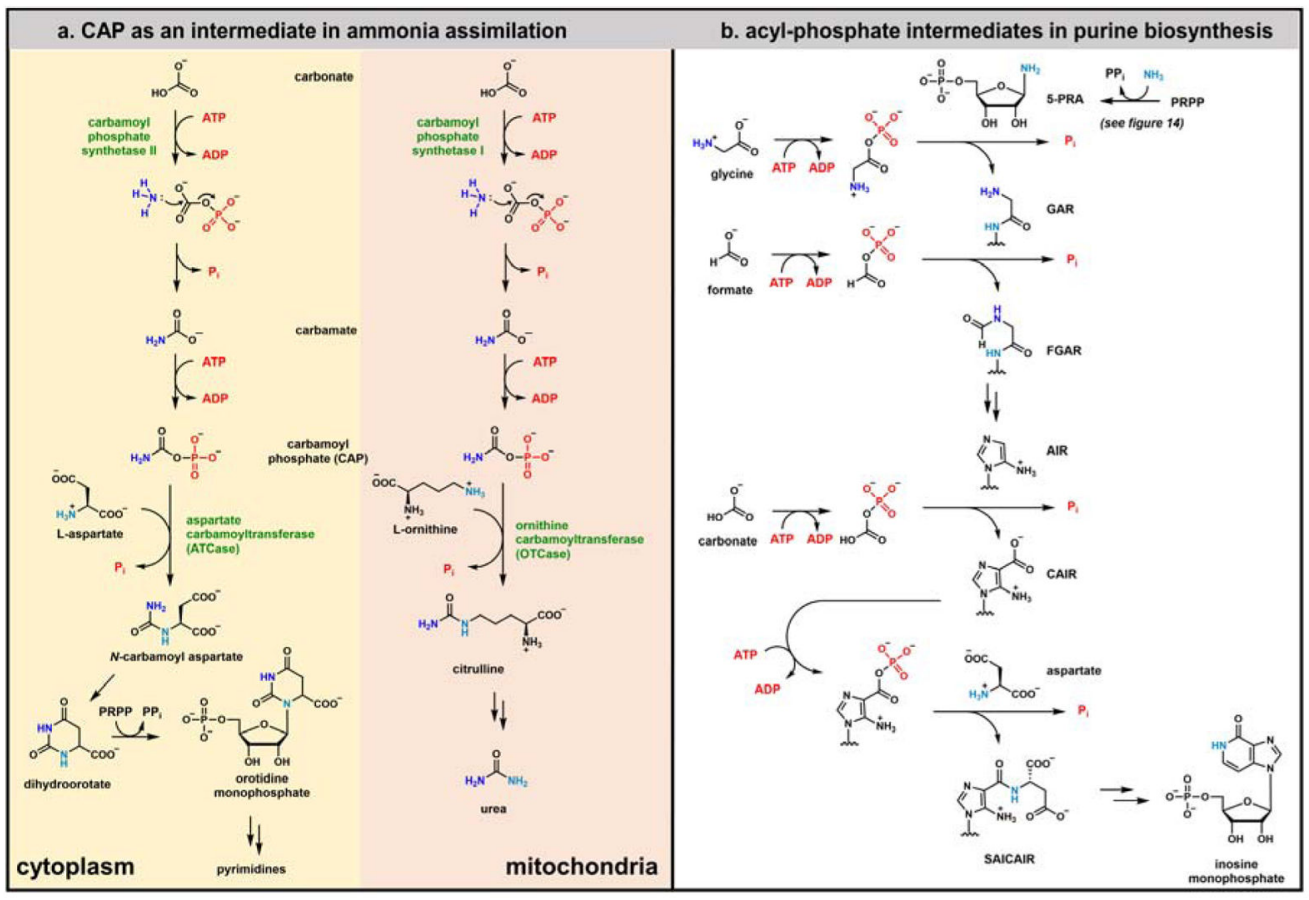

Figure 9.

Carbamoyl phosphate and other acyl phosphates in purine biosynthesis: (a) carbamoyl-P is generated from carbonate, ammonia, and two molecules of ATP with carbonyl-P as an intermediate. Carbamoyl-P is central to mammalian nitrogen metabolism as a carbamoyl donor in anabolic metabolism, cytoplasmic pyrimidine biosynthesis, and in catabolic metabolism, mitochondrial urea synthesis; (b) The utility of acyl phosphates as kinetically stable, thermodynamically activated acyl transfer metabolites is emphasized in purine biosynthesis where four enzymes make glycyl-P, formyl-P, carbonyl-P, and CAIR-P as bound acyl donor species, respectively. 


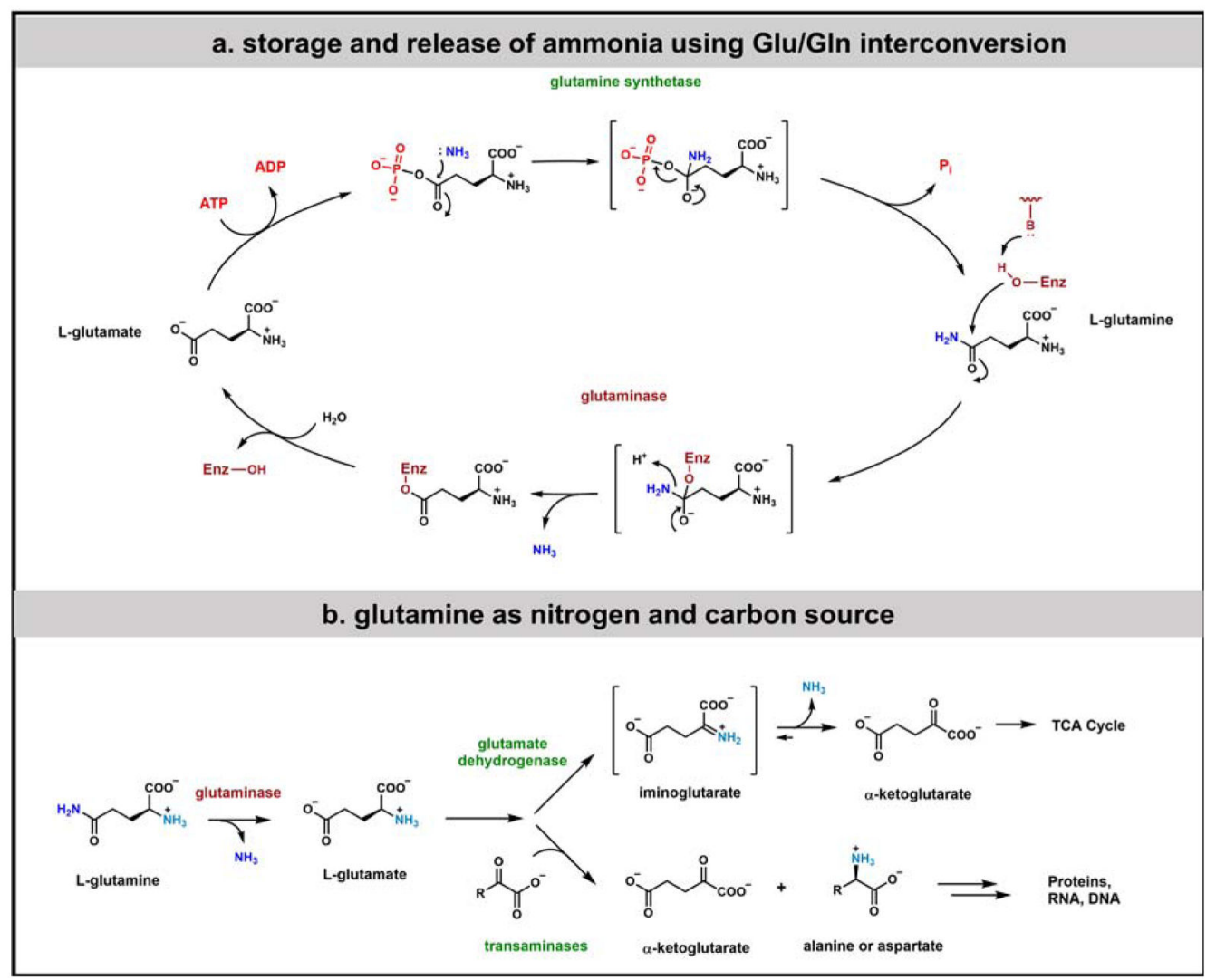

Figure 10.

Glutamine as a nitrogen source: (a) glutamine and glutamate as key amino acids in balancing the storage and release of ammonia. Glutamine and glutamate are interconverted by the enzymes glutamine synthetase and glutaminase. Glutamine synthetase catalysis involves the acyl-phosphate $\boldsymbol{\gamma}$-glutamyl-P; (b) exogenous glutamine can serve as both a nitrogen and carbon source; sequential action of glutaminase and glutamate dehydrogenase can liberate both amide and amino nitrogens as ammonia while transaminases that utilize glutamate as amino donor move the amino group onto many ketoacid frameworks. The deaminated aketoglutarate scaffold can serve as TCA cycle substrate and as cofactor for the oxygenases noted in Figures 15 and 16. 


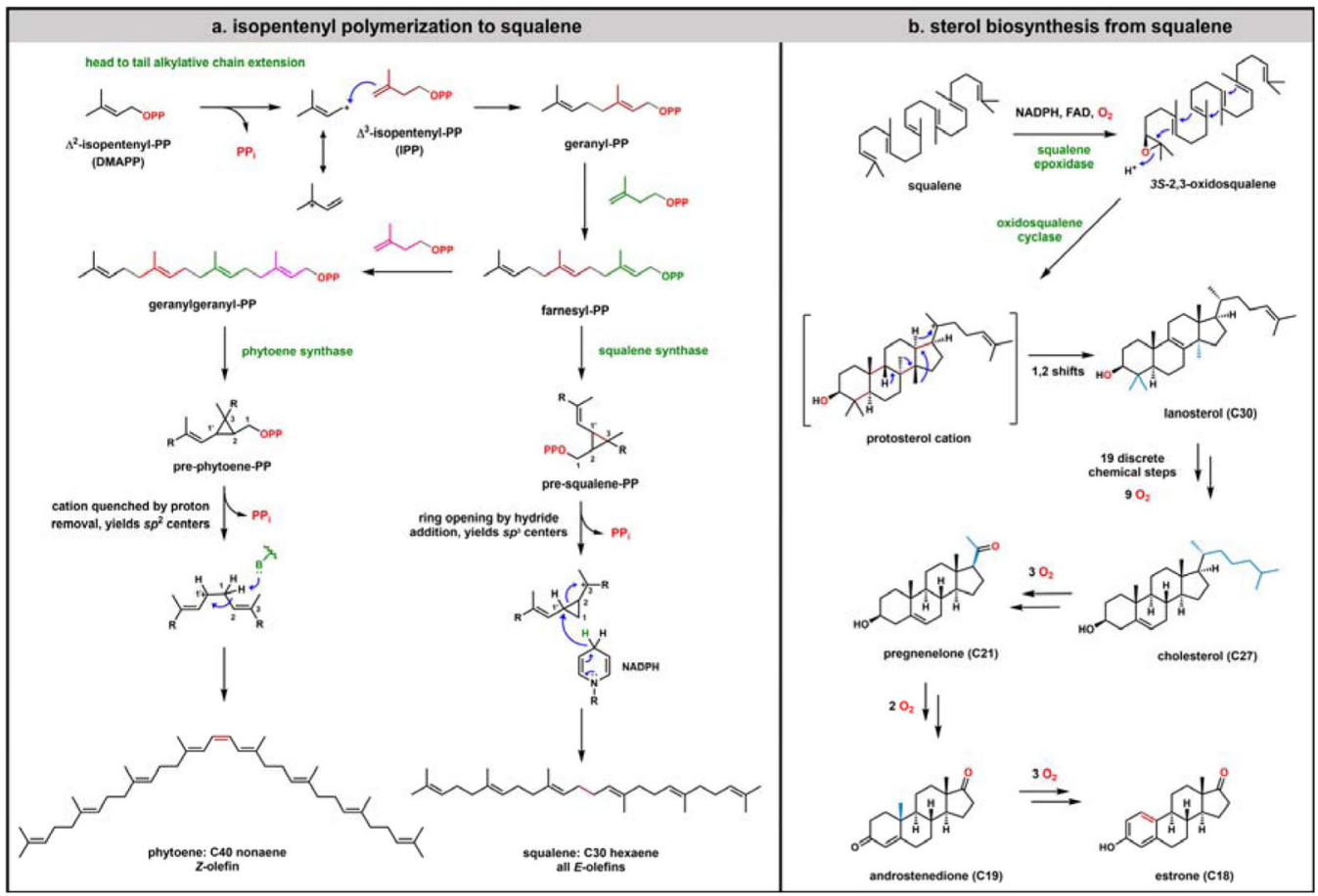

Figure 11.

Isoprenoid metabolism: (a) isopentenyl-PP regioisomers are the key building blocks for the $\mathrm{C}_{30}$ hexaene squalene and the $\mathrm{C}_{40}$ nonaene phytoene. Chain elongations go by $\mathrm{C}_{5}$ head to tail elongations via iterative ally cation chemistry up to the $\mathrm{C}_{15}$ and $\mathrm{C}_{20}$ stages before $\mathrm{C}-\mathrm{C}$ bond formation switches to head to head $\mathrm{C}_{1}$ to $\mathrm{C}_{1}$ connections in squalene and phytoene, with cyclopropyl cation formations and rearrangements involved in presqualene and prephytoene formation and breakdown; (b) sterol biosynthesis from squalene involves prior epoxidation of the 2,3-double bond, a cyclization cascade to create the familiar tetracyclic framework and a series of $1,2 \mathrm{H}$ and $\mathrm{CH}_{3}$ migrations before release of the $\mathrm{C}_{30}$ lanosterol. $\mathrm{A}$ series of oxygenases then act in different tissues, on unactivated carbon sites, to convert the $\mathrm{C}_{30}$ lanosterol to $\mathrm{C}_{27}$ cholesterol, to $\mathrm{C}_{21}$ pregnenelone to $\mathrm{C}_{19}$ androstenedione. The cytochrome $\mathrm{P} 450$ enzyme aromatase carves out the angular A/B ring methyl group of androstenedione to aromatize the $\mathrm{A}$ ring as male sex hormone is converted to the $\mathrm{C}_{18}$ female sex hormone estrone. 


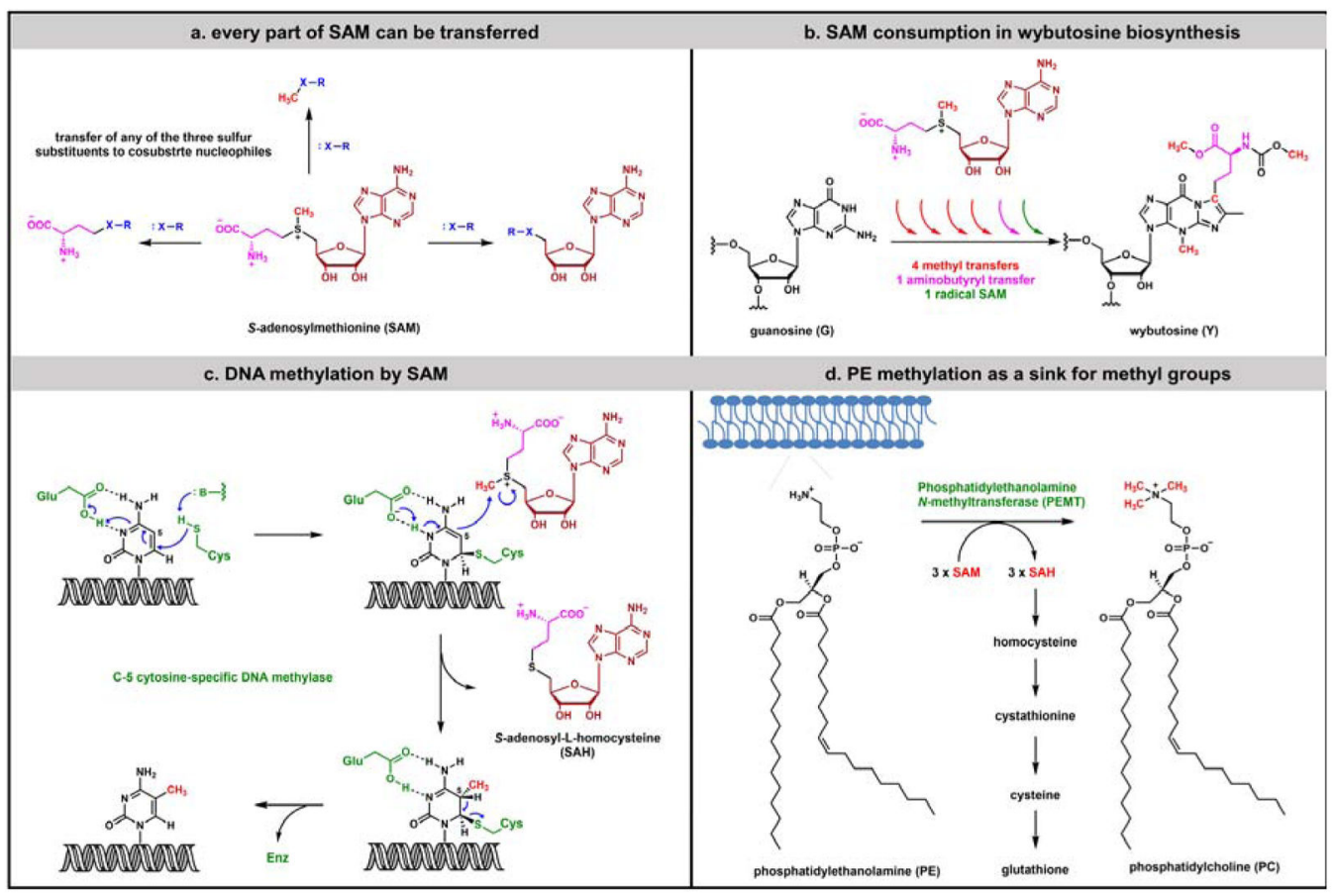

Figure 12.

$S$-adenosyl methionine (SAM) as thermodynamically activated alkyl transfer metabolite: (a) the sulfonium group in SAM activates all three substituents for transfer as electrophilic alkyl fragments, although methyl group transfer is by far the most common; (b) the versatility of SAM is evident in formation of the wybutosine modified base in tRNA. Six equivalents of SAM are consumed, four are moved as $\left[\mathrm{CH}_{3}{ }^{+}\right]$equivalents, the fifth as a $\left[\mathrm{CH}_{3}{ }^{\bullet}\right]$ equivalent. The sixth molecule of SAM instead donates an electrophilic aminobutyryl group; (c) DNA methylation at $\mathrm{C}_{5}$ of Cytidine residues occurs by the indicated addition/elimination mechanism with SAM as the one carbon donor; (d) SAM is also involved in membrane phospholipid maturation, converting hundreds of thousands to millions of phosphatidylethanolamine to phosphatidylcholine molecules via three consecutive $\mathrm{N}$-methyl transfers in mammalian cells. 


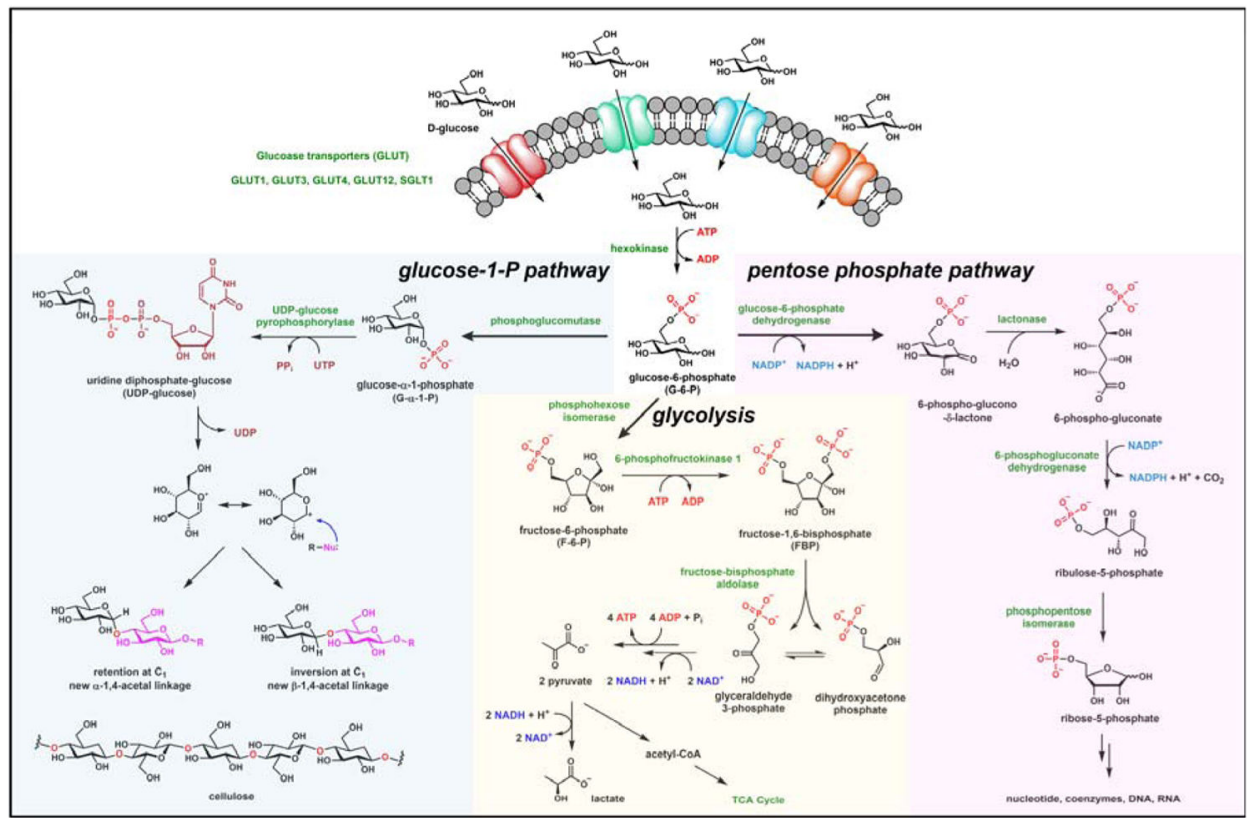

Figure 13.

Three main pathways for cellular glucose utilization: in addition to the glycolysis and pentose phosphate pathways for flux of glucose-6-P (refer also back to Figure 3), the third pathway branches off from glucose-1-P, via action of phosphoglucomutase. The resultant UDP-glucose is the proximal donor of glucosyl moieties as glucosyl $\mathrm{C}_{1}$ oxocarbonium ion equivalents in oligosaccharide, polysaccharide, and glycoprotein biosynthesis, resulting in $\mathrm{C}_{1}$ connectivity of all such transferred glycosyl moieties. Gluconeogenesis is not included in this figure. 


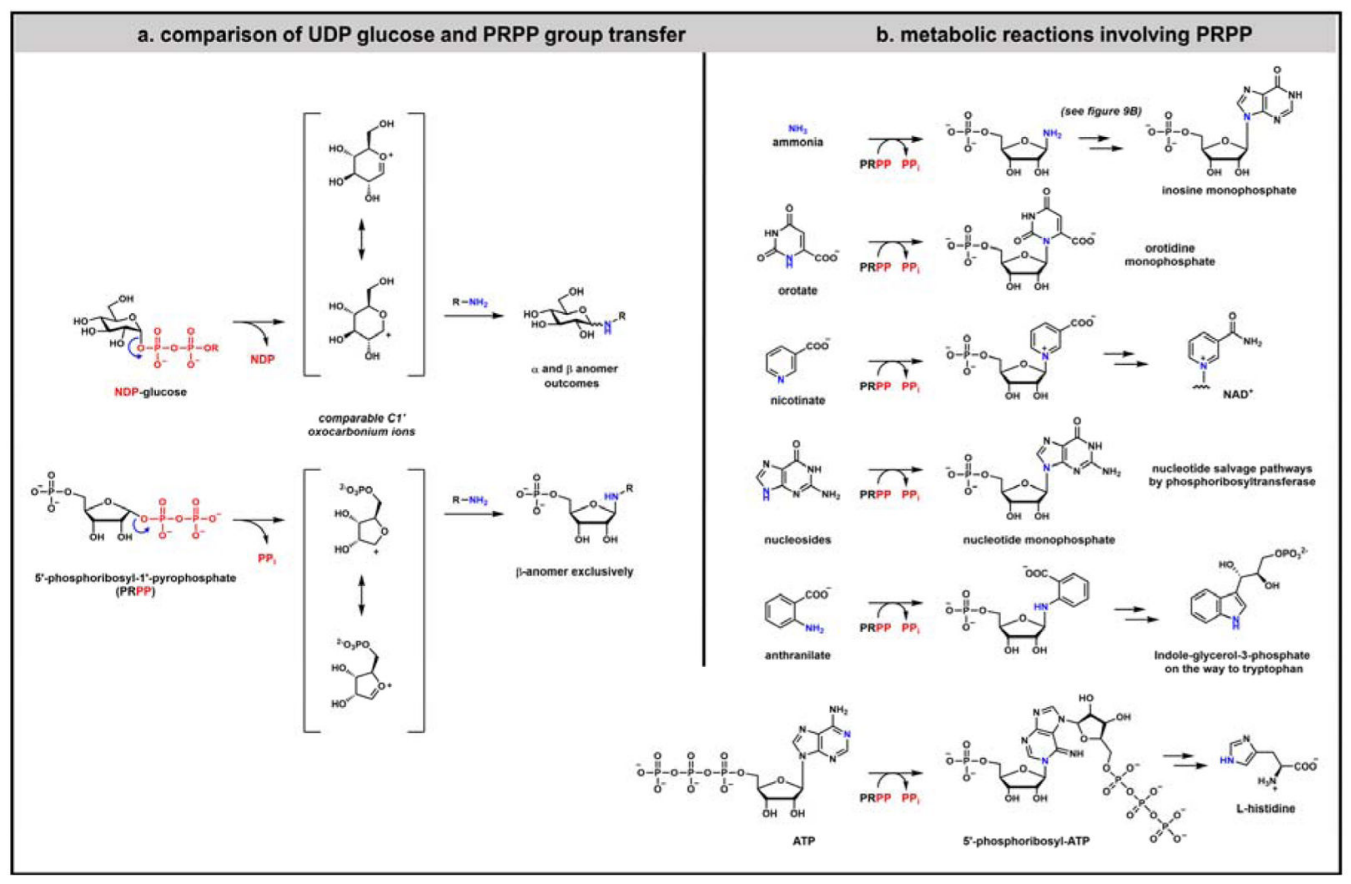

Figure 14.

5-Phosphoribose-1-pyrophosphate (PRPP) as activated phosphoribosyl donor (a) UDPglucose and PRPP are metabolites activated by the $\mathrm{C} 1$-pyrophosphate groups for $\mathrm{C} 1-\mathrm{O}$ bond cleavage via oxocarbonium ion transition states; (b) PRPP serves as an electrophilic phosphoribosyl donor to a set of cellular amine cosubstrates, including de novo purine and pyrimidine nucleotide biosynthesis, purine and pyrimidine salvage, $\mathrm{NAD}^{+}$biosynthesis, and also to provide some of the carbon atoms in both tryptophan and histidine biogenesis. 


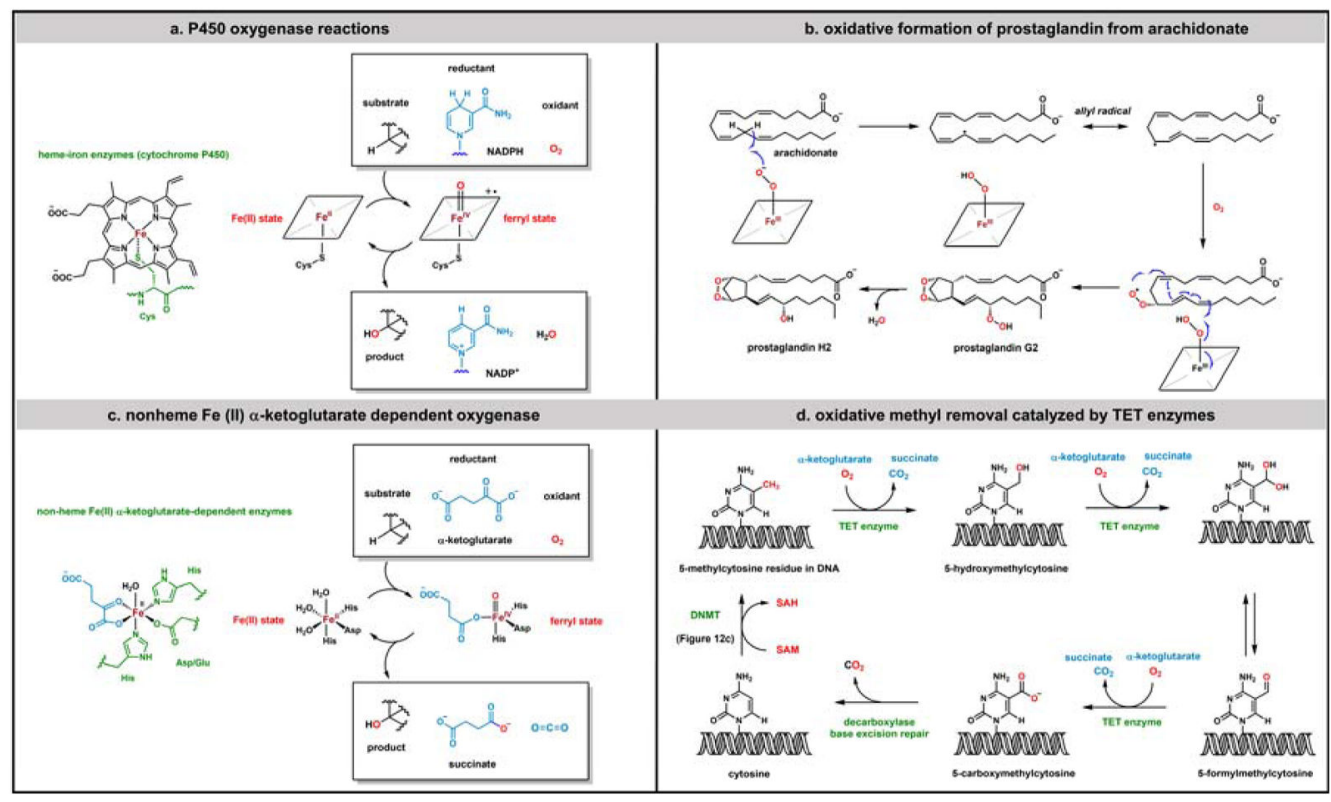

Figure 15.

Two main types of iron-based monooxygenases: (a) heme-based Cytochromes P450 use high valent ferryl oxygen intermediates as strong oxidants for one electron chemistry to effect $\mathrm{C}-\mathrm{H}$ bond homolysis at unactivated carbon sites and $\mathrm{OH} \bullet$ rebound for net hydroxylation; (b) the maturation of arachidonate into PGG2 and PGH2 involves an initial allyl radical conversion to a pair of peroxy radicals one of whch closes to the cyclopentane endoperoxide characteristic of PGG2 and PGH2; (c) the typical two His, one Glu/Asp coordination set for nonheme mononuclear iron oxygenases also includes cosubstrate $a$ ketoglutarate as the $4^{\text {th }}$ and $5^{\text {th }}$ ligands to $\mathrm{Fe}$. An analogous $\mathrm{Fe}^{\mathrm{IV}}=\mathrm{O}$ high valent oxoiron species performs comparable homolytic $\mathrm{C}-\mathrm{H}$ bond cleavage and $\mathrm{OH} \bullet$ equivalent transfer; (d) oxidative demethylation of 5-MeC residues in DNA is mediated by the TET subfamily of nonheme mononuclear iron oxygenases, in three sequential steps as shown. 


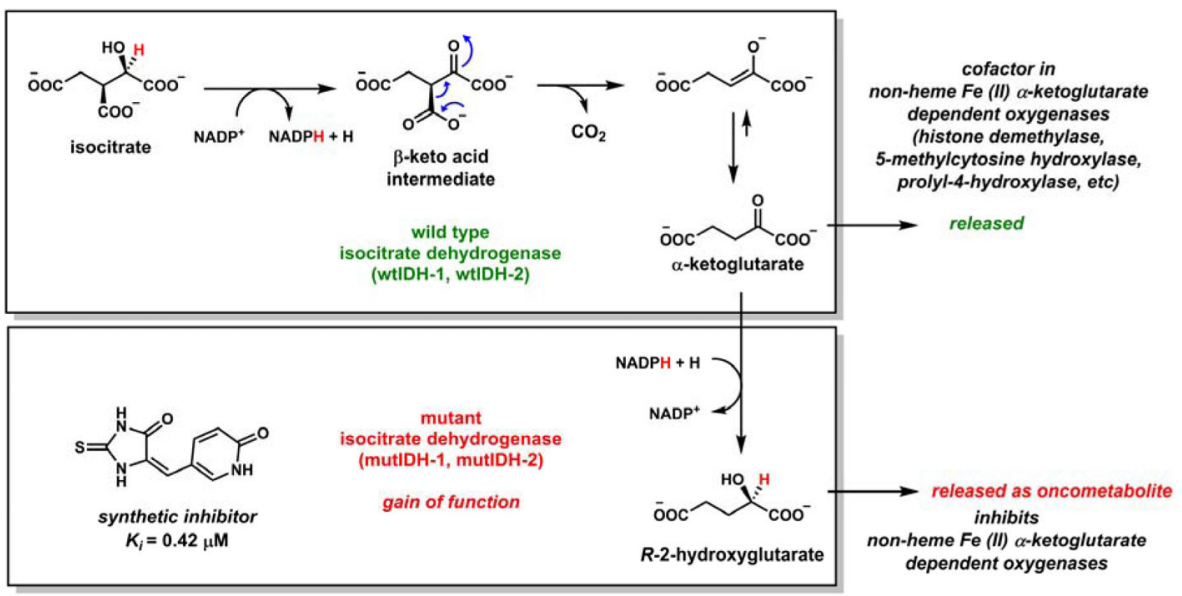

Figure 16.

Product profile from wild type and mutant form of isocitrate dehydrogenase (IDH-1): isocitrate is oxidized to the oxalosuccinate $\beta$-keto acid that is then subjected to actve sitemediated regiospecific decarboxylation of one of the three carboxylates to yield $a$ ketoglutarate. In addition to its role in the TCA cycle, $a-K G$ is the oxidizable cosubstrate for nonheme mononuclear iron monoxygenases, some of which are shown in the top panel (also see Figure 14). In the mutIDH-1 catalytic cycle, product release is slowed long enough for the nascent $\mathrm{a}-\mathrm{KG}$ to be reduced by the incipient NADPH product to yield $R$-2-

hydroxyglutarate. This alternate product is an inhibitor of the mononuclear iron oxygenases by competition at the $\mathrm{a}-\mathrm{KG}$ binding site and has been termed an oncometabolite. 


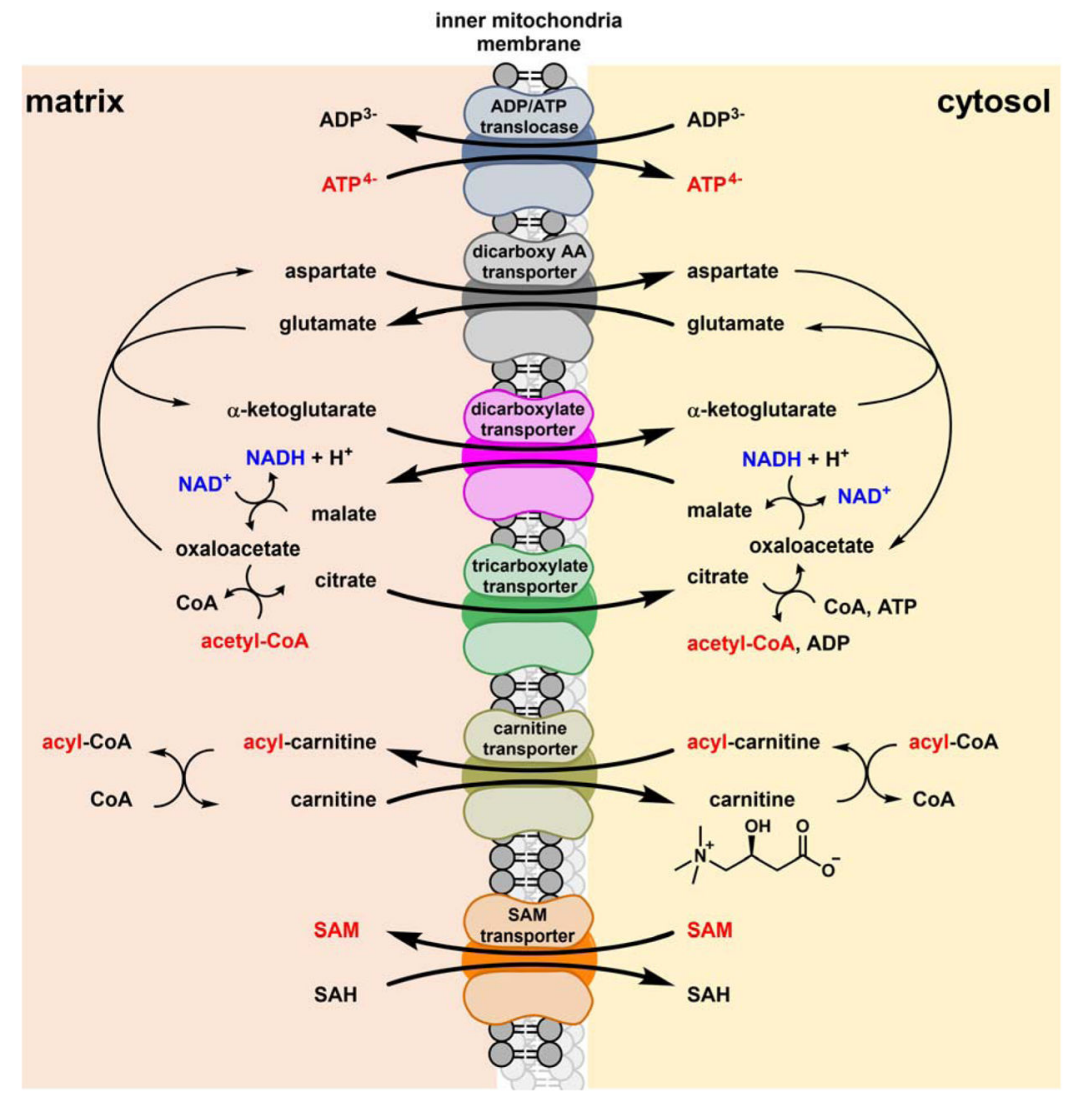

Figure 17.

Schematic of six inner mitochondrial membrane transporters for ATP/ADP, aspartate/ glutamate, a-ketoglutarate/malate. Citrate, acyl-carnitine/carnitine, SAM/SAH. 


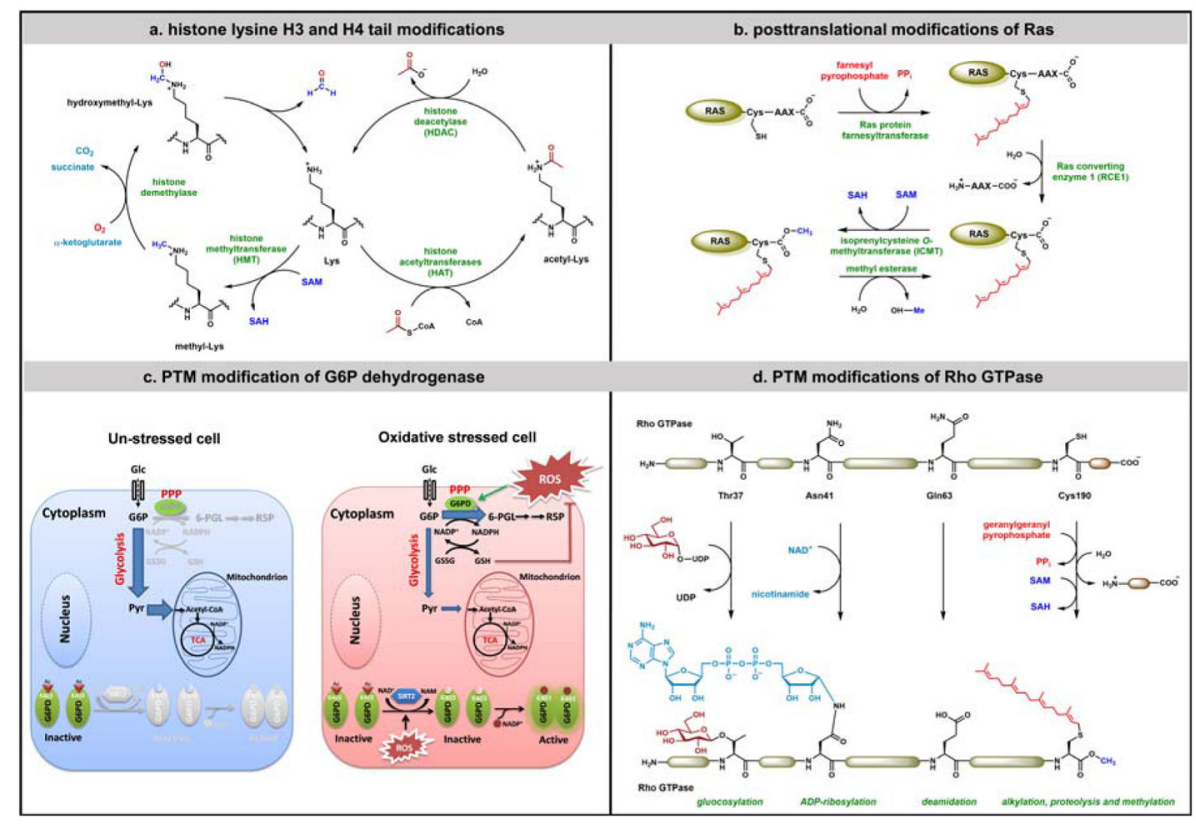

Figure 18.

The seven central metabolites that power small molecule metabolism also dominate posttranslational modification of proteins: (a) the two most common histone lysine $\mathrm{H}_{3}$ and $\mathrm{H}_{4}$ tail modifications involve acetyl-CoA for acetylations and SAM for methylations; (b) The small GTPase family member Ras is processed at the C-terminus for alkylation by a $\mathrm{C}_{15}$ $\Delta^{2}$-prenyl-PP (farnesyl-PP). This sets up proteolytic processing by Ras converting enzyme 1. The third posttranslational modification is a SAM-dependent carboxy- $O$-methyltransferase; (c) Glucose-6-P dehydrogenase, the gatekeeper enzyme to the pentose phosphate pathway, undergoes interconversion between acetylated inactive forms and deacetylated active forms, where the deacetylase is the $\mathrm{NAD}^{+}$-dependent sirtuin SIRT2; Reprinted with permission from Wang et al, "Regulation of G6PD acetylation by SIRT2 and KAT9 modulates NADPH homeostasis and cell survival during oxidative stress", EMBO J, 33, Copyright (2014) John Wiley and Sons. (d) Another small GTPase family member Rho undergoes a series of PTMs that use three of the key seven metabolites: UDP-glucose to glucosylate the side chain -OH of Thr37, ADP ribosylation from $\mathrm{NADP}^{+}$on the side chain amide of Asn41, and carboxy-Omethylation of Cys190 from SAM after prenylation and proteolysis to reveal Cys190 as the new C-terminus. 
Table 1

\begin{tabular}{|l|l|}
\hline Metabolic pathways & Key Substrates \\
\hline Glycolysis & ATP, NADH \\
\hline Pentose Phosphate & NADPH, D-ribose-5-P, erythrose-4-P \\
\hline Glycogen assembly & UDP-Glucose \\
\hline Glycoproteins & UDP-GlcNAc, GDP-Mannose, UDP-Galactose, UDP-Glucose \\
\hline Tricarboxylate Cycle & Acetyl-CoA, NADH, GTP, Enz-FADH 2 \\
\hline Fatty Acid Biosynthesis & ATP, acetyl-CoA, malonyl-CoA, NADPH, Enz-FMNH ${ }_{2}$ \\
\hline Fatty Acid $\beta$-oxidation & long chain acyl-CoAs, acetyl-CoA, NAD ${ }^{+}$, Enz-FAD \\
\hline Purine and Pyrimidine Biosynthesis & 5-P-ribose-1-PP, E-FAD, ATP, Carbamoyl-P \\
\hline Steroidogenesis & acetyl-CoA, IPP isomers \\
\hline Urea Cycle & ATP, Carbamoyl-P \\
\hline Gln, Glu, a-ketoglutarate & NAD ${ }^{+}$, ATP \\
\hline Phospholipid Biosynthesis & SAM \\
\hline Nitrogen Metabolism & Glutamine, glutamate, NAD \\
\hline Protein PTMs & ATP, SAM, NAD ${ }^{+}$, acetyl-CoA, FPP and GGPP, UDP-glucose, UDP-GlcNAc \\
\hline
\end{tabular}

